\title{
IN A CONSTANT STATE OF FLUX: THE CULTURAL HYBRID IDENTITIES OF SECOND-GENERATION AFGHAN-CANADIAN WOMEN
}

\author{
By: \\ Saher Malik Ahmed, B. A \\ A thesis submitted to the Faculty of Graduate and Post-Doctoral Affairs in partial fulfillment \\ of the requirements for the degree of
}

Master of Arts

In

Women's and Gender Studies

Pauline Jewett Institute of Women's and Gender Studies

Carleton University

Ottawa, Ontario

July 2016

(C) 2016

Saher Malik Ahmed 


\begin{abstract}
This study, guided by feminist methodology and cultural hybrid theory, explores the experiences of Afghan-Canadian women in Ottawa, Ontario who identify as secondgeneration. A qualitative approach using in-depth interviews with ten second-generation Afghan-Canadian women reveals how these women are continuously constructing their hybrid identities through selective acts of cultural negotiation and resistance. This study will examine the transformative and dynamic interplay of balancing two contrasting cultural identities, Afghan and Canadian. The findings will reveal new meanings within the Afghan diaspora surrounding Afghan women's gender roles and their strategic integration into Canadian society.
\end{abstract}




\section{Acknowledgments}

I am deeply indebted to my thesis supervisor, Dr. Amrita Hari. I thank her sincerely for her endless guidance, patience, and encouragement throughout my graduate studies. I have benefited from her wisdom and insightful feedback that has helped me develop strong research and academic skills, and for this I am immensely grateful. I would like to thank Dr. Karen March, my thesis co-supervisor for her incisive comments and challenging questions. I will never forget the conversation I had with her on the phone during the early stages of my research when she reminded me of the reasons why and for whom this research is intended. I would also like to thank my thesis committee members Dr. Megan RiversMoore and Dr. Xiaobei Chen for taking the time to be an important part of this process.

The completion of this thesis would not have been possible without the support of my mother, Masooda Ahmed. I cherish her stories of Afghanistan, including those that disclose her migratory journey as an Afghan refugee. She is the most intelligent, brave, and caring person I know. Thank you Mothar-jaan for sharing your personal experiences that are rarely shared between mothers and daughters in our culture. Dooset Daram.

I would also like to take this opportunity to thank my father, Arif Malik Ahmed, for I have felt his prayers and steadfast love even distance apart. I admire his strength in character to overcome adversities and I am thankful for his dedication in creating a space his daughters can always call home. I thank my sisters, Sabah and Kauser, for their love and emotional support throughout my academic development. They are my strength and inspiration. 
To my Khala-Jaan, Najia Azmat, who although physically not present, she has spiritually guided me through this process. You have taught me how to strive for excellence and the discipline that is required to attain it.

Finally, and most heartfelt, I owe an enormous debt of gratitude to my partner and best-friend, Liam Devine. I am thankful for his unwavering support of me throughout this journey, as we moved across the country, and transitioned from new Bachelor's graduates to Master's students. He has spent countless days and nights listening to my ideas, concerns and frustrations, and selflessly extended his advice and empathy while pursuing his own graduate research. Thank you Liam for making our journey more enjoyable when life became difficult. I am looking forward to our future adventures as a team (including wee Shanoos!), as individuals and as human rights activists— as we are always becoming and have never arrived. 


\section{Dedication}

For the resilient Afghan-Canadian women,

I hope your imaginaries of Afghanistan continue to safeguard the flourishing images of a country that once was.

For my mother,

My academic achievements are as much yours as they are my mine. 


\section{Table of Contents}

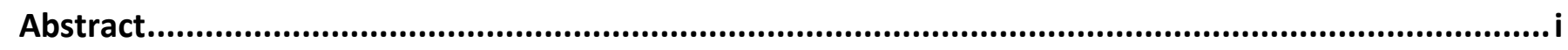

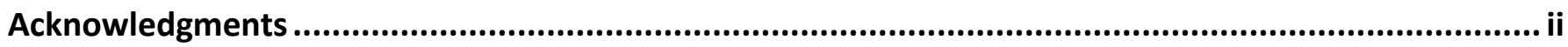

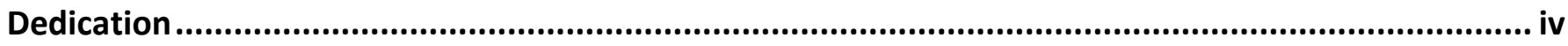

Chapter 1: Migration and memories of the Afghan diaspora in Canada .......................................... 1

Chapter 2: Building a Theoretical Framework - Cultural Hybrid Identity .......................................... 7

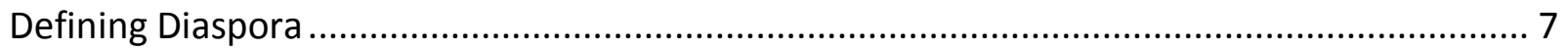

Hybridity and Hyphenated Cultural Identities ........................................................... 11

Homeland and Second-Generation Afghan Women ........................................................ 15

Research Questions: Building on Narratives and Creating New Discussions ........................ 16

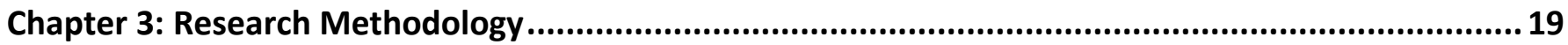

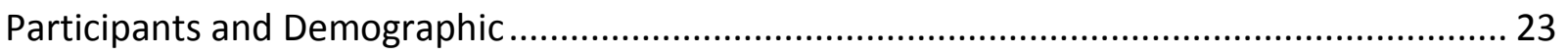

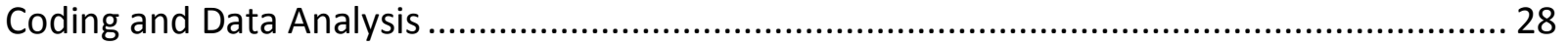

My Hybridity: Both an Outsider and Insider ........................................................... 29

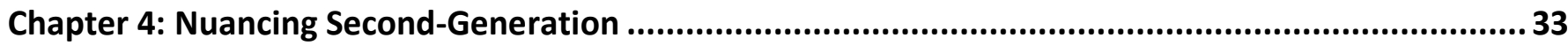

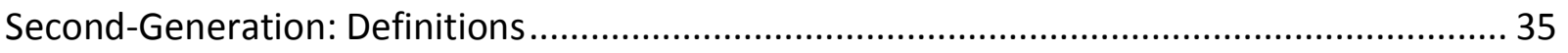

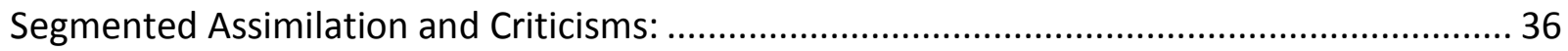

Defining 'Second-Generation' for themselves ............................................................ 40

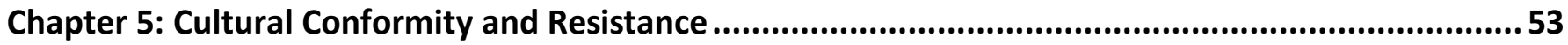

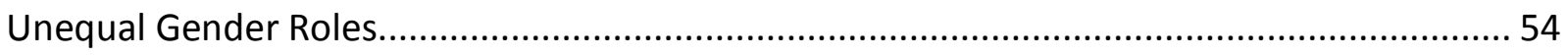

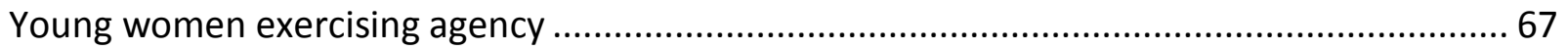

Fear and Anxiety of the Afghan diaspora

Second-generation Afghan Women Expressing Hybridity ........................................... 90

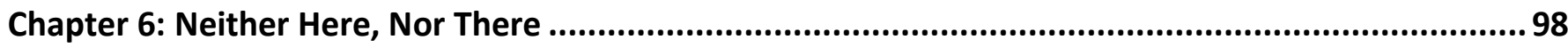

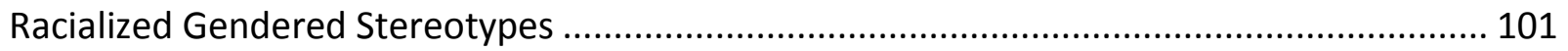

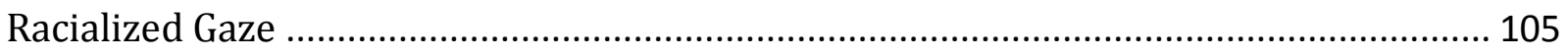

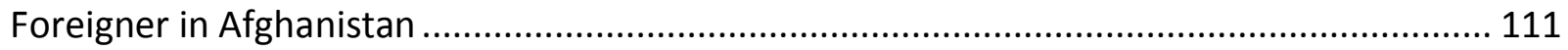

Creating an Hybrid Identity as Outsiders in Afghanistan and Canada .......................... 115

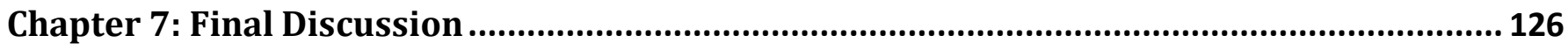


Further Research and Limitations to this study ..................................................... 128

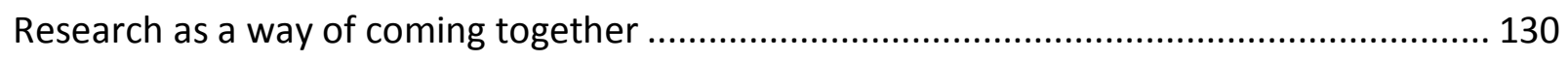

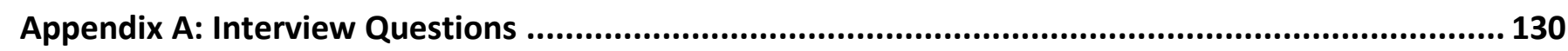

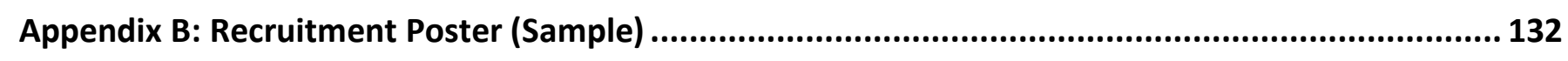

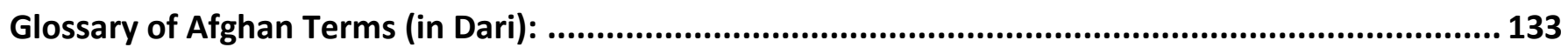

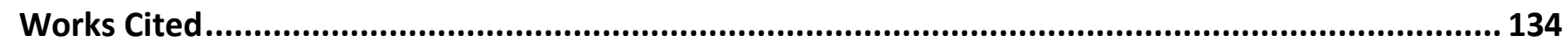




\section{Chapter 1: Migration and memories of the Afghan diaspora in Canada}

Migration is often understood as the traveling of populations between different regions of the world motivated by opposing 'pull factors,' such as increased socio-economic opportunities and family-reunification, and 'push factors' such as famine, war, global injustices of conflict or profound social and economic equities (Brah 1996). 'Push factors' are primarily associated with 'refugee' or 'involuntarily' migrations of those who have been forcefully displaced from their home-countries. This thesis focuses mainly on push factors because, as will be seen below, the majority of Afghans who come to Canada do so as refugees rather than seeking family reunification and/or socio-economic opportunities.

Push and pull factors become significant in identifying the diverse combinations of motives and external circumstances that create distinct typologies of migrants and contribute to the flows of migration. To understand the migratory and settlement experiences of Afghan refugees, we need to look at not only "who travels but when, how, and under what circumstances (Brah 1996, p. 182). In this introductory chapter, I will discuss the waves of Afghan refugee migration instigated by Afghanistan's tumultuous conflicts from 1979 to 2013 . Following this discussion, I briefly review the existing scholarship on Afghan refugees, specifically Afghan women's migratory and settlement experiences in Canada, to introduce the research questions addressed in this study. 
Waves of Afghan Refugee Movements (1979-2013)

There are three significant conflicts that have contributed to the out-migration of Afghans: the Soviet Invasion of 1979, the Afghan civil war from 1994-2001, and the U.S invasion of 2001. These conflicts have had a profound impact on the lives of Afghan people as the violence caused hundreds of thousands of Afghans to flee the country as refugees. Scholarship on Afghan refugees (Dossa 2005; Koplik 2003; Otoukesh et al 2012;Safri 2011) have associated these three periods with war, civil strife, protracted conflict, tremendous government instability, and the significant displacement of Afghan people.

During the ten-year Soviet occupation of 1979, six million Afghans escaped protracted conflict situations and, settled as refugee claimants in the neighbouring countries of Pakistan and Iran. Other regions within Europe and North America accepted fewer numbers of Afghan refugees during the war. Canada's immigration history shows Afghanistan to be the largest refugee producing region during the Soviet invasion; despite this, Canada allocated the lowest refugee quota for Afghan refugees (Pigott 2007).

The second wave of Afghan migration to Canada was a result of the sustained attention paid to Canada by non-government organizations that began to challenge the international reputation of Canada as a humanitarian country (Fielden 1998; Pigott 2007). The 1994 Afghan civil war grew out of the Soviet invasion and was fought between rival extremist warlords. The persistent conflict led to a significant second wave of Afghan refugees. In contrast to the first wave, the Afghan civil war not only generated refugee flows to Iran and Pakistan but also further afield to Western states. The United Nations 
High Commission for Refugees (UNCHR) released a report indicating that 10,960 Afghan refugees arrived to Canada during the Afghan civil war (UNCHR 2005; UNCHR 2009).

The largest wave of Afghan refugees accepted in Canada arrived following the U.S. invasion of Afghanistan of 2001.The U.S. invasion of Afghanistan was a response to the terrorist attacks of September 11, 2001. The U.S. originally invaded Afghanistan to dismantle the Taliban that was suspected of harbouring terrorists from the prominent international terrorist group, Al Qaeda, and its ringleader, Osama bin Laden. In 2003, Canada's military was sent to Afghanistan to establish peace and security within the country. Similar to the Afghan civil war, Afghan refugees also dispersed to different regions of the world. During this time, Canada accepted 15,000 Afghan refugees in 2004 and 14,000 Afghan refugees near the end of 2006 (Statistics Canada 2007; UNCHR 2007).

These three waves of migration of Afghan refugees were the result of many years of internal turmoil and international interventions that constitute Afghanistan's sociopolitical history. Presently, Afghanistan remains plagued by war, poverty, and unjust social and political policies surrounding human rights. Canada maintains its long-term goal of facilitating the voluntary return of Afghan refugees; however, many Afghan refugees, particularly Afghan women, fear returning to Afghanistan because of the continuation of conflict and violence against women (Khan 2002), exacerbated by the rigid gender policing by the Taliban. Afghan refugee women's migratory and settlement experiences need to be understood as distinct from Afghan refugee men's; this is the point of departure of this thesis. 


\section{Afghan Refugee Women's Migratory and Settlement Experiences}

Scholarship on Afghan refugees shows that women's migratory experiences often include gender-specific violations such as rape, sexual or emotional abuse, persecution, and arrest (Dossa 2005; Hyder et al 2007; Khan 2002; Koplik 2003; Lindgren et al. 2004; Otoukesh et al 2012; Ross-Sheriff 2006; Stack 2009; Safri 2011). Hyder et al's (2007) study finds that Afghan women who live in refugee camps in neighbouring countries such as Pakistan and Iran experience high levels of intimate partner violence and psychological abuse during their flight.

In the post-migratory context, Afghan refugee women also experience challenges in settling within their new host-societies. This is exemplified in the 2012 report released by the Canadian Council for Refugees, which found that refugee women experience more obstacles than men in adjusting to Canadian society. These obstacles include limited access to employment, health care systems, and educational attainment. Afghan women emphasize language barriers and feelings of social exclusion and alienation as some of the major issues experienced during settlement (Dossa 2015; Khan 2002; Ross-Sheriff 2006).

Ethnographic research on Afghan refugees in Canada finds that Afghan women experience tremendous distress during migration and settlement in Canadian society (Ahmad et al 2010; Dossa 2005, 2014; Kohistani 2012; Nourpanah 2014; Stack 2009). Parin Dossa (2014) writes in her book Afghanistan Remembers that Afghan refugee women continuously recall the gender-based violence they have experienced in fleeing Afghanistan as well as the extreme violence and repression they were subjected to prior to fleeing Afghanistan. Dossa (2014) adds however that social barriers such as access to health and 
social services exacerbate such feelings of isolation and alienation among Afghan refugees, especially Afghan women.

Despite the obstacles that Afghan refugee women face in Canada, these women are also constantly adapting and formulating strategies to mitigate their pre-migration trauma and overcome barriers to settlement. Kohistani (2012); Dossa (2015); Nourpanah (2006) discuss Afghan refugee women's resilience and agency in developing a sense of belonging in Canada, through food, friendship, parenting, religion, and education. For instance, the act of praying for Afghan women is a quest for healing the wounds that are deeply embedded within their memories of displacement (Dossa 2015; Nourpanah 2014). It is within the domain of their everyday life, that Afghan refugee women rebuild their lives by overcoming adversities through exercising resilience and agency.

This thesis aims to build on studies that have adopted_a gender lens to explore the migration and settlement experiences of Afghan refugee women in order to reveal the multiple circumstances that affect the lives of these women. Dossa argues that the hardship that Afghan women endure within the pre-migratory context become socially invisible after settlement within a new country is achieved (Dossa 2005). This leads me to reflect on the testimonies my mother shared when discussing her own experience of fleeing Afghanistan and arriving in Canada in 1986 during the Soviet invasion. Despite the decades that have passed since this traumatic conflict, the violence my mother experienced and observed during the war persist in her memories of these events. Seen also in Dossa's and Kohistani's participant testimonies, Afghan women have not forgotten how the displacement of Afghan people occurred through war and violence. This study aims to trace 
how these testimonies are passed down to the second-generation, infused with different meanings for the diaspora, contributing to their sense of belonging and construction of identity in Canada. 


\section{Chapter 2: Building a Theoretical Framework - Cultural Hybrid Identity}

Prolonged violence and political instability, described in the previous chapter, have rendered Afghanistan as an undesirable homeland for Afghan migrants to return to once they have left. Instead, Afghans tend to form new homes (both physically and cognitively) in their host-country, thereby contributing to the growth of the Afghan diaspora.

The second-generation Afghan women in my study identify as being a part of the Afghan diaspora in Ottawa and are linked to the global Afghan diaspora. The term diaspora is used to explain transnational movements, dispersion, dislocation, and exile (Gilroy 1993;

Safran 1991). These variations in the use of the term have made the task of defining diaspora increasingly difficult. In consequence, for purposes of coherence and clarity, I explore hybridity as it has emerged within postcolonial diasporic discourse and reflect on the ways in which my participants understand and experience their culture and their countries (both Afghanistan and Canada), and the ways in which this impacts their identities and relationships with their families and partners.

\section{Defining Diaspora}

William Safran's theoretical analysis of diaspora is often cited when defining the term diaspora. Safran begins by drawing attention to the historical significance of the term, originally referred to as "galut," to describe the Jewish colonies that 'scattered' outside of Palestine as a result of the Babylonian exile that took place in the $6^{\text {th }}$ century BCE. Greek colonization of Asia Minor through migration, trade, and conquest dated in 800-600 BCE led to the dispersion of the Jewish people (Safran 1991). For Safran, the etymology of the term is integral to the development of diaspora theory as it stands now. Safran defines 
diaspora as "expatriate minority communities...who have retained a memory and a cultural connection with their homeland culture and/or religion" within their new host communities. Safran further specifies that diaspora consists of group that is "committed to the maintenance or restoration of [their] homeland" (Safran 1991, p. 83-84). Safran (1991) also posits additional definitive elements that constitute the diaspora: the forced movement of people from their homeland, the inability or refusal to assimilate or adapt into the cultures of the new host society where people have relocated, and the formation of a diasporic community within the larger 'host society.'

Safran's definition is widely and harshly criticized by post-colonial theorists for its essentialism. Post-colonial discourse has been influential in adapting the usage of the term diaspora to better understand transnational mobility, dislocation of people and cultures, and cultural identities. Post-colonial/ism is predominantly understood as a paradigm of thought and as Stuart Hall (1990) declares, it should be perceived as not the end of colonisation, but rather a critique of the lingering consequences of imperialism and colonial occupation across borders. Ania Loomba et al (2005) also cite the derived theory within post colonialism - postcolonial theory — as a theory that calls for the "shifting and often interrelated forms of dominance and resistance; about the complex forms in which subjectivities are experienced and collectivises mobilized" including the politics of representation and cultural translations within First World states (Loomba et al. 2005, p. 13-14).

In contrast to Safran, this thesis adheres closely to the discussions of the term diaspora and diasporic by prominent post-colonial theorists such as Stuart Hall (1990) and 
Paul Gilroy (1993). Hall and Gilroy theorize diaspora as a response to the essentialist and biological claims located within racist ideologies that have developed in tandem with colonial exploitation. ${ }^{1}$ These theorists conceptualize and analyze diaspora in a way that addresses the socio-cultural dislocations of people over time and the cultural practices of those who are both forcefully exiled and voluntarily migrate. Both Hall and Gilroy argue that traditional conceptions of diaspora are often obscure and misleading, as they cannot adequately accommodate the diverse experience of groups. Hall argues that diaspora does not refer to the scattering of groups whose identities are dependent on a "sacred homeland" that they must return to. For Hall, this perception of diaspora supports "the imperialised [and] the homogenizing forms of ethnicity" (Hall in Rutherford 2004 p. 235). Similarly, Gilroy (1993) discusses how the interpretation of diaspora becomes a heuristic and provisional method to think about questions of belonging and identity in the context of dispersal and transnational mobility.

Scholars James Clifford (1994) and Avtar Brah (1996) build on Hall's and Gilroy's work on diaspora to further critique traditional definitions of diaspora that have relied on the historical Jewish exile as a 'model' diaspora community (Brah 1996; Clifford 1994, p. 304). By relying on Safran's definition of diaspora, there is a risk of creating illusions of an 'authentic diaspora' that also, allows for a hierarchal structure of diaspora. Given these critiques, it is apparent that definitions of diaspora need to transgress the boundaries of its traditional conceptual and etymological framings that theorists such as Safran promote. More specifically, the definition of diaspora needs to be extended to include all persons

\footnotetext{
${ }^{1}$ In this context, both Hall and Gilroy write about African diaspora and Pan-Africanism as connected to people who are of African descent, who experienced marginalization due to colonialism, slavery, and forced migration.
} 
who experience transnational movements, dispersion, dislocation, and exile from homelands, thereby constituting a heterogeneity of imagined pasts, imagined futures, and self-consciousness that allows for multiple variations of cultural identity.

\section{Diasporic Identity}

Diasporic identity occurs as the result of the multiple variations and heterogeneity discussed above and refers to those who have been displaced and experience ongoing challenges in settling into their new host-country. Returning to William Safran, identity in “...diaspora implies a tension between being in one place physically—the place where one lives and works - and thinking regularly of another place far away" (Safran cited in Kokot et al. 2004, p. 12). Once again, Safran's definition of diasporic identity implies that there is only one type of diasporic identity, an original diasporic identity, which constitutes memories and desires to return to one's homeland. Tololyan (1991) agrees with Safran in seeing the geographical displacement of people as an opportunity for transnational formations of identity to emerge out of their shared experience of dispersal and memories of the homeland, including the desire for eventual return (Tololyan 1991). In conceptualizing the idea that an original diasporic identity exists only within the confines of homeland memories and desires of return, scholars such as Safran and Tololyan also risk reinforcing essentialist and static notions of cultural identities.

Paul Gilroy (1997) critiques the essentialist notions of identity as posed by Safran and Tololyan. Gilroy argues that cultural diasporic identities are manipulated, created, and maintained in varyingly diverse ways among the diasporic, and that conceptualizations of an original diasporic identity is an outcome of European colonialism (Gilroy 1997, p. 310). 
Gilroy also cautions against entertaining the idea of a fixed identity that marks originality, as such conceptions reduce identity to a fixed essentialist category of sameness. Stuart Hall's (1990) discussion on Caribbean diasporic identities also reveals the limitation of conceptualizing an original diasporic identity. He argues that 'identity is not a fixed essence but instead something constructed through memory, fantasy, myth, and narratives as they are constantly "reproducing themselves anew, through transformation and difference" (Hall 1990, p. 236). Hall's description of diasporic identities implies that diasporic identities are continually being negotiated and reconstructed. If there is therefore nothing original about one's diasporic identity, then diasporic identities are always becoming, as they are mediated by history, language practices, memory, and fantasy. More importantly, the process of forming an identity is continuous as the diasporic embodies the transformation of national, cultural, and ethnic identifications, including an imaginary way of being and reconstituting itself in relation.

\section{Hybridity and Hyphenated Cultural Identities}

Avtar Brah (1996) discusses this continuous negotiation and reconstruction of diasporic identity using a gendered lens and by applying the concept of hybridity to nuance how gender impacts the formation of diasporic identities in addition to other modalities such as class and race. The term 'hybrid-ity' is one of the most popular terms to emerge within post-colonial diasporic literature. The term was originally coined by post-colonial theorists such as Homi K. Bhabha, Paul Gilroy, and Stuart Hall to resist narratives of cultural hegemony. This thesis seeks to use these theorists' conceptions of hybridity to 
For instance, in his influential collection of essays in, The Location of Culture (1994), Homi Bhabha asserts that hybridity can help address the complex dynamics between colonial identities and cultural differences; between the self and the other (Bhabha 1994). He argues that the space that we construct as hybrid provides the colonized with the potential to find agency and legitimacy outside of the colonial condition. Indeed, for Bhabha this indeterminate space is perceived as the third space that 'in-between,' the locale in which hegemonic colonial narratives of cultural identity and practices are disrupted. Bhabha draws on the Freudian term 'unhomely' to describe the third space and argues that the construction of hybrid identity involves a "sense of the relocation of home and the world - the unhomeliness - that is the condition of "extra territorial and cross-cultural initiations" (Bhabha 1994, p. 9). Bhabha's conceptualization of hybridity denotes elements of seemingly two contradictory cultures that meet and combine to create a third space of identity.

Stuart Hall builds on hybridity theory to argue that identity 'lives with and through, not despite, difference by hybridity" (Hall 2005, p. 235). By using the term hybrid identities, we can resist claims of stagnated or fixed identities and identify the ambivalent site where cultural meanings and representations have no 'primordial unity or fixity' (Bhabha 1994). Under this conceptualization of hybridity, the hybrid subject is traversing cultures and is both negotiating and mediating similarities and differences within the space that is 'in-between.' The ambivalence within this third space also works as a strategic mode of articulation of new forms of cultural identities that subvert the concept of an authentic origin or identity. 
In the process of constructing a cultural hybrid identity, individuals also apply new meanings to their hyphenated identities. The term 'hyphenated identity' has emerged out of post-colonial studies that have theorized hybridity to address how multiple cultural identifications are formed and constructed among diasporas. Hyphenated identity is particularly useful to understand the various cultural, ethnic, and national identities that exist in a globalising world (Cagler 1997). Thus, Cagler (1997) explains that hyphenated identities can be employed to capture the complexities of cultural configurations and identity formations of trans local and culturally migrants groups (Cagler 1997).

In many cases, hybrid and hyphenated identities are used interchangeably to illustrate the relationship between territory, culture, and ethnicity (Modood et al. 1997). However, hyphenated identity may also imply that there are two cultures within the hyphenated labels, illustrating that identities, despite their hybridity, remain anchored in fixed territorial (national or transnational) markers. As James Clifford (1994) remarks in his analysis, despite these critiques, the hyphenation of identity is a positive articulation of diasporic identity that challenge tropes of original European nationalities by claiming shared cultural-national roots (Clifford 1994, p. 307). Given Clifford's defence for the hyphen, the hyphenation of identities is seen as an empowering marker used by the hybrid subject to reclaim identity.

Scholars outside of post-colonial scholarship also critique the theorization of concepts such as 'hybridity,' 'hyphenated' and 'diasporic' identity, as being framed within a neo-colonial ideology (Acheraïou 2011; Dirlik 1997). They argue instead that the celebration of hybridity is a privilege amongst the immigrant elites. 
Only privileged groups can take advantage of the potentials that the transgression of culture implies (Acheraïou 2011). Stuart Hall has addressed this critique by reiterating that hybrid, hyphenated, and/or diasporic, is not about a "pleasant mixture of culture, but instead about the displacement and the 'double consciousness' of those who have or continue to experience exile (Hall 1996). Hall employs the term 'double consciousness,' originally proposed by W.E. B. Du Bois (1994), to describe the awareness one has in assimilating to a normative Western culture while also maintaining a distinctive culture of one's own.

This double consciousness is perceived as an extension of the hybrid subjects' agency in constructing a cultural identity. In Paul Gilroy's highly acclaimed book called The Black Atlantic (1993), Gilroy expands on the critical notion of double consciousness by exploring the shifting of people, ideas and cultures that began with the trans-Atlantic slave trade. He argues that "the invigorating flux of those mongrel cultural forms" has been significant for cultural renewal in Europe, Africa, the Caribbean, and America (Gilroy 1993, p. 3). Thus, the diverse mixing of cultures continues to be reconstructed and claimed by various nationalities across the globe.

Gilroy explicitly asserts that culture cannot be essentialized or seen as unchangeable because of multiple moments of displacements and assimilations that have occurred during the formation of nation-states. Moreover, he claims that a striking "doubleness" occurs as a result of being in the West, however not completely part of it (Gilroy 1993, p. 58). Gilroy's articulation of hybridity reveals that inevitably double consciousness arises during the construction of identity. What is most pivotal about postcolonial theorizing of hybridity is 
that it reveals the complex social process behind the deployment of ethnic, cultural, and national labels that inform the diasporic subjects ethnic-national and cultural identity that is both fluid and in continuous re-construction.

\section{Homeland and Second-Generation Afghan Women}

Homeland and belonging remain prominent themes in conceptualizing diaspora and diasporic identity. Brah (1996) nuances homeland and belonging to address how hybrid subjects negotiate their multiple locales of identity. She argues against fixed origins of diaspora and argues that 'homing desire' is not the same as the desire for the 'home-land' (Brah 1996). 'Homing desire' refers to the home as a mythic place of desire in the diasporic imagination. The 'home-land', however, is not a place where one can always return.

Borrowing from Brah, I argue that the integration of homing desire becomes ever more crucial in understanding the heterogeneity of diasporic women's social conditions and construction of identity. My own research will uncover how imaginaries of belonging to multiple localities are achieved among second-generation Afghan women. More importantly, I employ a gendered lens to understand Afghan women's experiences of constructing cultural hybrid identities. Furthermore, I build upon the postcolonial definitions of diaspora and cultural hybrid identities offered by Stuart Hall, Paul Gilroy, and Homi Bhabha to identify the processes of identity formation by second-generation Afghan women in Canada in a way that shows how it involves a fluid and complex interplay of culture, environment, and community. Therefore, the following discussion will address the research questions that have been employed to identify how second-generation Afghan women construct their dynamic, situational, and unique cultural identities. 


\section{Research Questions: Building on Narratives and Creating New Discussions}

Within this study, I will explore how second-generation Afghan-Canadian women construct their hybrid identities by negotiating gendered cultural practices, while also integrating into the wider Canadian society as Afghan-Canadians. I will address the following questions by conducting face-to-face interviews with ten participants who identified as second-generation Afghan women: How do second-generation AfghanCanadian women construct and continually negotiate their hybrid identity while integrating into Canadian society? To what extent do they make conscious efforts to preserve their 'Afghanness?' How do these women transform their social environment to accommodate the cultural and national elements of their hybrid identities?

To answer these broader questions, the interviews will be conducted using these three thematic questions:

1. How do second-generation Afghan women conceptualize the term 'second-generation?

2. How do second-generation Afghan women negotiate traditional gendered cultural practices within the Afghan diaspora?

3. How do second-generation Afghan women challenge racialized and gendered stereotypes within both Canada and Afghanistan?

Second-generation Afghans remain a relatively under-studied population in scholarly discourse. In fact, most academic studies on second-generation Afghan women have mainly explored the cultural differences between second-generation Afghans and their immigrant parents (Abbasi-Shavasi et al. 2014; Abbasi-Shavasi et al. 2012; Hynie et al. 
2012; Khanlou et al. 2008; Sadat 2008; Shakya et al. 2010). While the studies noted above have addressed the gendered cultural expectations second-generation Afghan women face, a significant gap exists in the research literature on how these women have negotiated their cultural expectations, while also balancing their hybrid identities, leaving little room for the analysis of these women's agency This study addresses this issue of negotiation through an exploration of the experiences described in open-ended interviews with ten second generation Afghan women.

The thesis proceeds in five chapters towards its conclusion. The next two chapters establish the theoretical framework and detail the methods of data collection and analysis. The collection of stories and anecdotes that were shared by the second-generation Afghan women I interviewed revealed several themes, which I detail in three chapters that follow. In Chapter 4, entitled “Nuancing Second-Generation," I explore participants conceptualization of the term second-generation. This analysis will challenge traditional definitions of the term "second-generation" that have been developed from large-scale surveys, and will introduce the hybrid identities of second-generation Afghan women. Chapter 5, "Cultural Conformity and Resistance" discusses how second-generation Afghan women have resisted or conceded to gendered cultural practices related to marriage and intimate partnerships. The chapter presents the sense of ambivalence of and acts of resistance by these women as they are confronted with these expectations. Chapter 6 entitled, "Neither Here, Nor There," will explore the participants' racialized and gendered experiences within Canada and Afghanistan, building upon key themes of homeland, belonging/not belonging and a sense of being an 'outsider'. The chapter will also demonstrate how second-generation Afghan women are reclaiming their identity through 
small acts of resistance and agency, thereby forming a hybrid identity that includes both their Afghan and Canadian experiences.

Using a gender lens, this study contributes to a greater understanding of hybridity as neither a happy nor an undesirable mixture of two contrasting cultural identities. More specifically, this thesis will present a new narrative to the theoretical framing of cultural hybridity through identifying how second-generation Afghan women navigate there hybrid identities, while actively negotiating Afghan cultural norms and challenging cultural stereotypes of Afghan-Canadians both in Canada and in Afghanistan. The following chapter will explore how this study has been designed to present the narratives of secondgeneration Afghan women. 


\section{Chapter 3: Research Methodology}

In this study I will employ qualitative interviews as the main method of data collection to understand how second generation Afghan women construct, maintain, and negotiate their cultural identity and the meanings they inscribe to their hybrid subjectivities within the Afghan diaspora and the broader Canadian society. This chapter details the relevance of using qualitative interviews to study diasporic communities and the steps taken to conduct my research, including discussions on my unique position as an insider in the community under study, recruitment methods, and details on my participants.

\section{Choosing Qualitative Interviews}

Feminist researcher Sandra Harding outlines three forms of data collection that help feminist researchers identify the social reality of their participants' lives: 1) listening to participants; 2) observing participant behaviour; and 3) examining the data collected (Harding 1986). Feminist qualitative interviews in particular achieve the goals outlined by Harding by reversing the perceived inequality between researchers and participants (Reinharz 1992) when conducting scholarly research. Qualitative interviews encourage participant testimonies and create a welcoming space for engagement (Warner et al. 2010). While there are many ways to conduct qualitative interviews, such as unstructured, semi structured, and structured, my research relied on semi-structured in-depth interviews. My interview guide included pre-determined, open-ended questions that precede additional more free-flowing questions based on the dialogue between researcher and participant. 
Semi-structured, in-depth interviews allow feminist researchers to understand meanings while reconstructing perceptions around the participants' past experiences. Mary Margaret Fenow and Judith Cook explain that feminist research methods such as qualitative interviews actively challenge the common misunderstandings of those who are socially marginalized (Fenow et al. 2005). By using in-depth interviews, researchers explore in detail the experiences, motives, and opinions of those who do not represent the larger population of others. I have found this point to be particularly helpful in further developing my researching design. The in-depth interviews collected for this study from second-generation Afghan women provide unique experience in negotiating cultural expectations and challenging the racialized stereotypes of this group of women, discussed in greater detail in Chapter six and seven. However, in-depth interviews can present many new challenges. Ribbens et al argue that while conducting in-depth interviews, the researcher can face many challenges including developing friendships, and ensuring emotional and physical safety. The researcher, particularly when considered an 'insider' of the community being studied, can also be prone to the 'researcher's assumption' that a participant might be more open to conversation and thereby missing probes that may lead to more informative and enlightening data (Ribbens et al. 1998).

Researchers using in-depth interviews to explore sensitive topics need to examine how their interview questions affect the type of answers provided in dialogue. In this vein, Susan Chase argues that the questions researchers ask make a difference to the quality of data we collect (Chase 2003, p. 275). In-depth interviews provide researchers with flexibility in phrasing interview questions in ways that ask participants about their feelings, experiences, and thoughts. Chase quotes Livia Polanyi, a feminist writer, who argues that a 
clear distinction is needed between the researcher inviting stories from participants rather than inviting only brief responses (Chase 2003). Similarly, within my own research, interview questions were developed to ensure that the interview process accounted for participants' experiences and feelings. For example, the use of open-ended questions throughout the interviews provided my participants the opportunity to share their personal stories. In exploring the value of using in-depth interviews, it can be argued that in employing this research method, feminist researchers are responsible for constructing meaningful interview questions that create a space for open engagement and opportunity by which participants may raise issues and events relevant to their own interest in the research topic

In depth interviews remain a conventional research method when studying identity construction in transnational and diasporic cultures, families, and within migration studies. The study of immigrant Muslim women in Canada has mainly been conducted through faceto-face in-depth interviews by an array of academics (Dossa 2005; 2009; 2014; Dwyer 2000; Kalvir 2011; Kirk 2006; Kohistani 2012; Nourpanah 2014; Shiva 2014; Stack 2009). One of the most notable contributions to this research has been that conducted by Parin Dossa. In her book, Racialized Bodies, Disabling Worlds: Stories Lives of Immigrant Muslim Women, Dossa chose in-depth interviews as her research method because of its capacity to reveal Muslim women's experiences by allowing them to discuss those experiences in their own words as the stories naturally emerged in the interview setting (Dossa 2009). Maissa Khatib also used semi-structured in-depth interviews as her research method in her study of Arab-Muslim immigrant women's experiences in the United States (Khatib 2013). She 
explains that in-depth interviews helped her identify themes that continue to be missing from broader scholarly research on Arab-Muslim immigrants.

The majority of research conducted on the transnational and/or diasporic subject has been done by feminist scholars who identify as belonging to the same cultural diaspora as their research subjects. By conducting in-depth interviews, Giti Kalvir explains that she was able to establish rapport with her participants because the interview situation allowed her to acknowledge her Iranian identity so she could engage with her participants more closely and learn their stories. For example, one of her participants stated that she would have felt "uncomfortable" if she had to explain her thoughts and experience in Canada with somebody who was not familiar with the cultural backgrounds and beliefs (Kalvir 2011, p. 88). This is not to suggest that so-called outsiders are not conducting excellent academic scholarship on minority diaspora communities - persons who do not belong or identify with the group under study; but, it reaffirms the significance of the need to establish rapport in the interview situation and the potential of one's own identity being a positive factor in that process.

Julie Stacks et al (2009) employ qualitative interviews to discuss the adaptation process of Afghan refugees in Winnipeg. The use of in-depth interviews helped these researchers to maintain an overall structure of the interview session, but also allowed for flexibility in probing with follow-up questions. The researchers' outsider position positioned them well to abandon all prejudgements and presumptions about Afghan refugees during their study (Stacks et al. 2009, p. 245-246). However, outsider researchers might have more difficulty building rapport with participants and as a result might receive 
less 'authentic' data from their research participants (May 2014). In my own research, my Afghan identity presented as an advantage and allowed me to establish rapport with my Afghan participants during the interview process because of our shared cultural and gender identity.

The aforementioned qualitative research on Muslim and Afghan women has demonstrated how semi-structured in-depth interviews allow for a space to be created in which participants can share their personal stories and narratives. In-depth interviews in this study on second-generation Afghan women proved to be particularly useful for understanding participants' experiences in negotiating their identities as Afghan-Canadian women. More importantly, when planning in-depth interviews for the study, I made sure that the questions remained open-ended (see Appendix $A$ ) with the intention of providing participants with the opportunity to share only the experiences they wish to disclose.

\section{Participants and Demographic}

Participants were selected based on the following criteria. First, the participant is a self-identified second-generation Afghan woman born in or arrived to Canada at an early age. While scholars have indicated that an early age of arrival for a second-generation immigrant is at least 12 years of age (Portes et al. 1993), during my recruitment this age-range was not addressed, as I was intent on asking participants how they define this category. Second, the participant is at least 18 years old as this is the age that participants can provide individual consent to this research study. Third and finally, the participant lives in Ottawa or the surrounding area. In addition, given the time constraints, it was most feasible to conduct research in the current city in which I reside in. The embassy of Afghanistan is also located in Ottawa and often remains an active site of 
political involvement for young Afghan-Canadians. Thus, recruitment from within this city allows me to attract a distinct group of Afghan-Canadian: those who may have significant insight on Afghan-Canadian relations.

I recruited 10 participants, who met the criteria, and consented to participating in the study. The ten participants who agreed to participate in the study were between the ages of 18 and 33, thereby providing a diversity of distinct experiences of secondgeneration Afghan women. Participants' demographic information was also collected during the beginning stages of the interview process. They were asked to introduce themselves, and were given the option to share their ages, marital status, education attainment, and religious beliefs (see Appendix A). All ten participants shared that they were university-educated and had relationships across the Afghan diaspora as mothers, partners, and daughters (see table 1.0, p. 25). More specifically, participants emphasized their roles as Afghan daughters and their social progression in education attainment and partner relations. Therefore, the relationships as mother, partners, and daughters were found as the defining social markers for participants and are significant in understanding why these categories are highlighted more than others. 


\begin{tabular}{|c|c|c|c|c|c|c|}
\hline \multicolumn{7}{|c|}{ Table 1.0: Participants Demographic } \\
\hline Pseudonym & Age & Education & $\begin{array}{l}\text { Marital } \\
\text { Status }\end{array}$ & $\begin{array}{c}\text { Family } \\
\text { Relationships }\end{array}$ & \begin{tabular}{|l} 
Ages Arrived \\
to Canada \\
(or born in \\
Canada) \\
\end{tabular} & $\begin{array}{l}\text { Transit Country } \\
\text { (Yes/No) }\end{array}$ \\
\hline Afia & 18 & $\begin{array}{c}\text { First Year - } \\
\text { Bachelor's Degree }\end{array}$ & Single & Daughter & $\begin{array}{l}\text { Born in } \\
\text { Canada }\end{array}$ & No \\
\hline Salma & 19 & $\begin{array}{c}\text { Second Year - } \\
\text { Bachelor's Degree }\end{array}$ & Married & $\begin{array}{l}\text { Daughter } \\
\text { Wife }\end{array}$ & $\begin{array}{l}\text { Born in } \\
\text { Canada }\end{array}$ & No \\
\hline Maryam & 22 & $\begin{array}{l}\text { Advanced } \\
\text { Diploma }\end{array}$ & Single & Daughter & $\begin{array}{l}\text { Born in } \\
\text { Canada }\end{array}$ & No \\
\hline Sharbat & 23 & $\begin{array}{c}\text { Second Year - } \\
\text { Bachelor's Degree }\end{array}$ & Single & Daughter & 10 years old & Yes (Pakistan) \\
\hline Sabrina & 27 & $\begin{array}{c}\text { Bachelor's } \\
\text { Degree-Master's } \\
\text { Degree }\end{array}$ & Married & $\begin{array}{l}\text { Daughter } \\
\text { Wife }\end{array}$ & 9 years old & $\begin{array}{l}\text { Yes (Saudi } \\
\text { Arabia) }\end{array}$ \\
\hline Afsoon & 26 & Bachelor's Degree & Single & Daughter & 2 years old & No \\
\hline Parisa & 20 & $\begin{array}{c}\text { Second Year - } \\
\text { Bachelor's Degree }\end{array}$ & Single & Daughter & 9 years old & Yes (France) \\
\hline Tamana & 27 & $\begin{array}{l}\text { Bachelor's Degree } \\
\text { First Year- } \\
\text { Master's Degree }\end{array}$ & Engaged & $\begin{array}{l}\text { Daughter } \\
\text { Fiancé }\end{array}$ & 15 years old & Yes (Russia) \\
\hline Sarah & 27 & $\begin{array}{c}\text { Second Year - } \\
\text { Bachelor's Degree }\end{array}$ & Married & $\begin{array}{l}\text { Daughter } \\
\text { Wife }\end{array}$ & 12 years old & Yes (Pakistan) \\
\hline Alia & 33 & Bachelor's Degree & Married & $\begin{array}{l}\text { Daughter } \\
\text { Wife } \\
\text { Mother }\end{array}$ & 20 years old & Yes (Pakistan) \\
\hline
\end{tabular}


As indicated in the above chart, pseudonyms were assigned to maintain anonymity. All participants read and signed consent forms. The consent form in qualitative research often includes a brief statement explaining the research and informing them of their rights as participants, such as being able to withdraw from the study at any time, confidentiality and anonymity. While this study was not considered high risk, participants were informed during the recruitment phase of the intended length of interviews (one hour) and were periodically reminded that they are welcome to end the interview or refuse to participate any time before the withdrawal date in December 2015. I informed participants that if that all interviews will be audio-recorded, with their consent. Participants were also informed that the interviews will be transcribed using their pseudonyms and that these transcripts will be saved on my personal computer in password protected files, thus ensuring participant confidentiality.

\section{Recruiting Second-Generation Afghan-Canadian Women}

Due to the smaller population of Afghan women living in Ottawa, my research relied on the snowball sampling technique, whereby researchers' study participants are gained through their own and participants' social networks. Participants for this study were recruited through my own social media networks and those of student groups that are frequented by Afghan youth. The snowball sampling method was particularly chosen as recruitment technique as it would allow for a diverse selection of participants to share their distinct narratives.

At the early stages of the research process, I designed a recruitment poster (see Appendix B) for the study and posted copies at the University of Ottawa, Carleton University and Algonquin College. I decided to begin recruitment within the universities as 
I would be able to access participants ranging from ages 18-33, which is the trend in age composition of post-secondary students in Canada (Statistics Canada 2010). Additionally, in March 2015, I attended the Afghan New Year celebration called Nowruz, which was organized by the Afghan student group in Ottawa. I became aware that there were many Afghan students who have graduated and are still active members in organizing Afghan events. Since I did not only intend to recruit current students, I made the decision to contact through an email, the Afghan Student Association (ASA), a student led group at Carleton University and University of Ottawa. The decision to recruit participants from ASA was due to the feasibility of accessing Afghan women who consider themselves as belonging to the second-generation category, some of whom who may not be students. The association also invited me to their meetings and posted my recruitment poster on their social media pages.

Recruitment posters were also distributed among the non-government organizations based in Ottawa such as Canadian Women for Afghan Women and University Women helping Afghan Women. The Afghan Association of Ottawa (AAO) and the Muslim Association in Ottawa were also contacted through their social media groups on Facebook and informed about the objectives of my research and need for participants. During the recruitment phase, the recruitment letter and poster continued to be distributed among the groups contacted and the participants who consented to participate in the study.

The online distribution of the recruitment poster presented some particular challenges. I received emails and messages on social media websites (Facebook and Twitter) from Afghan women who saw my recruitment poster on Afghan social media 
groups, asking if they could participate in my study. One woman who contacted me lived in Afghanistan and worked for a grassroots organization in the country. It was difficult to read their messages pleading to share their stories and have to turn them away as they not fit the participant criteria that I set for this research. For example, another young woman who lives in another city in Canada also sent me a message on a social media site, asking whether she could participate in the study. This specific contact proved to be the most challenging to address as the young woman voluntarily shared her traumatic experiences as a recent Afghan migrant, who was forced to marry at a young age and had difficulty attaining education in Canada. Given the geographical criterion set for the study (Ottawa), I was unable to accept her as a participant for this study. In my response to these women, I outlined my research objectives and thanked them for their interest in my research study.

\section{Coding and Data Analysis}

Due to the low-risk nature of this project, all participants consented to having their interviews audio-recorded. I completed transcriptions of interviews while conducting others. The qualitative data analysis software NVivo was used to code the data to identify the themes that were found throughout all transcripts. Using NVivo query, I was able to analyze the intersections between themes, participant's characteristic, and the common concepts that have arisen within my data. During the transcription process, I often found myself realigning some of my questions to elicit more clarification or thought on an issue in the interviews that followed.

In analyzing the transcripts, I uncovered various themes such as goals and accomplishments, gendered cultural expectations and beliefs, incidents of racism or 
alienation from community (either Canadian or Afghan), and issues related to national events in Canada and global events in Afghanistan. When participants discussed these themes, their stronger emotions were also revealed, either in tears, contagious laughter, and other physical gestures that depicted their frustration or anger. I identified significant quotes that best represented participants' thoughts and emotions. Therefore, the themes within this study have been developed from the shared narratives that participants spoke passionately or emotionally about, including their stories that they want heard.

While reviewing participants' transcriptions, it became apparent that the some of the stories participants were sharing with me had not been shared with anyone else. For instance, during the interviews, some participants shared their experiences with men or conflicts within the family. In sharing these stories with me, participants would state comments similar to "no one else knows this" or “I haven't told anyone this before." It should be noted that after these comments were made, I would ask participants whether they would like me to stop the recording. However, participants rejected my asking, and proceeded to tell their stories.

\section{My Hybridity: Both an Outsider and Insider}

These moments of disclosure obliged me to reflect more strongly on my role within this research study beyond that of the researcher. As a second-generation Afghan-Canadian woman, my identity surely informs my research. I am reminded of my social location and position as an insider by some of my participants who use phrases such as "us" or "we" to include me within their narratives. Their willingness to participate in my study and to have their stories told also surfaced strongly throughout my interviews with these women. For 
instance, one participant asked me to also write "more about our experiences than the wars and Afghanistan's problems."

My experience interviewing second-generation Afghan-Canadian women revealed a shared sense of familiarity and comfort that helped me to establish rapport with my participants. Due to my position as an 'Afghan insider,' these women felt comfortable in sharing cultural scripts that I readily understood. Similarly, scholar Sherri-Ann Butterfield, who studies second-generation West Indian immigrants in New York City, also reports that her respondents could relate to her to in culturally specific ways as soon as she shared with that she too was also "from a yard," (Jamaica) (Butterfield 2004. p. 81).

This unfettered sharing of personal stories by participants also caused me to question my position and motives to undertake this study. I wondered about the stories that might not have not been shared with me because I was simultaneously perceived as an outsider by some of my participants. Throughout the recruitment and beginning stages of the interview process, I became increasingly aware of my mixed identity as an AfghanPakistani woman and saw how my participants read me. My surname- Ahmed - became an immediate marker of my mixed heritage, as it is not a common or traditional family name among Afghan people. It became a topic of conversation during interviews when each participant asked me about my ethnic, religious, linguistic background, and in particular about my experiences of balancing the two cultures - in this case Pakistani and Afghan. I wondered whether participants would not see me as a 'true' Afghan-Canadian due to my mixed cultural identity, possibly restricting my access to some of their stories. For instance, participants would comment on my facial features that looked "Afghan" such as my skin 
tone and thickness of hair and the features that did not. What remained clear to me was that for the participants I too was a hybrid form; however, I was a hybrid that is not only Afghan-Canadian. Throughout the research, I straddled this dichotomy of the insider and outsider.

Miller et al. previously stated that researchers must recognize their social location when attempting to change power dynamics between the researcher and participant, and develop a research design (Miller et al. 1997). I made similar efforts to shift the power dynamics within my own research design by establishing a relationship with participants where they are recognized as knowledge producers - a concept that has received much positive discussion amongst feminist researchers (Harding 1986; Reinharz 1992).

Naples (2003) argues that while power dynamics are inherent in any qualitative research, these differentials can never be overcome or erased; however, reflexivity throughout the research process can help address them, while also remaining aware of the limitations of reflexive practices. Additionally, in her book, Feminist Dilemmas in Fieldwork, Dianne Wolf argues for consciousness-raising in research where researchers actively subvert their power hierarchy with the participants (Wolf 1999). In my own attempts to remain reflexive, I had to constantly remind myself about my own social location and that of the participants - and this helped me better situate myself as a researcher. Reflexivity includes acknowledging power differentials between my participants and myself, while also remaining open to reciprocity in the pursuit of knowledge. Throughout the interviews, I reiterated to my participants the purpose of the research and their rights as participants 
to choose the time, location, length of interviews, to refuse to answer specific lines of questioning, and to end the interviews at any time.

The insider and outsider identities embodied during my research are not rigid or static; these identities are always shifting throughout the research process. My experience of interviewing participants revealed how my insider status as an Afghan-Canadian fostered a sense of rapport where participants felt comfortable sharing their personal stories. However, the research process in and of itself situates me as neither fully an insider nor an outsider but rather occupying an in-between or hybrid position. This positioned me well to discuss the findings of this research study and to present the voices, stories, and experiences of second-generation Afghan-Canadian women. Their narratives illustrate the complexities of identity construction, transformation, and preservation, all of which resonate deeply with my own experiences as a second-generation Afghani-PakistaniCanadian. As a result, when presenting the research findings, I am more interested in exploring how these women define their identity markers and the meanings they ascribe to their hybrid identities. This is the focus of the next chapter, "Nuancing Second-Generation". 


\section{Chapter 4: Nuancing Second-Generation}

Sociological literature on second-generation adolescents has relied on large-scale data - primarily census data - to define second-generation immigrants, thereby excluding, migrants' and refugees' self-determination and agency. Using feminist methodology, I explore how Afghan women migrants in Ottawa, Canada, have come to define and identify with the term 'second-generation'. I have also explored how they (re)construct both their Afghan and Canadian identities in relation to this scholarly concept. In this chapter, I will begin by analyzing existing definitions of second-generation that have been applied within segmented assimilation theory. Alejandro Portes, Ruben Rumbaut and Min Zhou are among the most influential scholars to conceptualize second-generation and propose segmented assimilation, as a theory of the multiple paths of assimilation that children of immigrants tend to take. Following a discussion of this body of literature, I will review the sociological scholarship critiquing segmented assimilation theory. Building on these critiques, I will then problematize the rigid definition of second-generation by exploring the narratives of second-generation Afghan women in this study by using gender and race as analytical lenses.

In 1993, Portes and Zhou (1993) developed segmented assimilation theory to examine the experiences and outcomes of immigrants and their children in the United States. Specifically, segmented assimilation theory argues that there are "segments" of society that immigrants may assimilate into more than others. The theory is important because it has since been taken up by sociologists to address both the processes and outcomes of assimilation among second-generation individuals. 
Portes and Zhou's research on assimilation has been appropriately critiqued and questioned, however, by scholars who call for a more nuanced interpretation of gender (Curran et al. 2006; Donato 2006; Nagasawa et al. 2001; Waldinger et al. 2004). Scholars have advocated that gender is an integral factor in social processes that shape secondgeneration immigrants' life experiences (Curran et al. 2006; Donato 2006). These scholars many of whom have written on the intersections of gender and migration processes - have also drawn attention to the limitations of Portes, Rumbaut and Zhou's over-reliance on survey data (Curran et al. 2006; Donato 2006). These scholars have argued that one weakness of large survey data is that it is limited in its capacity to capture how gender imbues social relations and how these gender distinctions may influence life experiences (Curran et al. 2006; Donato et al. 2006). I have conducted research that similarly challenges such aspects of segmented assimilation theory and restrictive definitions of secondgeneration. By using feminist qualitative interviews, I will expand upon the methodological approaches to a topic that has relied primarily on large-scale data to define the secondgeneration and their assimilation or rather integration experiences. Using qualitative interviews, I argue that Afghan women are self-determined agents who continuously challenge fixed definitions of what it means to be 'second-generation'. My study therefore provides a social forum in which Afghan women define second-generation themselves, whether or not they identify as such, and how such identification has subsequently impacted their Afghan and Canadian identity. 


\section{Second-Generation: Definitions}

Research on second-generation immigrants has received ample scholarly attention in the United States, Canada, and the United Kingdom (Gans 1992; Portes et al. 1993; Portes 1996, Portes et al. 2005; Portes et al. 1994;Rambaut et al. 2001;Waldinger et al. 2004). Many of these contributions have examined the experiences of second-generation youth and adolescents in their respective host countries. In their earlier literature on secondgeneration immigrants, Zhou and Portes (1993) include native-born children who have at least one foreign-born parent as the basis for categorizing youth as second-generation. This definition includes children who were born in a foreign country and have settled in a new host country before the age of twelve (Portes et al. 1993, p. 75). Rumbaut (2002; 2004) makes further generational distinctions among immigrants who settled in the United States as children (Rumbaut 2002; 2005). Rumbaut, for example, categorizes children who arrived in their host country as immigrants into three separate categories: 1.75 generations are those who arrive between 1-5 years old; 1.5 generations includes those who arrive between 6-12 years old; while, 1.25 generations includes those who arrive between 13-17 years old (Rumbaut 2002; 2005). As can be seen from this categorization process, the concept of second generation is not a singular, unified entity but dependent upon how others define a person and how a person defines self.

Portes and Rumbaut's (2005) work is one example of the type of scholarship that has imposed fixed definitions of second-generation. From 1992-2006, Portes and Rumbaut conducted a study called the "Children of Immigrants Longitudinal Study (CILS)" which set out to explore the adaptation processes of second-generation immigrants. During this time 
period, a total of three surveys were conducted on second-generation children and adults in the metropolitan areas of Miami and San Diego. The total sample size of each survey ranged from 2,442 to 5,262 respondents across several nationalities. The CILS was initially set out to further understand the demographics of second-generation children. This study explored the various social factors such as educational levels and linguistic abilities that determined to which segments of society second-generation immigrants would most likely adapt.

Portes and Rumbaut do not critically analyze their definitions of second-generation that were discussed in their earlier publications (Portes et al. 1993; Rumbaut 2002). This is especially evident within their most recent survey that was conducted from 2003-2006 (Portes et al. 2005; Rumbaut et al. 2006). The more recent survey focuses on adaptation outcomes for second-generation adolescents including their employment status, income, ethnicity of spouses, political attitudes, and plans for the future. In this survey, Portes and Rumbaut apply the same definitions for second-generation as those who are children to at least one foreign born parent or who have arrived to the U.S. before the age of 12 (1993; 2002). In consequence by imposing their definition of second-generation, Portes and Rumbaut fail to realize how their definition of the term presents limitations on those who identify as second-generation.

\section{Segmented Assimilation and Criticisms:}

The question Portes and Zhou aim to address in their 1993 study is not how do these immigrants assimilate into American society, but rather, which segments of American society are they most likely assimilate to. Portes and Zhou delineate three possible 
assimilation pathways which second-generation immigrants may take. The first path of assimilation predicts that children of middle-class immigrants will join the American 'mainstream' and achieve higher educational levels compared to children of lower-skilled immigrants. This assimilation pattern involves children of middle class immigrants integrating into the mainstream middle-class, also known as "upward mobility" (Portes et al. 1993, p. 82- 85). Portes and Zhou's second pattern of assimilation involves acculturation into the urban underclass - understood as 'downward assimilation' (Portes et al. 1993, p.82- 85). The third pattern of assimilation called "selective acculturation", involves the "deliberate preservation" of the immigrant's "community" culture and values, including economic integration (Portes et al. 1993, p. 83). Acculturation within segmented assimilation theory refers to the changes that occur after individuals of "minority" cultures are in contact with people who belong to the dominate culture (Gibson 2001)2.

Portes et al (2005) assert that there only two ways to disprove segmented assimilation theory: 1) to demonstrate that downward assimilation does not exist or at the very least affects a small number of people; 2) to demonstrate that "difference between immigrants are random so that, regardless of the average human capital and mode of incorporation of different groups, they will have the same number of success stories and failures in the second-generation" (Falkner 2008, p. 16; Portes et al. 2005, p. 1019). Brian Gratton (2002) challenges this claim by arguing that because segmented assimilation theory is incredibly broad it is difficult to find evidence against it (Falkner 2008, p. 16).

\footnotetext{
${ }^{2}$ Portes and Rumbaut (2001) discuss five types or modes of acculturation processes and outcome: Consonant, two types of dissonant acculturation, and selective acculturation. Portes, Rumbaut, and Zhou use these categories of acculturation to explain the various paths second-generation immigrants may to assimilate.
} 
Gratton (2002) states that the term 'segmented assimilation' already presumes that assimilation has a variable number of outcomes. The ambiguity of the theory is that it is descriptive in nature and includes a wide range of assimilation experiences such as upward assimilation, downward assimilation, and selective acculturation (Gratton 2002). Segmented assimilation theory also includes a broad characterization of those who will adapt into the 'underclass.'

Portes, Zhou, and Rumbaut argue that assimilation into the lower-class as defined by these scholars is an oppositional response by second-generation immigrants that involves socially 'declining' conditions which are incompatible with assimilation into a higher class. Some of these incompatible conditions include the over use of narcotics and alcohol, early pregnancies, and failure to pursue higher education. For Portes, Zhou, and Rumbaut, 'decline' in segmented assimilation theory implies second-generation immigrants' integration into the underclass. However, another set of theorists (Alba et al. 2003; Farley et al. 2002; Waldinger et al. 2004) further argue that those individuals who choose to live within this 'oppositional culture' are also not guaranteed integration into society's lower-class.

Critics of segmented assimilation theory are correct to address the limitations of assuming second-generation decline particularly because the study of segmented assimilation may not be able to determine what segments of society these secondgeneration youth may adapt into overtime. Alba and Farley (2002) also find no evidence of intergenerational decline amongst second-generation South-American adolescents in the United States. Nonetheless, critics have also addressed the insufficient research regarding 
gender within segmented assimilation theory. While Portes, Zhou, and Rumbaut briefly discuss gender, they do not explain how male and females may have different assimilation outcomes and explanations.

Previous research on second-generation immigrants has found that gender is a significant factor in understanding assimilation experiences amongst men and women (Fleischmann et al. 2014; Holtmann et al. 2012; Lopez 2002). However, within their literature review on segmented assimilation theory, Portes, Zhou, and Rumbaut do not thoroughly examine how assimilation experiences differ by gender (Portes et al. 1993; Portes et al. 2005; 2001 a; Rumbaut et al. 2007). Yet, by examining gender differences in assimilation outcomes, researchers have found that social processes such as cultural practices and expectations are different for men and women (Foroutan 2008; Nadim 2014). Additional studies have also found that men and women in the labour market are valued differently by family members and have different occupational expectations based on cultural beliefs and traditions (Padavic et al. 2002; Nadim 2014).As such, gender is a factor in the process of assimilation that cannot be ignored.

The brief and desultory discussion of gender in Portes and Rumbaut's theory is evident also in their renowned book, Legacies: The Story of the Immigration Second Generation (2001). Portes and Rumbaut argue that second-generation males and females become socialized to play different roles during adolescence-while females in particular are less autonomous and "under the influence of their parents" due to the "protective character of their upbringing" (Portes et al. 2001 a, p. 64, p. 64-68). However, Portes and Rumbaut only briefly discuss gender gaps that are attributable to social class, education 
attainment, self-esteem, and language acquisition for second-generations (Portes et al. 2001 a, p. 13). No further discussion exists on how the gendered social processes the systemic and institutional impacts of gender, such as their different experiences at home or school create or support these differences.

\section{Discussion on Literature}

Curran et al. remind us that survey data may be incapable of translating gender variables in an analysis of specific assimilation outcomes to reveal different assimilation outcomes between men and women (Curran et al. 2006, p. 215). Similarly, Portes, Zhou, and Rumbaut's over-reliance on large-census data fails to adequately address how social and institutional spaces are gendered and lead to different assimilation experiences. The term second-generation requires a more nuanced interpretation than what can be achieved by_Portes, Zhou, and Rumbaut's proposed quantitative data.

For example, through conducting in-depth interviews with second-generation Afghan women, I found that many of my participants who have arrived in Canada with their parents after the age of 12 identify as being part of the second-generation and therefore have subliminally helped develop new conceptualizations of 'second-generation'. In exploring the term second-generation category, it is clear that Portes, Zhou, and Rumbaut's have generalized the definition of second-generation adolescents using a wide range of fixed variables, to determine paths of assimilation among this demographic, but in neglecting to consider gender, have eliminated a major variable in the assimilation process. 
I use qualitative interviews to provide data containing a more nuanced exploration

of the term second-generation. More specifically, the narratives of Afghan-Canadian women will provide significant insight as to how gender and race are integral to understanding the distinct adaptation processes existing among second-generation females. The following discussion addresses how those factors appear in the narratives of ten Afghan women and how they define the term second-generation.

\section{Defining 'Second-Generation' for themselves:}

In this section, I will discuss how ten Afghan women (between the ages of 18 and 33 in Ottawa, Canada) define and self-identity as 'second-generation'. Out of the ten participants who participated in the study, three were born in Canada (Afia, Salma, and Maryam), four arrived to Canada before the age of twelve (Sharbat, Sabrina, Afsoon, Parisa), and three settled in Canada after the age of twelve (Tamana, Sarah, Alia). It is important to acknowledge that prior to recruiting participants for this study; the necessary requirements were met to ensure that only those who identified as second-generation Afghan women were recruited to represent the diverse spectrum of the term. For instance, the recruitment poster and initial email explicitly stated that I was seeking secondgeneration Afghan women in Ottawa and the surrounding areas. Furthermore, this point was reiterated to the participants recruited through snowball sampling and also stated in the consent forms that were signed by each participant.

During the interviews, the participants applied their own meaning towards 'secondgeneration'. For instance, when I asked the participants, "What comes to mind when I say 
the word 'second-generation'? (S2, Q1; see Appendix A), all of the participants described in their own words what it meant to belong to this social category. It needs to be noted that the meaning that the participants associated with second-generation challenge existing definitions of the term as stated within Portes and Zhou's theory of segmented assimilation. Significantly, the narratives attached to their explanation of secondgeneration indicate that second-generation Afghan women are integrating rather than assimilating into Canadian society

Participants also problematize the existing definitions of second-generation through narratives that reveal a variety of factors being used to establish their 'second-generation' identity, such as comparisons across generations and the state of home-countries-thus rendering the 'age of arrival' as an ambiguous defining factor of belonging to the second-generation category. Additionally, by addressing their transnational migratory mobility, the participants also draw into question the importance of origin and destination countries as playing the major role in how to theorize the concept of second-generation. Lastly, the interview data casts doubt upon Portes and Zhou's definition of second-generation pathways being driven by structural constraints on social mobility such as racism. As, the following statement by Tamana will demonstrate, the women I interviewed do not support Portes and Zhou's definition of second-generation and segmented assimilation but see their second generation status as more of a hybrid of both their experiences as children raised by Afghan parents and their experiences growing up in Canada. To quote: 
Second-generation... is a combination of environment and cultures that I have lived in...Not necessarily having the option to choose one or the other [but] making the best of both worlds.

Tamana's above response includes a description of second-generation that is integral to understanding the term: a combination of two differing cultures. She further states that second-generation for her means to "accept a second culture" in addition to her Afghan culture. From this statement it is also apparent that for Tamana her second culture is Canadian. By constructing her own unique cultural identity, she maintains her Afghan identity within a Canadian culture, by 'combining' the two but still seeing each as distinctive. This finding matches Sangeeta Gupta's (1998) statement in her own study of South Asian immigrants that children of immigrants balance both world-views of their identity in an attempt to construct one cultural identity (Gupta 1998, p. 123). In a similar fashion, Tamana's statement offers a more complex analysis of integration that coincides with Gupta's theorizing of cultural identity through her reconstructing of a second generation Afghan identity that is also Canadian.

The participants in my study also demonstrated their negotiation of an AfghanCanadian identity throughout the interviews by drawing comparisons between second and first generation Afghans. For example, one of the participants, Parisa, began her discussion of the term second-generation with a comparison of first-generation Afghan women and second-generation Afghan women:

[There are] different experiences from Afghan women who have lived [in Afghanistan]. There's a huge gap between first-generation and second-generation because they live completely different realities. (My mother) had to live through 
the Soviets invading Afghanistan (and) had to go to university separated from men....then you see me twenty years later and my reality is completely different. -Parisa [Current Age: 22, Age of Arrival: 9]

Parisa is drawn to the different lived realities between first-generation and secondgeneration Afghan women. She reflects that many first-generation Afghans are those who have experienced Afghanistan's historical conflicts first-hand. By comparing her mother's experience as an adolescent in Afghanistan with her own, Parisa situates her own status as a second-generation Afghan woman. Similarly, another participant, Maryam, illustrates a hypothetical comparison of what her life would be like if she was not living in Canada:

If I [lived] in Afghanistan...I know that I would [be living] in one room with my brothers, my mom, and my dad, [in a shared] house with 10-12 of our cousins. -Parisa [Current Age: 20, Born in Canada]

For Maryam and Parisa there are clear social differences between their lived realities in Afghanistan and in Canada. While the two participants do not formally define 'second-generation', they subliminally apply meaning to the term when mentioning that second-generation Afghans adolescents live in significantly different (and preferable) social environments than Afghan adolescents who currently live in Afghanistan. Maryam demonstrates this further by stating:

I have a lot of opportunities... that I wouldn't have in Afghanistan. I'm twentytwo. If I was twenty-two in Afghanistan, I would probably be married [and] have my first child by now. - Maryam [Current Age: 22, Born in Canada] Maryam uses the word "opportunity" to describe what second-generation means to her. Coincidentally, Sharbat's response to the same question also makes mention of the 
word "opportunity." When I asked Sharbat if she would like to expand on what she meant by "opportunity", she stated:

[Opportunity means that] I can choose something and there is a chance for me to go far with education, work, and life. - Sharbat [Current Age: 23, Age of Arrival to Canada: 10]

For Sharbat, being second-generation means having access to opportunities that are limited in Afghanistan — such as education and employment. Second-generation includes meanings that express positive aspirations, such as her desire to "go far with education, work, and life". Sharbat's aspirations are defined within her conceptualization of secondgeneration as an 'opportunity'. This is further exemplified in the following passage about her cousins:

My cousins who are my age living [in Afghanistan]...they have gone to school...but the situation is so bad. You're not sure if something is going to happen [to them].-Sharbat [Current Age: 23, Age of Arrival to Canada: 10 ]

The distinct realities of Sharbat's cousins living in Afghanistan reveal why, for Sharbat, the meaning of second-generation coincides with 'opportunity'. Significantly, the term 'opportunity' has rarely been used when conceptualizing a definition for the term second-generation. This is particularly the case with segmented assimilation theory by Portes, Zhou and Rumbaut (1993; 2003; 2005). 'Opportunity' for these theorists is a term used to 'measure' the various assimilation outcomes amongst second-generation immigrants quantitatively rather than guiding an assessment of the meaning immigration may hold for identity. For instance, Portes, Zhou and Rumbaut refer to "socioeconomic opportunity structures" to determine the economic and educational attainments of second- 
generation immigrants in the United States (Portes et al. 1993). However, they do not discuss how such opportunities may be perceived or how they may impact one's satisfaction with the decision to reside in a new country

A significant limitation of Portes, Zhou, and Rumbaut's quantitative study on segmented assimilation is their assumption that being second-generation is an opportunity that is either exceeded by individuals, notably those who use the privilege of being in an advanced society of upward mobility, and that some individuals do not take advantage of it. Due to these assumptions, these scholars also do not make room for the second-generation to define the experiences for themselves. In contrast, my data indicate that opportunity can be perceived as having 'choice' that is, the freedom to engage in non-traditional activities, marry when and who one wants to marry, and strive for the educational or job opportunities one desires. As a result, second-generation as a social category has been viewed as inherently opportunistic by some of the participants, thereby redefining the category to more accurately reflect these qualitative measures is imperative.

\section{'Second-generation' developed en route}

As aforementioned in this chapter's literature review, the category of secondgeneration also includes children who are born in their parent's host country and have one or more foreign born parent or children who have arrived to the new country before the age of twelve (Portes et al. 2003). However, Portes and Zhou (1993) fail to acknowledge this heterogeneity of migration experiences, especially the fact that many children of immigrants may experience temporary homelands prior to settling in a new host-country. Within my study, those participants who were not born in Canada expressed their 
migratory experiences as a process that begins from the country of origin to their final destination. I found that regardless of the age the participants arrived in Canada, their second-generation identities began to develop in the homelands that they lived in after leaving their country of birth (albeit temporarily) and before arriving to the final hostcountry—Canada.

Participants Alia, Sarah and Tamana arrived in Canada after the age of twelve. My interviews with these three participants revealed that the definition of second-generation used in the research literature does not account for people like Alia, Sarah and Tamana who have experienced transnational mobility. Transnational mobility in this context refers to a person migrating from one country to another (Sirkeci 2009). Transnational mobility also includes the 'liminal' space(s), such as the location of temporary residence that is in between the origin country and country of destination. This liminal space is often occupied by those who leave their origin countries to seek for immediate human security and those who are avoiding the root causes of human insecurity (Sirkeci 2009, p. 7).

The participants' experiences of migrating from one country to another further problematize definitions of second-generation. For example, prior to arriving to Canada in 2002, Alia and her family moved to Pakistan where they lived for ten years. While born in Afghanistan, Alia was only nine years old when she and her family had to leave their homecountry. In a similar fashion, Sarah and her family moved from Afghanistan to Pakistan in 1992 when she was three years old and eventually arrived to Canada in 2002, when she was thirteen. Tamana and her family left Afghanistan and moved to Russia in 1998 and were sponsored to move to Canada in 2001 when she was thirteen years old. In 
consequence, all three women had formed identities as refugee children growing up in other countries before they settled in Canada as hybrid Afghan-Canadians.

From Rumbaut's (2002; 2005) conceptualization of second-generation, Alia, Sarah and Tamana would not belong to the second-generation category but would be assigned to distinct generational cohorts. These generational categories are as follows: 1.75, 1.5, 1.25 generations - depending on the age they have arrived to Canada. However, Alia, Sarah, and Tamana's experiences of migrating from Afghanistan to Canada reveal that the temporary location of settlement is where their identity as second-generation Afghan women began to develop. All three participants use second-generation to situate their own migratory experiences as Afghan women. Thus, for example, Alia, Sarah and Tamana, all arrived at their temporary country of residence (Pakistan and Russia) well before the age of twelve and claimed that their identity as a second-generation Afghan woman began within Pakistan and Russia. Sarah provides a definition of what she thinks secondgeneration constitutes:

Second-generation...is anyone who is born in Canada and who wasn't born in Canada that has spent time in other [countries] and has arrived to Canada, like me and my bothers.- Sarah [Age: 27, Age of Arrival to Canada: 12]

For Sarah, the definition of second-generation includes those people who have migrated to Canada, including herself and her siblings. As stated by Sarah, secondgeneration also applies to those who are not born in Canada and have lived in other countries prior to arriving in Canada. Similarly, Alia, who arrived to Canada at the age of twenty, identifies herself as second-generation and defines second-generation in comparison to those who are of third-generation. She states the following: 
Second-generation...I am...second-generation....and my kids would be third generation. - Alia [ Age: 33, Age of Arrival to Canada: 20]

Alia's description of second-generation is developed in comparison to her actual children who she believes are of the third-generation. Alia further explains that as a second-generation Afghan woman, her "values are the same" as her parents as she is "very family oriented." The definition of second-generation for Alia implies familial cultural values that are similar to the cultural values from the first-generation. Alia's statement above reveals that despite her status as a second-generation immigrant, she still maintains similar cultural values as her parents thereby making her a 'hybrid' of sorts, that is, caught between the cultural values of the first generation (i.e. her parents) and the cultural knowledge she has formed through her experiences as a young woman living in Canada.

\section{Second-generation: An ambiguous category}

The second-generation category, by definition, imposes a classification that differentiates between those who are perceived as immigrants and those who are not. For example, one of my participants notes that mere usage of the term second-generation implies difference:

If you say you are [second generation] Canadian...people look at you and question you...You don't fit what the ideal is. You're not Caucasian, you don't have blue eyes and you always have to [share] the back story. "[I'm secondgeneration], but I immigrated here. - Sabrina

Sabrina's quote demonstrates how the term second-generation is used to make distinctions between those who look like they are born in Canada and those who are not. When I first asked Sabrina whether she identified as second-generation she stated that it was not until she saw the recruitment poster that she thought of herself as second- 
generation (see Appendix B). When I asked her whether she wanted to share why she did not see herself as being second-generation before she saw my poster, she responded with the following:

I just never had to use that term to identify myself ....I have never been put in a situation where I have been asked if I am first or second generation. People just kind of assume that if you look like an immigrant you must be new to the country.

Sabrina's statement demonstrates that, for her, there is no significant difference between whether one chooses to identify as second or first-generation. However, the identification of difference appears to be important to others. Thus, regardless of the generational cohort that one may belong to, the social application of these categories can alienate those who are visible minorities. This idea is also reiterated in the response by, Salma. When I asked Salma what comes to mind when I say the word second-generation, she gleefully laughed and responded with:

Honestly, Stephan Harper's second-citizenship [bill C-24] is the first thing that comes to my mind.

Salma draws attention to Bill C-24, after I asked her the question (S2. Q1, see Appendix A). I interviewed Salma on November, 2, 2015 when the controversy surrounding Bill C-24 had gained significant attention in the national media after Prime Minister Justin Trudeau campaigned on repealing provisions of the Bill just a month prior. This controversial Bill was passed by the previous Conservative government after the implementation of Bill C-51, the Anti-Terrorism Act, which gave the Canadian Security Intelligence Service (CSIS) and the RCMP unprecedented oversight in preventing future terrorism related incidents Bill C-24, however, introduced a two tier citizenship system, 
whereby second-class citizenship status would be assigned to second-generation citizens regardless of whether their place of birth was in Canada or not. Notably, Bill C-24 was opposed by ethnic minorities for implementing strategic clauses that revoke the citizenship of those who carry dual citizenship or those who are eligible to claim dual citizenship. As Sabrina's statement indicates, the publicity brought on by Bill C-24 tended to highlight for her (and possibly many other immigrants) how the term second-generation implies difference between those who are visible minorities and those who are not and how application of the term may result in prejudicial or harmful treatment.

\section{Conclusion}

This chapter demonstrates how definitions of second-generation are more nuanced and far more complex than the traditional definitions proposed by Portes, Zhou, and Rumbaut (Portes et al. 1993; Rumbaut 2002; 2005). Traditional definitions of secondgeneration have relied on large-scale data in identifying assimilation pathways of U.S. born children and adolescents, including those who have settled in the country before the age of 12. This has subsequently removed the capacity for migrants to define for themselves the meaning of second-generation. By using feminist methodology, I found that my participants have continuously challenged fixed definitions of what it means to be second-generation. All of the women I interviewed stated that they identified as a second-generation Afghan women. Two of my participants also applied new approaches for defining secondgeneration, such as the pursuit for wide ranging 'opportunities'. Three participants also defined second-generation by comparing the distinct lives of second and first-generation Afghan women. In addition, the three participants who arrived to Canada after the age of 
twelve offered further complexity to fixed definitions of second-generation based on their transnational migratory experiences and their development of a second-generations status in another country. Participants also demonstrated how the category of second-generation can create differences amongst those who are visibly perceived as immigrants and those who are not.

The women in this study have either redefined or reformulated the term secondgeneration to make sense of their own identities as Afghan-Canadian women. In certain cases, participants applied meanings to second-generation to situate their own cultural identity as Afghan-Canadians. For example, Tamana combined both Afghan and Canadian cultures and defines herself as embodying a hybrid identity as second-generation. It is clear that the process of defining second-generation made the participants in my study more self-aware of the significance of being second generation as well as the process of constant identity reconstruction that occurs throughout their everyday life. The construction of their cultural identities will be explored in the following chapter through an analysis of how these women negotiate gendered cultural practices within the Afghan diaspora. 


\section{Chapter 5: Cultural Conformity and Resistance}

Scholarship on migrant settlement and integration has found that women play an integral role in the maintenance of their culture (Abbasi-Shavazi 2014; Dasgupta 1998; Dwyer 2000; Gupta et al. 1997; Handa 2003; Sundar 2008; Rajiva 2013). Claire Dwyer (2000), in her study of young South-Asian Muslim women in Britain, illustrates that these women are often responsible for preserving their parent's cultural identity and values. During my interviews with second-generation Afghan females, I found significant parallels with the existing scholarship on the role of young women in migrant settlement and integration; in particular, cultural practices surrounding marriage. Marriage, the primary theme addressed in this chapter, emerged as a central topic when discussing gendered negotiations of cultural practices in all participant interviews.

To begin this chapter, I will explore literature on unequal gender roles and expectations that second-generation women encounter in the pursuit of preserving their traditional culture in a post-migratory context. In addition, emerging research on transnational marriages will be discussed to demonstrate how gendered practices have evolved within the Afghan diaspora. These two areas of scholarship are combined to situate marriage as an important cultural concept for understanding how second-generation Afghan women negotiate their traditional gendered practices within the Afghan diaspora. Next, I will discuss the experiences of second-generation Afghan women who participated in the study, a previously understudied demographic whose voices and lived experiences have been excluded in research on post-migratory experiences. Overall, the study revealed how these young women exercise agency and resist traditional gender norms. Building on 
the previous chapter, the goal is to provide a stronger understanding how participants use their hybrid identities to negotiate traditional cultural practices.

\section{Unequal Gender Roles}

Second-generation women within diasporic communities are often expected to conform to the cultural traditions of their and/or their parents' country of origin while simultaneously adapting to a new society. Post-migration scholars such as Gupta et al (1997) argue that these women are continuously negotiating identities between their parent's cultural values and the culture of their "adopted home" (Gupta et al. 1997, p. 585). In their study on second-generation Indian women, the researchers discuss the unequal gendered expectations within the home. Daughters are "disproportionately burdened with the preservation of culture in the form of religion, language, dress, food, and childrearing" (Gupta et al. 1997, p. 386). Moreover, parents are more restrictive with young women in terms of social activities than they are with their brothers (Gupta et al. 1997).

Continued research on the experiences of second-generation women (particularly South-Asian women ${ }^{3}$ ) has found they are often expected to fulfill the expectation of the 'good daughter' within their families (Dwyer 2000; Handa 2003; Sundar 2008; Rajiva 2013). These highly gendered interactions between daughters and their parents is further exemplified in Handa's (2003) research on second-generation South-Asian women in

\footnotetext{
${ }^{3}$ For the purpose of clarification, the term 'South-Asian' refers to the diverse ethno-cultural demographics originating from Pakistan, India, Bangladesh, and Sri Lanka (Abraham 2002). Due to the plethora of post-migratory research on second-generation South-Asian women from these cultural demographics, the term South-Asian will be used interchangeably throughout.
} 
Canada, in which she finds that unlike males in the family, females are expected to help their mothers with domestic labour and be the reproducers of culture (Handa 2003). In addition, marriage is seen as a significant symbolic cultural practice that young women are expected to adhere to, as the 'reproducers' of their own culture (Handa 2003).

The significance of marriage as a culturally-specific gendered expectation from young South Asian women is also reinforced in Dwyer's (2000) study on South-Asian Muslim women in Britain. Her study reveals that the unequal gender roles assigned to her participants are shaped by familial expectations of "appropriate femininity" (Dwyer 2000, p. 181). For Dwyer's participants, appropriate femininity means conforming to the traditional cultural behaviours and practices that are required of young women, including marrying within the diaspora, which is most often arranged by parents or family members (Dwyer 2000). Additionally, second-generation women are often seen as 'the daughters of the diaspora' responsible for maintaining their cultural identity by safekeeping their 'appropriate femininity.' Researchers Rajiva (2013) and Sundar (2008) argue that secondgeneration females also have to conform to patriarchal gendered roles such as carrying out household duties to remain "marriageable", to avoid disappointing their parents.

Marriage, as a significant cultural practice and modesty as an expected gendered behaviour, emerged as prominent themes in all of the aforementioned qualitative studies on second-generation women across a number of post-migratory contexts (Abbasi-Shavazi 2014; Dasgupta 1998; Dwyer 2000; Gupta et al. 1997; Handa 2003; Sundar 2008; Rajiva 2013). Specifically these studies have found that women who belong to minority ethnic diasporas occupy a particular status within their respective communities that situate them 
as the bearers of their culture (Yuval Davis 1989 in Dyer 2000, p. 477). The gendered expectations required of daughters in the South-Asian diaspora demonstrate marriage in particular as a cultural practice that secures cultural identity. These gendered expectations also resonate within the Afghan diaspora, in which Afghan women are expected to adhere to the cultural practices related to marriage (Sadat 2008).

\section{Second-Generation Afghan Women}

The research literature on second-generation Afghan women has emerged within the comparative studies undertaken by Abbasi-Shavasi et al $(2014 ; 2012)$, Hynie et al (2012), Khanlou et al (2008), Sadat (2008), and Shakya et al (2010). The brief literature review in this section reveals a tendency in these studies to sometimes represent racialized youth as a homogenous group. In particular, these studies rely on the experiences of Afghan men and racialized second-generation women from different ethnic groups to speculate on the experiences of second-generation Afghan female youth. As a result of this selection bias, the personal narratives of second-generation Afghan women that present their lived experiences through their own words have remained unexplored.

The absence of second-generation Afghan women's narratives is exemplified in Hynie et al's (2012) research on 'acculturation' within Canadian society. Hynie et al explore not only the acculturating experiences of Afghan adolescents, but also of Sudanese and Burmese adolescents. While the scholars employ focus groups and qualitative interviews in which they divided their participants by ethnicity, age, and gender - their analysis fails to demonstrate and explain if their participants' experiences vary based on these social identity categories. For instance, Hynie et al's Afghan female focus group found that Afghan 
female cultural responsibilities include taking care of the elders. More importantly, the study design appears to neglect the individual and personal narratives of the Afghan female participants, which could have been used to better understand how the young women interpret these unequal cultural practices, how they shape their experiences of integrating into a new society, and the ways in which they might resist such gendered expectations.

Khanlou et al (2008), use similar research methods to explore the experiences of Afghan and Iranian youth in Canada. The focus of their study is the shared challenges faced by Afghan and Iranian youth when integrating into Canadian society; however, they do not address how these experiences may also differ. For example, they conclude that both Iranian and Afghan youth felt discriminated against by their peers after the events of September $11^{\text {th }}, 2001$. As a result, the researchers inadvertently homogenize the experiences of two groups of youth based exclusively on their shared religious identity rather than considering such distinctions as gender, education or social class.

The research by Shakya et al (2010) relies upon qualitative interviews and focus groups to uncover the experiences of Afghan youth; however the researchers also continue to present similarities rather than differences in participant responses. Shakya et al also homogenize the experiences of their participants by addressing exclusively family-level responsibilities for second-generation women (Shakya et al. 2010, p. 70). In this way, the comparative methods of analysis used across different racialized youth groups within the Shakya et al (2010), Khanlou et al (2008) and Hynie et al (2012) studies have had a tendency to homogenize Afghan women's experiences based on their shared religious or 
racialized identities with other ethnic groups without further analyzing how these women may navigate the social and cultural terrains in which these experiences occur.

Other scholars such as Abbasi-Shavasi et al (2012) who explore the post-migratory experiences of second-generation Afghans also employ a comparative lens to address Afghan women. Unlike the previous studies, the participants within their studies are solely from Afghan cultural background; however, the researchers also pay less attention to the personal narratives of second-generation Afghan women. In their study on secondgeneration Afghan's in Iran, Abbasi-Shavasi et al (2012) conducted qualitative interviews with second-generation Afghans to identify the socio-cultural adaptation patterns among Afghan adolescents. While the authors did conclude that gender is an "important conceptual lens" in addressing the adaptation patterns of second-generation Afghans, they also claim that Afghan women are more likely to 'out marry' (married outside the Afghan culture) compared to Afghan men, however they do not further explore this finding nor do they address Afghan women's experiences in the integration process (Abbasi-Shavasi 2012, p. 124).

It should be mentioned that Abbasi-Shavasi et al's (2014) study on secondgeneration Afghans employs semi-structured interviews and focus groups with an equal number of male to female participants. Within this study, the researchers aim to address marriage and family formation practices among second-generation Afghans in Iran. While the researchers conclude that social and cultural expectations surrounding marriage for Afghan women are related to familial honour, they do not provide a forum for understanding how Afghan women perceive these gendered expectations (Abbasi-Shavasi 
et al. 2014, p. 846). For example, Abbasi-Shavasi et al discuss that a common response from second-generation Afghan women was that many felt that their brothers had more personal agency when choosing a marital spouse. The discussion that follows these findings in the study, however, does not address how these women view and negotiate these unequal cultural practices relating to marriage (Abbasi-Shavasi et al. 2014. p. 849).

Correspondingly, the research by Sadat (2008) relies on an ethnographic survey to determine the Afghan cultural practices across North America, Europe, and Australia. Sadat reveals that arranged marriages and traditional gendered customs associated with the practice are common within the Afghan diaspora. For example, Sadat asserts that within the Afghan diaspora, young men's social activities include late-night partying and dating. In contrast, young Afghan girls are expected to avoid these social activities, as their parents require them to act modestly and represent their family honour thus preserving their reputation as "marriageable" (Sadat 2008). However, despite the invaluable usage of Sadat's ethnographic survey in identifying Afghan marital customs, the surveys cannot account for how these women negotiate such distinctive cultural practices.

The scholarly research discussed in this review (Abbasi-Shavasi et al. 2014; AbbasiShavasi et al. 2012; Hynie et al. 2012; Khanlou 2008; Sadat 2008; Shakya 2010) reveals the significance of gendered cultural practises in the Afghan diaspora and the specific expectations from second-generation Afghan women. As discussed however, these studies have tended to homogenize the experiences of racialized youth adhering to similar (not the same) cultural responsibilities and in relation to Afghan males with little in-depth explanation of gendered expectations, attitudes and behaviours. Arguably, the 
shortcomings of these studies reveal a gap in understanding of how Afghan women interpret and negotiate cultural expectations. Using a gendered lens should require researchers to situate the voices of their participants (in this case second-generation Afghan women) at the forefront of their studies to further identify their integration and cultural negotiation practices. In comparison, the personal narratives of second-generation Afghan presented by my data analysis in this chapter provide significant insight as to how these women perceive gendered cultural expectations and whether they actively try to resist reform or change their outcomes

\section{Marriage}

Marriage is a central cultural practice that second-generation women are often expected to partake in if they are to maintain their cultural identity and family honour (Das Gupta et al. 1997; Dwyer 2000; Handa 2003; Sundar 2008; Rajiva 2013). The limited research on the marital practices within the Afghan diaspora (Abbasi-Shavasi et al. 2012; 2014; Sadat 2008) has found that some second-generation Afghan women tend to feel obligated to comply with the cultural practice of arranged marriages; however not all do. This study sought to find some of the ways in which women at the most might resist such cultural practices or at the least express their discontent. Although the majority of research on the practice of arranged marriages has focused on the South Asian diaspora, it still shows how marital practices and customs are avenues for the transnational and intergenerational transmission of culture. The following discussion will draw upon literature on transnational marriages, specifically arranged marriages within the SouthAsian diaspora, to reveal the ways in which marriage as a practice that works to maintain 
and transmit culture across borders and generations. More specifically, I will address how arranged marriages have been traditionally perceived in the West and ways in which the diaspora has influenced changes in the marital practices over time.

Medora et al (2003) assert in their research on South-Asian marital customs that marriages both symbolize and solemnize the unity between two families, sharing a common goal of maintaining cultural values and traditions. Traditionally, the unity of two compatible families is valued more than the 'love-interests' of the two individuals within arranged marriages. While marriage customs such as arranged marriages seek to transmit and maintain culture, arranged marriages today have also evolved, so to speak, in terms of tradition. Gender dynamics within these marital customs have also become more egalitarian with the advent of technological advancements, urbanization, industrialization and globalization (Aguiar 2000; Medora et al. 2003; Pande 2014).

\section{Defining Arranged Marriage}

Arranged marriages are prominently practiced within Indian, Asian, and Middle Eastern cultures. The cultural practice is commonly understood as a union between two individuals who have been 'matched' as compatible suitors for one another by members of their family (Shaw 2001). However, due to the amorphous set of cultural practices that fall under the category of 'arranged' marriages within the South-Asian diaspora, the concept is incredibly difficult to define. For instance, while arranged marriages are commonly seen as an arrangement made by family elders, the practice can also be arranged by a friend of the family who acts as a 'match maker'. Other practices within arranged marriages include marriages within the family and arrangements based on astrological signs. These diverse 
practices are identified and explained within the literature on South-Asian transnational marriages, including the practice of dowry (Aguiar 2000), the status of immigrant women as a factor in arranging transnational marriages (Rai et al. 2009), the practice of consanguineous marriages (Shaw 2001), and the practice of arranged marriages among educated South-Asians (Bhopal 1999, 2000; Pande 2014; Titzmann 2011).

Arranged marriages have also been criticized within Western media as a distorted marital arrangement that is common within the so-called backwards cultures of the East (Khandelwal 2009). For example, Western discourse prominent in productions such as The Generous Betrayal: Politics of Culture in the New Europe by Wikan (2002), and Is Multiculturalism Bad for Women by Okin (1999), have constructed arranged marriages as a patriarchal cultural practice and represent women as victims of their culture (Bhopal 1999; 2011; Khandelwal 2009). This negative portrayal of arranged marriages within the West invokes images of coercion, in which young women are treated as commodities and forced to marry older men (Khandelwal 2009). However, such stereotypical views preclude the agency of some women who have chosen arranged marriages. For example, research on second-generation women within the South-Asian diaspora has shown that women are actively negotiating their gendered expectations within arranged marriages (Dwyer 2000; Pande 2014; Shaw 2000).

In Dwyer's (2000) research on second-generation South-Asian women, she argues that her participants express their agency through partaking in an arranged marriage despite their awareness of the stereotype that depicts them as merely victims who are coerced (Dwyer 2000). Similarly, Raksha Pande (2014) also finds within her study on 
second-generation South-Asian women that her participants are actively negotiating gendered cultural expectations while participating in arranged marital practices. This image is exemplified in Pande's (2014) research where she discusses how her participants influenced their parents into arranging marriages for them with men of their choice, thus partly arranging their own marriage. Pande concludes that it is through a process of negotiating gendered customs that women not only demonstrate their agency in this cultural practice but also able to maintain their cultural identity and familial honour (Pande 2014, p. 177).

\section{Evolution of Arranged Marriages within the South-Asian Diaspora}

As illustrated within Pande's (2013) research, many second-generation South-Asian women have combined Western notions surrounding love-marriage and the cultural practice of arranged marriages into one system that meets their own ideas and needs. Osella (2012) defines 'love-marriage' as individuals who marry based on mutual attraction, romance, and companionship (Osella 2012). The practice is a 'self-choice' custom that many second-generation immigrants may also find liberating (Ahuwalia et al 2009; Pande 2013). Both 'choice' and 'freedom' are terms used to describe the evolving nature of arranged marriages within the literature on transnational marriage. Scholars such as Ahuwalia et al 2009, Pande 2013, and Zaidi et al 2002 have found that contemporary arranged marriages within the South-Asian diaspora have evolved to include more 'freedom' and 'choice' in partner-selection processes that are similar to Western practices of dating. 
Ahluwalia et al's (2009) study on South-Asian marital practices have identified the contemporary versions of these practices as 'introduced' or 'semi-arranged' marriages where parents will introduce potential suitors to their children through formal or informal meetings. The two individuals may choose to socially interact (privately or chaperoned) and may eventually decide whether they accept or reject one another as suitors. Khandelwal (2002) argues that these versions of arranged marital practice are a compromise made by the second-generation adolescent and his/her first-generation parents who are attempting to cope with Western cultural practices.

The practice of arranged marriages has become even more evolved in the modern day due to the technological advancements. For example, many existing matrimonial websites attempt to find users a potential partner to marry. Matrimonial websites within the South-Asian context also meet many parental expectations through categorizing identity traits such as gender, heterosexuality, socio-economic status, education, and cultural background (Titzmann 2011). The most revolutionizing elements of matrimonial sites within the South-Asian context are that practices of arranged marriages are retained within this transnational space. For instance, matrimonial websites allow adolescents to design and negotiate arranged marriages. However, these same websites also allow users to narrow their search parameters for the prerequisite conditions that their parents would approve (i.e. class, gender, race, etc.).

Scholars such as Titzmann (2011) and Ahluwalia et al. (2009) emphasize that matrimonial sites used by second-generation South-Asian women allow them to further exercise their subjectivity and agency in negotiating gendered cultural practices related to 
arrange marriages. Titzman found in her study on South-Asian transnational marriages that many second-generation women presented themselves on their online portfolios as confident, assertive, and ambitious career women who also emphasized traditional family and cultural values (Titzman 2011, p. 244). Her findings illustrate how these social media platforms partially allow these women to self-represent, through nuancing their identity traits that may otherwise remain unseen in a traditional marital arrangement. Thus, SouthAsian marital websites work as transnational spaces that allow for specificity in partnerselection. They also allow second-generation South-Asians to maintain and transmit their cultural identity to appease their parents thereby supporting the development of a hybrid identity that accommodates both 'new' and 'old' cultural customs.

The evolved practices of arranged marriages are also discussed within transnational literature as demonstrating how some cultural arrangements have been reconfigured to include male/husband-migration and female/wife sponsorship. These terms imply that men are also likely to migrate to their wife's home country and the wife becomes the sponsor (Charsley et al. 2005; Chopra et al. 2004). This reconfiguration has introduced a shift in gender roles within traditional arranged marriages. For instance, within traditional South-Asian cultural practices, daughters are taught at a young age that they will move to their husband's household after marriage. Within the shifting migratory practice of transnational marriage, the 'immigrant husband' now depends on his self-sufficient wife and her family to support him integrating into a new country (Charsley 2005; Chopra et al. 2004). This shift in gender roles within transnational marriages reveals how contemporary practices of arranged marriages have evolved to include more opportunities for women to exert their agency. 


\section{The Research Literature and Second Generation Afghan Women}

Within the broader literature on second-generation women, daughters are often expected to conform to gendered cultural roles to preserve their cultural identity and familial honour. Gendered cultural practices such as arranged marriages are emblematic of how second-generation women are situated as the reproducers and bearers of culture. Scholarly research on second-generation Afghan women has also found that Afghan women are responsible for maintaining cultural identity by adhering to gendered cultural practices relating to marriage. Despite this acknowledgment, I argue that the research on secondgeneration Afghan women has ignored how these women interpret and negotiate the gendered cultural expectations of the first generation through subtle acts of resistance and reformation. As a result, the experiences of second-generation Afghan women in navigating the social and cultural terrains in which these expectations are required of them have been rendered invisible. Thus, the agency of second-generation Afghan women has remained ambiguous throughout much of the literature described above.

The scholarship on transnational marriages within the South-Asian diaspora indicates how traditional marital customs are transformed when balanced against a new and different cultural context. In particular, the role gender plays in cultural transmission has shifted to become more egalitarian. This literature on transnational marriages has revealed that second-generation women are redefining paths to marriages while still incorporating their parent's cultural values. Guided by these scholarly findings, I analyzed how the second-generation Afghan women interviewed for my study have negotiated cultural practices relating to marriage. More importantly, the participants' personal 
accounts will reveal their unique perspectives and the ways through which they exercise agency that has previously been neglected within the broader literature on secondgeneration Afghans.

\section{Young women exercising agency}

During the interviews, participants were asked the following question: "What is your current marital status?" (S1, Q4; see Appendix A). Four participants replied that they were married (Sabrina, Alia, Sarah, Salma), one participant replied that she is engaged (Tamana), and five participants stated that they were single (Afsoon, Parisa, Afia, Sharbaat, Maryam). The discussions that followed throughout my interview with these women revealed three themes- agency and ambivalence, fear and anxiety, and expressive hybridity. This chapter reveals the diverse experiences and perceptions of how these women exercise agency in negotiating the types of marriage and marital ceremonies within Afghan diasporic culture. I also address participants' fear and anxiety relating to Afghan culture beliefs and practices. Finally, I demonstrate some of the ways participants express their hybrid identities by participating in the evolution of transnational marriages and partner selection practices.

\section{Re/-negotiating marital practices and ceremonies}

As mentioned in the literature review, arranged marriages are a common practice within the Afghan diaspora and are encouraged by family elders. Among the secondgeneration Afghan women who are married in my study, three indicated that their marriages were arranged. However, despite this situation, these women explained how they negotiated the gendered customs and traditions within their arranged marriage to 
gain a sense of personal agency. Within Afghan culture, daughters are expected to marry someone who is also of Afghan descent. Also prevalent within the Afghan diaspora, is the practice of consanguineous marriages, otherwise understood as marriage within the family. Traditionally, arranged marriages have been practiced to ensure that marriages remain consanguineous to maintain stronger kin-relations (Sadat 2008). Arranged marriages within the Afghan diaspora involve two significant events that occur prior to marriage: Khastegari and Lavs-Dadan.

Khastegari refers to an "honourable request" in which the suitor or his family asks for the woman's hand in marriage. Lavs-Dadan translates to "the word of approval," which is the response that the woman and her family would deliver to the suitor if they approve of the proposal. It is during the moments before the Lavs-Dadan when the woman decides whether she wishes to consent to the marriage or not. After the woman has provided the suitor with her Lavs-Dadan, she is then allowed to meet with the suitor. Depending on whether the family patriarch agrees to the 'unsupervised' meeting between his daughter and the suitor, the social interactions between the two are usually chaperoned until they are married. In addition, women who have intimate interactions with their suitor before marriage are considered to bring shame and dishonour to their family because they are seen to have participated in immodest activity (Bhopal 1999).

Salma's statement below demonstrates both the traditional elements of arranged marriages and her deviation from the traditional practices related to arranged marriage:

[My husband] asked for my hand in marriage, the Khastegari, two years ago... I always follow my parents decisions...but this time I [told them] if you want me to marry him you have to buy my flight to go to [Tajikistan] to see him... we 
lived together before getting engaged...I really liked him so that's why I said yes to him. - Salma

Salma reveals that while she approved of her parents' decision for a transnational arranged marriage, she was also resistant to the practice of not meeting or knowing her potential husband before she agree to marry him. Her resistance is illustrated in the conditions that she imposes upon her parents such as demanding that they allow her to live with the suitor before providing her consent. Salma's ultimatum signifies her agency in the marital negotiation process. As such, she also challenges existing Western discourses that mainly construct racialized women as passive victims of their cultural practices. Additionally, Salma's deviation from traditional arranged marital practices, and her parents' acceptance of that deviation, demonstrates her sense of personal power to make the decision to live with her husband before providing her Lavs-Dadan. For Salma, knowing her suitor was important enough for her to take the risk of breaking cultural tradition before she could agree to the arranged marriage.

Salma's negotiation of the arranged marriage practice also represents her integration of 'Western' ideas surrounding marriage that include love and freedom. Scholars such as Netting (2006) and Lalonde et al (2004) have also found that secondgeneration women are demanding more freedom to incorporate Western notions of love into their traditional marriages. These sentiments are further reiterated within the above literature review on arranged marriages which found that in some cases parents are introducing suitable young men to their daughters and allowing them to interact socially prior to being married (Ahuwalia et al. 2009; Pande 2013; Zaidi et al. 2002). 
In many ways agreeing to an arranged marriage for Salma was not only desirable but was also consistent with her beliefs. For instance, Salma later shared that the arranged marriage was consanguineous in nature as the khastegari was from her "cousin's son." Salma explicitly demanded to her parents that if they "choose a guy" for her to marry, she does not "want him to be from [Canada]." In fact, she noted,

I wanted to be with someone who lives in Afghanistan because they culturally and personally respect me. I don't want my kids to be White washed like I am. I want them to be somehow involved with their community as well, and by having a husband from there helps. - Salma

Salma's decision to have a transnational arranged marriage in Afghanistan was a decision that she felt would help her build a sense of identity, including her future children's identity, by becoming the wife of someone who has similar "beliefs and ideologies" and as the mother of children who will be raised accordingly. More specifically, Salma expresses her guilt in negotiating two cultural identities, a process that has also caused her to remain cautious of the type of Afghan man she marries. Salma's narratives reveal the ambivalence she feels when balancing these two cultural identities Afghan and Canadian. In providing her 'lavs-dadan' to a transnational consanguineous marriage, Salma accepts her Afghan cultural obligations in preserving kin-relations and cultural values, while also exercising her agency, by adding the condition that she and her suitor live together before agreeing to the arrangement.

Salma also shared that both first-generation and second-generation women within her Afghan community in Ottawa constantly scrutinized her decision to agree to a transnational arranged marriage. This situation is partly explained in the quote below: 
My best friends who are Afghan, oh my god...they [asked me] "Why would you go ruin your life like that, why would you marry from back home, you're going to have to support him.'....also this Khala (Khala refers to Aunt in Dari, the term is often used to address older women) came into my workplace and she [said] "You're the girl who ruined her life and married a guy from back home." I didn't even know her. - Salma

The excerpt above highlights the judgement Salma was subjected to from her secondgeneration Afghan friends who were shocked at her decision to consent to having a 'transnational husband' and also from a first-generation aunt whom she did not know. As indicated in the experiences of the South Asian diaspora, however, transnational marriages have evolved to include a shift in gender roles where women are not the only ones traversing boundaries to settle in their husband's host-country. Men are also becoming 'migrant' husbands who are depending on their wives to sponsor and support them. Still, it does not appear that other members of the Afghan community in Canada are sympathetic to this trend. As such, Salma's decision to marry a man from 'back home' demonstrates personal strength and resilience in the face of potential social disapproval from a peer group that does not fully understand her need to express her own sense of identity as a second-generation Afghan.

I have to explain to my friends about the sponsorship and they get shocked [and ask] "How do you live like that? How can you do that? Why is it taking so long?" They get suspicious about my husband...It's frustrating. - Sarah

Sarah's quote demonstrates how transnational arranged marriages within Afghanistan are viewed with hostility and uncertainty amongst second-generation Afghan women. More specifically, Afghan men within Afghanistan are viewed with suspicion. Sarah's frustrations also an outcome of the lengthy process of sponsoring her husband and the resultant misunderstandings this fosters about her husband within the larger Afghan 
diasporic community of which she is a part. Instead of transnational arranged marriages being viewed as an evolved practice - or as Salma asserts, a "good practice" that her friends should be "more proud of" - the scepticism surrounding the practice continues to resonate amongst many Afghan-Canadian women.

The experiences of Salma and Sarah demonstrate the sense of ambivalence that resonates across the Afghan diasporic community in Canada when it comes to arranged marriages particularly with men in Afghanistan. The comments that were made to Salma signify the opposing perspectives surrounding transnational arranged marriages among Afghan diasporic women. This opposition is representative of the underlying fear within the Afghan diaspora (particularly of women) about Afghan men living in and moving from Afghanistan and bringing with them more repressive cultural values, especially those that may bring tighter controls on the conduct of women.

The presumption is that marrying an Afghan man in Afghanistan is a decision that will 'ruin' your life. This presumption is based on the perceived socio-economic as well as cultural differences between the diaspora and those "left behind" in Afghanistan. These perceptions emerged clearly in my conversations with Maryam and Parisa. For example, Maryam said that she wanted "... someone who is on the same level" as her, "both educated and have good jobs." She views herself as an educated and self-determined Afghan woman looking for an equal partner who is desirable and self-sufficient. However, the common assumption is that in having a transnational husband who lives in Afghanistan, it is less likely that he will be on the same social level as an Afghan-Canadian woman. Parisa adds to 
this by characterizing Afghan men in Afghanistan as having an "old-school mentality" that is "not compatible" with second-generation Afghan women.

For Maryam, the ambiguity surrounding traditional arranged marriages and not knowing one's husband before marriage has caused her to resist the practice altogether. She shares that her mother's marriage to her father had a profound effect on her and thus influenced her decision to defy arranged marriage as a cultural practice.

I also don't want an arrange marriage because of my mom's [experience]...she [agreed] to an arrange marriage [to my dad] because his brothers [wives] were so happy, and she's the least happiest. She didn't know my dad before [and that he] smoked, drank, [and] gambled. I saw my mom suffer. She didn't know he was like that. - Maryam

The above excerpt from Maryam describes her anxieties about the lack of compatibility with a partner from traditional arranged marriages. Notably, Maryam's memory about her mother's experiences has fostered a sense of resentment against the cultural practice. During the interview, Maryam displayed a range of emotions such as sadness and anger while discussing her mother's hardships. It was apparent in Maryam's account that she believed the cultural rules and traditions surrounding arranged marriages had set her mother's marriage up for failure. When arranging marriages, the family's reputation is used to evaluate whether the males who are matched to the daughters are 'good people' who come from 'respectable families' (Shaw 2001). Maryam's mother consented to the proposal because of the 'good' impression Maryam's father's brothers left on her mother and had not realized this brother was not like the others.

Maryam strongly emphasised the importance of "getting to know the person and not just the family" before marrying. Her comments align with what is established in the 
existing research on intimate and familial relationships in the diaspora (Das Gupta 1998, Dwyer 2000) which finds that when compared to men, women's bodies are more often policed by family members in maintaining familial honour, as the women are the sole representatives of their families' reputation. Maryam's belief that individuals should get to know one another and not just their family members also points to a more egalitarian and transparent process in forming a marital union. Her resistance to arranged marriages is grounded within this interpretation of arranged marriages as an obscure and out-dated cultural practice that often situates women unequally.

The unequal gendered cultural practices related to marriage have caused many young Afghan women to defy arranged marriages altogether. During my interview with Salma, she shared with me her present situation in regards to her transnationally arranged marriage. By providing her lavs-dadan to the khastegari, Salma also agrees to the marital cultural practice that reinforces gendered cultural scripts. The popular proverb shared by Salma provides more context to understand the gendered cultural beliefs surrounding women's bodies:

A girl is like a mirror. If there is one crack in the mirror, no one would want it. [Similarly] if a guy touches a girl, she is broken, and no one would want her. Salma

The above quote is a popular proverb in Afghan culture that is typically shared by older-generation women with younger-generation women. The proverb describes the fragility of women and their reputation and the stigma surrounding intimate relationships before marriage. Within Afghan culture, a family's perceived honour is inextricably linked to the daughter's virginity prior to marriage, a cultural script that is common within many 
Abrahamic cultures. Researchers on the topic of virginity in Islamic cultures (Amer et al. 2007) found that the cultural subordination of women through the policing of women's sexuality is seen as integral to preserving familial honour; a practice that continues to operate even now. Virginity has been employed within cultural narratives that have relied on traditional patriarchal tropes engrained within religion and cultures surrounding the 'modest' Muslim woman (Amer et al. 2007).

During my interview with Salma, she revealed how cultural scripts related to virginity have instilled anxiety and fear surrounding the 'Takht-Jami,' meaning, the night after the wedding or the wrap up program. As mentioned earlier, Salma decided to live with her now-husband in Tajikistan before she provided him with her consent for marriage. During that time, she recalls that her husband's mother called them every day to tell them:

Make sure you guys don't have sex, because I and [the grandmothers] want [Salma] to bleed at the night of the wedding and we need to look at the cloth. Salma

Within traditional Afghan customs, the common belief is that a bride's 'intact' hymen will bleed during sexual intercourse on the night of her wedding; this is a test of her virginity. A new bride is supposed to bleed on a handkerchief or a cloth and present it to the older women in the groom's family as proof of her virginity. ${ }^{4}$ Despite the growing consensus that resists such a custom (Coyne 2000; Vincent 2006), it continues as a cultural practice in the Afghan diaspora as proof of women's purity. Salma said she "hated that

\footnotetext{
${ }^{4}$ When a marriage is arranged transnationally, it is not uncommon within Afghan culture for the bride and groom to have their religious marital ceremony before the Afghan cultural wedding. In such cases, the Takht-Jami takes place after the Afghan cultural wedding, however the couple are considered to be married after the religious ceremony.
} 
[virginity] is a big issue" within Afghan culture. She also shared her fear that she will not bleed the night of her wedding

I don't want my parents to be ashamed of me... my Mom told me [that] if I lose my virginity my value will go down and in the future if I wanted a big wedding reception my in-laws would [respond with], "No, why the hell would you want a big wedding if you're not a virgin." - Salma

Salma's primary concern is bringing shame to her family. She is caught between negotiating her choice to live with her partner before marriage and also maintaining her parent's honour and her own values as an Afghan woman in the eyes of her husband and her extended family. She reconciled this dilemma by translating her parent's traditional expectations into a 'vernacular' that represents her diasporic identity as an AfghanCanadian.

My mom herself didn't bleed [on her wedding night]. So I don't know why she doesn't understand the fact that I may not bleed. If I talk to her about [my concerns] about this she's going to [assume I] had sex...And she told me that if I don't [bleed], I am going to be 'Chatal'e Zameen' (dirty as the floor). - Salma

Salma is perplexed by her mother's lack of empathy for her concerns relating to the Takht-Jami. In her book entitled, Dear Zari: Hidden Stories from Women of Afghanistan (2011), Afghan author Zarghuna Kargar, finds that cultural discussions surrounding virginity and women's sexuality were considered taboo if discussed by men. However, Salma recounts that after a brief intimate moment where both she and her then-fiancé "were close" to having intercourse, her fiancé immediately stopped the act and reminded her that "her aunts (his mother and grandmother) want to see the bloody cloth, because [she's] from [Canada] and [is] dirty." Salma recalls feeling shame and guilt in almost committing an act that would prove her fiancé's mother's beliefs that Afghan-Canadian girls 
are 'dirty.' In an effort to maintain her 'Afghanness' and abstain from any activity that may rupture her hymen such as "sitting a certain way," Salma attempts to safeguard her virginity to avoid being perceived by her husband as a "White girl." Moreover, Afghan women, particularly mothers and grandmothers, are seen as responsible for ensuring that their daughters remain virgins until the night of the wedding (Kargar 2011). Salma's virginity is also a reflection of her mother's ability to parent and failure would be read as her incapability in raising a 'good Afghan daughter.' Salma expresses feelings of despair in not being able to share her concerns with her mother but also expresses anxiety about possibly bringing shame to her family (more specifically her mother). As such, Salma's situation exemplifies the type of 'push-pull' experiences that second-generation Afghan women often face in managing the competing norms of Afghan and Canadian culture and how such experiences lead to the formation of a hybrid Afghan identity.

The extent of Salma's anxiety is evident in our discussion of how she might mitigate the situation if she does not bleed. She shared that she would resort to faking the rupture of her hymen by "staining the cloth with fake blood." In a moment of heightened anxiety, she also asked me whether I had any "better ideas". Salma's narrative of anxiety demonstrates how she can exert some agency afforded to her by her status as an Afghan-Canadian; however, her sense of self remains significantly linked to how other Afghans recognizes her.

\section{Afghan Culture and Gender Policing}

Throughout my interviews, all participants spoke about the gendered expectations of women within Afghan culture that is often reinforced by their parents. The narrative 
participants shared echoed concerns expressed in the research literature over the role of families in maintaining gender role division and expectations. The gendered expectations were enforced by parents through firm household regulations such as not being allowed to date. More specifically, participants discussed these gendered expectations in relation to patriarchy and masculinity. Participants were particularly bothered by the double standards and different gendered expectations that they were subjected to compared with their male counterparts. For example, Afsoon shared her feelings regarding the double standards that she witnessed within her Afghan community in her notion that:

[A man] can impregnate hundreds of girls [but] girls needs to keep their virginity. If a [girl] dresses a certain way, then people think that she lost her virginity and if a guy has touched [a girl], it [also] means that [she] lost [her] virginity. - Afsoon

Afsoon's response demonstrates her anger with Afghan cultural scripts that seek to police women's bodies, while Afghan men are allowed to exercise more freedom. Such participant statements resonate with the broader literature review on unequal gender roles which also finds that young women are often pressured to conform to traditional gendered practices in comparison to their brothers or other male-counterparts (AbbasiShavazi 2014; Dasgupta 1998; Dwyer 2000). Afsoon's anger in negotiating these cultural expectations reveals her frustration with the patriarchal gendered script that allows men to exert their masculinity through having more sexual freedom and women to remain within the confines of their home to preserve their purity.

Another significant but complementary finding emerged in the participants' discussion of their efforts to engage in autonomous decisions related to virginity. For instance, Maryam's tendency to problematize customs related to arrange marriages 
illustrates her vigilance in assessing cultural practices that she does not wish to follow. This vigilance is revealed in the following quote which describes the type of wedding she wants:

I do want an Afghan cultural [wedding] ...I want to wear a green dress. But no TakhtJami. I'm against that stuff...not everyone has to bleed on the night of the wedding. But we [are] required to keep our virginity until the night of our wedding... I follow that but it's also a choice maybe that changes. - Maryam

Maryam's statement demonstrates that, while she is willing to conform to traditional practices such as wearing the traditional Afghan green dress on the wedding day, she is also aware of cultural expectation of remaining a virgin until the night of the wedding - despite her opposition to the Takht-Jami. However, Maryam's awareness in negotiating her cultural identity also reveals her ambivalence about remaining a virgin. Specifically, in questioning the possibility of losing her virginity before marriage, Maryam acknowledges that she does not consider being a virgin to be important and she may also change her mind about keeping her virginity until she is married. It remains clear that Maryam experiences identity ambivalence due to the various cultural and social messages surrounding marriage, virginity, and intimate relationships that she has been exposed to throughout her life. Despite her ambivalence, Maryam shows self-agency in regulating her own sexuality to ensure that she is following her own personal familial and cultural values. In this way, by resisting the cultural tradition of the virginity test and by conceding to cultural tropes that expect women to remain 'chaste,' Maryam attempts to balance her two cultures, Afghan and Canadian, without fully complying to the customs and beliefs of either. 
As exemplified within Maryam's statements, I also found that participants were actively conforming to gendered expectations surrounding virginity despite their opposition against such gendered cultural beliefs. Participants engaged in the conscious act of balancing their 'Afghanness' against their 'Canadianess' and vice versa. For example, participant Afia explained that she “doesn't care if [an Afghan girl] wants to lose [her] virginity," and that such incidents can occur when "it happens in the moment." She further shares: "I know why a girl would want to lose her virginity if she is in love with that person... But I just can't [lose it]."

Afia's statement reveals her consciousness in making her own decisions to regulate her own sexual desires even though she is supportive of other women who choose to deviate from these cultural scripts. It is also evident that Afia is familiar with the emotional aspects of intimacy. Her ambivalence is revealed in her acceptance of Western practices surrounding pre-marital love and intimate relationships, although remains wary of accepting these practices entirely.

Afia, Maryam and Afsoon feel perplexed in negotiating her Afghan and Canadian cultural expectations surrounding virginity. Their ambivalence is in response to their struggle with the idea that they may not be a 'true' Afghan woman if they resist conforming to the gendered cultural beliefs within their culture. It can be argued that this form of straddling between two cultures is also caused by the pressure Afghan women experience in meeting the cultural expectations of a culture that is not dominant in the country they are living in. Parisa recounts this in the following quote: 
My dad never put pressure on me. But I do know a lot of Afghan girls who have lived here their whole lives and [have experienced] pressure, [such as] to be 'Sangeen' (to be decent). - Parisa

Parisa uses the word "pressure" to describe the experiences of second-generation Afghan girls who are expected to conform to traditional practices. While she does not feel pressured by the patriarch within her family, Parisa demonstrates her own ambivalence in navigating her cultural identity. For example, she shares that even though her parents allow "interactions with men", it is not "to the extent where they can come over and hang out." In conceding to Western social practices such as interactions with the opposite sex, Parisa also knows there are limits to what her parents consider appropriate and remains careful in ensuring that these social interactions remain outside the boundaries of her parents' home. By implying that she is not pressured yet is conforming to what is expected of her, Parisa depicts that she too is navigating between her two cultural identities through the self-regulation of her decisions. Parisa's self-regulation of her social interactions is an example of the ambivalence that remains a part of her when making a decision that may be perceived as incompatible with her 'Afghanness'.

\section{Fear and Anxiety of the Afghan diaspora}

The discussions surrounding unequal gendered expectations that I had with my participants often resulted in conversations related to the gendered expectations within the Afghan diaspora that also lead to violence against Afghan women. For example, Parisa briefly discussed the horrific killing of three teenage Afghan sisters - known as the Shafia sisters - that took place in 2009 in Kingston, Canada. It is not surprising that Parisa mentioned the Shafia sisters as the event was documented by multiple media outlets throughout Canada and caused uproar amongst many Afghan-Canadians (Jiwani 2014). 
The three sisters and their step-mother were killed by their parents and their eighteenyear old brother because they believed that the three girls were participating in activities that were not compatible with their familial cultural and religious values - such as having non-Afghan boyfriends, wearing revealing clothing, and possibly engaging in sexual activities. This event was characterised as an honour-killing 5 , a term often used interchangeably to discuss honour-based violence within minority ethnic groups, especially in Muslim and South-Asian cultures (Gill et al. 2014, p. 161). Those who support the practice believe that the act is committed to purify the family name and restore the honour that has assumingly been tarnished in the broader cultural community (Gill et al. 2014).

The most recent magazine publication of the Shafia killing provides a detailed archival report about the events that occurred leading up to the death of the Shafia sisters, as well as the court procedures that followed (Friscolanti 2016). Notably, an in-depth archival publication in MacLean's magazine (2016) referenced Rona Mohammad's (Shafia's first wife) personal diary that contained details of the unjust treatment that she and her three stepdaughters were regularly subjected to. These excerpts also revealed that the Shafia's son, Hamed, despite his age, was situated by his parents as the second patriarch in the family. As indicated within Rona's diary when the Shafia father traveled overseas, Hamed would take his place and enforce the house rules as "his father's eyes, ears, and fists."

\footnotetext{
${ }^{5}$ Within this chapter I employ the term 'honour-killings' cautiously to address how it has been depicted within Western media outlets. I remain mindful of feminist scholars such as Yasmin Jiwani (2014) and Aisha Gill et al(2014) who have argued that the term denies victims a voice and cloaks the larger social structures of patriarchy that perpetuate all types of violence against women.
} 
Parisa draws on the Shafia's killing to address how within traditional Afghan families the patriarchs have more freedom, and due to their roles as patriarchs are complicit in restricting the women in the family from participating in Western social activities. As Parisa states:

I see Afghan boys who end up going into drugs or like you know illegal stuff its usually because they have been bought up in a house that allows them to [have more freedom] and the [Shafia's] I feel like that's the perfect example... the father had money, had a good job, and two wives... he didn't care about [his daughters], and then when they would go have boyfriends he and his son went and killed them. -Parisa

Parisa's statement addresses the gendered dynamics that can exist within an Afghan home, in which Afghan men have more freedom to exercise their desires compared to Afghan women. Within the Shafia household, these gendered dynamics were aggressively pursued by the Shafia parents. Not only was Hamed Shafia given extra privileges to exert his own household rules onto his sisters but the father, Mohammad Shafia, also freely practiced traditional gendered customs such as having a polygamous marriage.

Parisa also addresses the above statement in an effort to make sense of how the Shafia family could have dealt with the issues within their home differently. Specifically, she draws on the case to argue that the Shafia's are "not proper Westerners and not proper Afghans either." When I asked Parisa what a 'proper' Westerner and Afghan would look like, she stated that a proper Afghan-Canadian was someone who integrated "the best of both worlds [instead] of the worst of each sides." However, even within this statement, Parisa was uncertain of what exactly these two worlds looked like, and specifically, what cultural elements were to be resisted or conceded to when navigating between them.

The killing of the Shafia sisters caused many young Afghan-Canadian women to remain cautious and in some ways fearful of deviating from their parents' Afghan cultural 
values. For instance, this event took place when Afsoon was in her early teenage years. During this time, her parents were quite strict in the type of social relationships and interactions she was allowed to have. Due to this event and her parent's firm household rules, Afsoon grew fearful of even mistakenly deviating from her Afghan cultural values. This is exemplified in the following quote:

I was never allowed to have boyfriends; I was never allowed to go out, not even to my friend's birthday parties.... But [during a school trip] that I was allowed to go on, something really bad happened and I told the teacher, like "if my parents find out about this, they are literally going to kill me, literally, I'll invite you to my funeral." - Afsoon

Afsoon's illustrates her fears in participating in social activities that her parents do not approve. Her comment about being killed, even if it is was implied as an exaggeration, reveals her fears in participating in a social activity that could be interpreted as an act that might draw a similar outcome to the Shafia case. Afsoon's narrative also reveals how efforts to navigate between two different and distinct cultures can also be disrupted by a social group - in this case, her parents - to create an identity that favours traditions in one culture over the other.

Afsoon felt pressured by her parents to resist a Western social practice which has also caused her to turbulently navigate her Afghan and Canadian identity. Thus, for example, Afsoon disclosed that she would "do crazy things" to herself, such as commit acts of self-harm, which also led her to become "really angry" in not having the freedom to navigate her desires in engaging in social relationships. Within Afsoon's narrative, it became evident that her parent's imposition of cultural values has caused an inner conflict over how she should construct her Afghan-Canadian identity. More specifically, in 
conceding to her parent's preferred Afghan identity, Afsoon felt constrained in constructing an identity that included her Canadian experiences and, by doing so, created a situation where Afsoon had to deny significant parts of herself.

The pressure that many of the participants felt in either resisting or conceding to the specific cultural practices of their Afghan heritage was also a result of their Afghan parents attempting to protect their daughters. For example, Salma commented on the Shafia killings in her description of how older Afghan women discussed this case within their own social circles. While the Shafia parents were continuously condemned for their horrific crime, the daughters were also perceived as rebels. Furthermore, Parisa states that the daughters were seen as being "lost [within] the Western [culture]." Salma also shares that within her own Afghan community, if an Afghan girl was to conform to Western practices such as dating, the "Afghan ladies would talk [negatively] about the girl [because] she has become Whitewashed." Salma's fears emerged more strongly when she disclosed her parent's comments:

My parents say that the day I hear someone else talking [negatively] about you that will be the last day of you. - Salma

This quote sums up the situation for the women I interviewed. In other words, by partaking in public social interactions with the opposite sex, second-generation Afghan women are likely to be scrutinized not only by their parents but also by the broader Afghan community. These circumstances can often lead to these women feeling fearful, ambivalent and frustrated when maintaining their Afghanness whilst integrating into Canadian society. 


\section{Fear and Anxiety of Afghanistan}

My conversations with second-generation Afghan women also revealed their sense of fear and uncertainty to also be influenced by recent events in Afghanistan, changing how they perceive their 'home country', in particular the status of women and the role played by men in maintaining a dangerous and unequal status quo. The recent killing of an Afghan woman not only informed my participant's views on Afghanistan but also their views on Afghan men and as an extension arranged marriages within Afghanistan. Parisa, Sarah, and Maryam drew attention to the event that took place on March 19th, 2015 - the tragic death of a twenty-seven year-old Afghan woman, Farkhunda Maikzada, who was brutally attacked and set on fire by a mob of Afghan men in Kabul after she was falsely accused by a religious leader for burning the Koran, the holy book of Islam (Faizi2015). The 'slaying' of Farkhunda stunned the nation and caused social upheaval among Afghan people (Faizi 2015).

Afghan women in particular took to the streets of Kabul and rallied to demand justice for Farkhunda. A pivotal moment during this event was that the Afghan women in Kabul collectively carried Farkhunda's casket to the burial ground without allowing any Afghan men to touch it. This significant gesture and moment marked the first time in Afghan history that women carried a casket to the grave to finish the burial ceremony. Within Islamic tradition, it is both a religious and cultural tradition for only men to carry bodies to the grave and perform the burial services (Milewski et al. 2016).

In discussing this event, Parisa said that she is uncertain about "how these men [in Afghanistan] are raised," and that she feels there is a possibility that Afghanistan's ongoing 
"political instability" and "violence has [caused] them to [have] "psychological or mental issues." From her comment, it is apparent that the murder of Farkhunda and the ongoing violence against women within Afghanistan has instilled in her a sense of fear that influences her attitudes towards men in Afghanistan, causing her to question their mental stability and whether they are safe to be around. The death of Farkhunda also caused Sarah, whose husband lives in Afghanistan, to question her own safety and security if the sponsorship of her husband to arrive to Canada was unsuccessful:

I have the luxury of going [to Afghanistan], living there and being able to come back [to Canada]. And if [the sponsorship doesn't] go through, if it turns out that it doesn't work out, I will go back...but also depending on the security, I mean the case of Farkhunda...I'm going to try hard for [the sponsorship], like, I mean if worse came to worse, than I would move [to Afghanistan] to live with my husband. - Sarah

The statement by Sarah illustrates how the recent events have made her fearful of her own security causing her to question her decision to move to Afghanistan if the sponsorship is not successful. Her statement also reveals both the positive and complex outcomes that arise from the hybrid experience. For instance, Sarah acknowledges her privilege in being able to travel to Canada and Afghanistan, a positive outcome that arises from her hybrid status. However, because of this privilege and despite her fears, Sarah also remains mindful of her role as a wife and strongly considers moving to Afghanistan for her marriage. Thus, the advantages of her hybrid and transnational status have allowed Sarah to negotiate her living situation between the two countries, Canada and Afghanistan. 
An additional theme that became significant within the participant's narratives regarding the recent events in Afghanistan and their fears of the country was their concern over Afghan cultural beliefs and practices.

My interview with Maryam revealed that her resistance to transnational marriages was also influenced by the death of Farkhunda and the archaic cultural practices within the country. For instances, When I asked Maryam whether she wishes to visit Afghanistan (S3, Q2; see Appendix A), she began discussing her willingness to visit her home country but also expressed fears of being pressured into marrying a man who lives there through the use of witchcraft. This fear is clarified in the following statement by Maryam:

I would love to [visit Afghanistan]. The only reason I wouldn't want to go is because I don't want to get married to someone from there and I know I would be pressured by family there. They would do [sorcerous] thing's [like black] magic...I actually think they would put something in my drink and I would end up getting married to some random guy I don't even know. Because of that, I am mostly against arranged marriage. - Maryam

Maryam's concern with black magic ${ }^{6}$ is widely interpreted within the broader Western community as a spurious belief (Kamali 2011). Maryam's fear and suspicion of the use of black magic among family members in Afghanistan is based on the ongoing belief in such practices in the Afghan culture. The tragic death of Farkhunda, also serves as a case that signifies the prominence of such practice within Afghan culture. As mentioned above, Farkhunda was accused of burning the Koran; however, what caused the religious leader to falsely accuse her of this act was that Farkhunda opposed his business of selling 'tawiz,'

\footnotetext{
${ }^{6}$ Within Islamic diaspora's, black magic is still a common belief in which the 'sorcerer' may resort to "irrational and impermissible" means to inflict harm or create outcomes desirable to him/her (Kamali 2011, p. 591-592).
} 
which is scraps of religious verses that are strategically placed within an amulet to cast powerful spells. It is therefore not surprising that Maryam make reference to Farkhunda to justify her fears about black magic in our interview.

Scholarship on black magic also addresses the significance of this belief as it relates to family formations. For instance, Mikkel Rytter (2010) finds in his qualitative research on the practice of black magic amongst Pakistani migrants in Denmark that black magic is used as a malicious practice with the aim of reorganizing family structures - particularly in forming and maintaining intimate relations within the extended family network. Rytter also asserts that because second-generation Danish-Pakistani women are educated and independent, many of them may challenge the practice of transnational arranged marriages by choosing their own spouse (Rytter 2010). This challenge to family/marriage tradition has led many family members to resort to black magic to rearrange the transnational family by manipulating religious scripts.

Borrowing from Ryterr's analysis, Maryam's status as an educated and selfdetermined Afghan woman may pose a threat to her family members living in Afghanistan because she chooses to select her own partner, and may rupture transnational family networks. For Maryam, the thought of marrying a "random guy" is unfathomable. Her resistance to the practice of arranged marriage is a testament to her agency, particularly since she experiences "constant pressure" by family members to consent to an arranged marriage. Regardless of whether there are any truisms to the practice of black magic, for Maryam, agreeing to an arranged marriage would only occur if a questionable practice such 
as black magic was involved. Returning to visit Afghanistan would make her exposure that magic a stronger possibility and adds to her fear of visiting her homeland.

\section{Second-generation Afghan Women Expressing Hybridity}

The distinct perspectives that my participants have towards arranged marriages provide a glimpse into how this practices has evolved within the diaspora. More specifically, from the narratives that these participants shared, it is evident that the practice of arranged marriages is both supported and defied amongst this diverse group of women. For example, Maryam and Parisa remain fearful of arranged marriages due to their personal exposure with this practice. Both participants defy transnational arranged marriages in Afghanistan due to the unpredictable outcomes that may result from this practice, such as incompatible education levels of potential partners. In addition both participants are fearful of the practice because of the inherent violence within Afghanistan, especially towards women. Due to this violence, Sarah, who supports transnational arranged marriages, also expresses her fear in having to relocate to Afghanistan if her transnational partner's sponsorship is not successful.

Participant Salma's personal narrative is in contrast to the experiences described by Maryam and Parisa, as she supports the practice of transnational and consanguineous arranged marriages. Other participants also expressed views that were neither resisting nor conforming to the practices related to arranged marriages. This heterogeneity in experiences and attitudes is evidence of unique patterns of 'self-regulating' or 'self-policing' of social activities and decisions related to marriage and dating that participants make. What is found within this study is that because these participants chose not to have an 
arranged marriage they had to reconcile their deviation from the practice by adhering to different social and cultural practices that would still allow them to maintain their 'Afghanness' and their parent's cultural values while maintaining their own independence.

This balancing act is best exemplified in the discussion I had with Sharbat in which she shares how she negotiates Canadian cultural practices relating to the partner-selection process in an effort to fulfill her own desires while still maintaining her cultural identity and parents' wishes. Sharbat begins by discussing her freedom to select her own marital partner:

My Mom and Dad [had an] arranged marriage. They didn't really know each other. They know [in Canada that] I have a choice to get to know a person. I don't feel any pressure. My mom subliminally tells me "you have a choice." She says [to my Dad], "She's smart, she's old, and she'll figure it out." - Sharbat

The above quote by Sharbat illustrates how marital arrangements are continually evolving from traditional practices of marriage in Afghanistan to more independent and negotiable partner-selection processes by the Afghan diaspora in Canada. Sharbat's statement serves to nuance previous research that has shown the ways in which intergenerational conflicts between first-generation immigrant parents and their secondgeneration children occur when both parties have differing views on socio-cultural decisions such as marriage (Lalonde et al. 2004; Netting 2006; Pande 2014). In Sharbat's case, her parents are aware that she will most likely choose her own partner thereby reflecting the specific diasporic culture experienced in Canada. However, despite the freedom and agency that Sharbat has had in pursuing in her own partner-selection process, Sharbat tends to regulate her autonomy to ensure that she stays within the margins of 
Afghan cultural values. For instance, Sharbat shares the expectations she requires of herself in self-selecting a marital partner:

In terms of marriage, I don't want an arranged marriage but I feel like I am limited to an Afghan guy. I don't feel obligated by my parents but I want to raise my kids more traditional, [because] I lost a lot of my [culture]. I still want to keep it, you know? - Sharbat

Sharbat's comment portrays her conscious process of negotiation in selecting a partner that will allow her to maintain her Afghan cultural identity on her own terms. By self-selecting an Afghan man to marry, Sharbat can still hold on to some of the Afghan cultural values and identity markers while still resisting the practice of arranged marriage.

I perceive the negotiation of marital and partner-selection practices as an appeal to the multiple ways hybridity is constructed. Regardless of the freedom and choice the participants have had in selecting their own marital partners, they still chose to conform to selected cultural practices that are compatible with traditional Afghan martial customs. Thus, although the existing literature establishes how women's bodies are often 'policed' by their family members to ensure that women are upholding family honour and are on the path to adhering to gendered cultural practices such as arranged marriages (Dwyer 2000; Handa 2003; Rajiva 2013). Sharbat's narrative adds more nuance to these accounts: it becomes clear that such policing can be mutual on both sides, that is from - parents who seek to maintain the Afghan culture they were raised in and from the young women such as Sharbat who autonomously decides to safeguard her cultural identity.

I had a very similar conversation with Afia, when I asked Afia whether there were any cultural expectations that she felt obligated to fulfill (S3, Q5; see Appendix A), she replied that she was "expected to get married" and that this expectations was "not [only 
from] my parents, but Afghan society as a whole." Afia's following statement also indicates her hesitance towards the practice of arranged marriages:

[My parents] arranged my sisters marriage for her...but I told [my parents] don't expect that from me because I don't want to get an arranged marriage. Afia

From Afia's statement it is evident that she is moving towards greater individualism in pursuing her personal fulfillment and desires. While arranged marriages are a normative cultural practice within Afia's family, telling her parents that she will not adhere to the practice signifies her own agency and self-determination. Despite Afia's affirmation in her own partner-selection process, she often regulated her autonomy to ensure that she stayed within the cultural constraints that her parents expected of her. This is exemplified in the statement below:

I'm not one to just talk to guys. I don't just date guys or have boyfriends just for the fun of it. He has to be Afghan. Like there has to be real potential for marriage. I mean, why would I waste my time... but it sucks because sometimes there are really good guys [that are] not Afghan, but you have to remind yourself that there are some good Afghan guys [as well], like guys that are not super Afghan, but not super White. I wonder if I [will] find that. - Afia

While Afia is open to Western practices of dating, she is also vigilant about the types of relationships that arise from dating practices where marriage is not the end goal. In specifying her intent to date or have a pre-marital relationship - which includes both Canadian and Afghan practices - Afia's negotiation of both her cultural values and her own desires are further distinguished. Other scholars such as Lalonde et al (2004) and Ahulawaia (2009) also found in their research on second-generation South Asians that 
even though their participants wished to select their own partner - through Western practices of dating - they were only selecting partners who they felt were compatible with their families and who shared the same religious and/or cultural values thereby revealing a hybrid identity that expresses a combination of the two cultures of which they are a part.

Afia's frustration and confusion is also noticeable when she describes her anxiety about finding an Afghan-Canadian man who can evenly balance her own need to follow both cultures. As a result, Afia remains in a constant state of ambivalence as her decisions in partner-selection is neither settled nor fixed. In specifying the type of Afghan-Canadian man she wishes to marry, Afia attempts to negotiate her cultural values so she can appease both her parents' cultural practices and her own desires and expectations.

In a similar way, Sabrina also revealed the ways she has moulded herself to meet her parents' cultural expectations after she made the decision to self-select her own marital partner (who is non-Afghan). This need to take such action is apparent in Sabrina's statement below in which she reveals her parent's feelings towards her marital decision:

It took my parents a long time to accept that [my husband was from Kenya] ... They were worried that [their] kids are marrying people who are not Afghan [and] are going to forget who they are. - Sabrina

The excerpt by Sabrina indicates her autonomous decision to marry a non-Afghan who she fell in love with, despite her parent's concerns that she will "forget" her cultural. Sabrina nonetheless concedes to her parents' wishes by partaking in a traditional marriage ceremony. Sabrina shared that her "wedding was very Afghan," and because of this, her "parents were happy:" 
I have one foot in the door and one foot outside the Afghan door, I'm kind of balancing it, my parents are okay with my marriage... I'm showing my parents that I'm not forgetting my culture. In fact, my husband is learning Dari so he can communicate with my grandparents and my parents. - Sabrina

Sabrina's statement reveals her guilt in deviating from her parent's plans and regulates her behaviour to constantly express her parents' and also her own cultural values. In choosing a partner who is accepting of her religious and cultural beliefs, she continues to express her unique Afghan-Canadian identity.

Second-generation Afghan women's narratives describe marriage and partnerselection processes in ways that are neither traditionally Afghan nor Western. The participants who wished to select their own partners also ensured that they negotiated their Afghan cultural identity carefully thereby resisting traditional arranged marriages but accepting more agreeable parts such as religious ceremonies. Salma who agrees to an arranged marriage managed to obtain a partner who incorporates a more egalitarian process of decision-making in their relationship. Some participants however, continue to resist the practice due to uncertainty and fear around gendered violence that can be associated with some Afghan cultural practices. In particular, some recollected the tragic death of Farkhunda in Afghanistan and how that event influenced the participant's views and attitudes towards Afghan men living in Afghanistan and in turn informed their decisions regarding arranged marriages. What I found throughout this analysis was that participants are expressing their hybridity by shifting away from the conventional modern/traditional dichotomy and, transforming the practice of arrange marriages and self-partner selection to reflect their Canadian and Afghan self. 


\section{Conclusion}

When addressing gendered practices and expectations within Afghan culture, it is imperative to remain mindful of how second-generation Afghan women negotiate fulfilling their own desires and meeting these cultural demands. This chapter has focused on how second-generation Afghan women have navigated between what they perceive to be two contrasting cultural identities, through selectively conceding to or resisting particular cultural values and traditions. The chapter also explored how these participants constructed their Afghan-Canadian identity when faced with social and cultural pressures relating to marriage and marital ceremonies. My findings demonstrate that it is through a process of individual selective decision-making surrounding perceptions of conformity and resistance that, the women continually negotiate and rework their hybrid identities. While some of the participants shared varying narratives that addressed their fears, anger, guilt and resentment, all of the participants revealed their ambivalence in navigating the contrasting worlds they are simultaneously living within.

The ambivalence experienced by these women demonstrates the dynamic and ongoing nature of identity construction often rendering them in a constant state of flux. What is most significant in their efforts to balance two cultural identities is that the act of 'self-regulating'; that is, exercising agency in continuously making vital decisions on when to reject of accept differing cultural values. For the participants in my study, preservation of an Afghan identity means living with the socially constructed gendered expectations that they have internalized at varying phases throughout their lives. Despite their deep felt ambivalence, the women have shown how they are maintaining, challenging, and resisting elements of their cultural identities altogether. As such, the data lead me to posit that the 
second-generation Afghan women in this study are consciously engaged in the act of maintaining their cultural hybridity to negotiate an imagined Afghanistan and the social reality in Canada that they encounter every day. 


\section{Chapter 6: Neither Here, Nor There}

In the previous chapter, I discussed how participants engaged in the ongoing reconstruction of their hybrid/diasporic identities by conforming to and/or deviating from cultural marital practices and customs as well as traditional gender roles within the Afghan diaspora. In this chapter, the concept of 'racialized gaze' will be used to understand how the participants continuously negotiate identities and characteristics imposed on them by persons outside of the Afghan-Canadian diaspora. Drawing on the scholarly work of postcolonial theorists Avtar Brah, Stuart Hall, Edward Said and Homi Bhahba, I will present participants' complicated discussions of "homeland", belonging, and the persistent outsider status assigned to them by members outside the Afghan-Canadian diaspora. Lastly, I will discuss how my participants have reclaimed their cultural identity through challenging racialized stereotypes, achieving 'homing desires', pursing education as a form of empowerment, and changing traditional Afghan cultural definitions of feminine occupations.

\section{Perceptions of the Homeland and Belonging}

Post-colonial scholarship on diaspora and identity have contributed to theorizing how diasporic landscapes are experienced, imagined, mediated, and negotiated by immigrants who left their ancestral homeland (Brah 1996,2003; Bhabha 1994; Hall 1992). Embedded within these discussions of diaspora, is the concept of 'home' and 'belonging.' Avtar Brah (2003) asserts that 'the home' is a spatial notion that the diasporic imagination constructs to achieve a 'homing desire.'(Brah 2003: 614). Brah's concept of homing desire challenges traditional conceptions of migration that perceive the homeland as a fixed origin 
that the diasporic subjects will always intend to 'return' to. In reconfiguring this dichotomy within diaspora discourse, Brah asserts that diasporic subjects construct a home within their "diasporic imagine" that is sustained by the emotional connection to the origin country rather than by the desire to physically relocate to the homeland. Brah's notion of homing-desire situates the imaginary homeland ${ }^{7}$ as a space that can never be physically experienced, as it is a homeland that only exists within the diasporic mind.

Similarly, Stuart Hall also argues that cultural and national identity are not always constructed to maintain one's origin homeland, but are constructed to belong to a variety of homelands (Hall 1992, p. 310). Borrowing from Brah (2003) and Hall's (1992) reconceptualization of the home, diasporic subjects are negotiating dynamic intercultural relations that create new subjectivities to mitigate processes of inclusion or exclusion. This reconfiguration of the home is pivotal to understanding the experiences of secondgeneration immigrants, for whom the ancestral homeland is an unfamiliar space or a collective memory that is displaced by the construction of a cultural hybrid identity. By deviating from traditional conceptions of the homeland, we allow for the integration of discourse surrounding second-generation immigrant's experiences of belonging and longing to belong to multiple homelands.

For second-generation immigrants, tropes of belonging are imagined within the construction of their hybridized identity. Mari Toivanen et al. (2014) in their research on second-generation Kurd youth in Finland discusses how this demographic constructs an

\footnotetext{
${ }^{7}$ The diasporic 'imaginary homeland' is also echoed in Benedict Anderson's influential scholarship on the imagined community. Anderson (1991) asserts that the nation as a community is an imagined construct, the boundaries of which serve as a demarcation through categories of difference such as class, religion, and ethnicity. (Anderson 1991). Similar to homelands, nations are also imagined and created by the individual. Thus, both imaginings of homeland and nations involve boundaries and definitions of inclusion and exclusion (Anderson 1991, p.10).
} 
imaginary of multiple homelands to achieve their homing desire. More notably, the scholars find that while the home signifies a physical location of the participants' lived experiences; imaginaries of the homeland are evoked by cultural and national symbols that are formed by memories and emotional attachment. The diasporic experience for secondgeneration immigrants is shaped by their emotional or ontological search to belong to a homeland and constitutes the lived experiences and idealised imagination of a place that accommodates their homing desire and hybridity altogether. Thus, it is appropriate to perceive 'belonging' as a dynamic process that reflects "emotional investments and desire for attachments" to various collectivities and groupings (Yuval-Davis, 2006, p. 199) and is integral to the ongoing construction of identity for the diasporic subject.

Additionally, while notions of belonging are created within the diasporic imaginary of homelands, feelings of not belonging are influenced by the diasporic socio-cultural experience within their homeland. Homi Bhabha asserts that the hybrid diasporic does not belong to "neither the one nor the other" (home or homeland culture) (Bhabha 1994, p. 25), despite the individuals physical location as being as part of one and the other. As an outcome of not belonging, the individual constructs an imaginary of homelands within the construction of the hybrid third space (as discussed in the theoretical chapter). Edward Said's theory of metaphorical exile also echoes Bhabha's conceptualization of the hybrid diasporic not belonging to either home or homeland culture. For Said, metaphorical exile is the "state of mind" that the diasporic individual constructs himself/herself as an outsider within his/her respective homelands (Zeleza 2005). Bhabha's discourse of not belonging can also be intertwined within Said's narrative of exile to understand how homeland 
imaginaries are viewed and constructed within the hybrid third space by the young Afghan women who participated in this study.

\section{Racialized Gendered Stereotypes}

Edward Said's book entitled 'Orientalism’ (1978) illustrates that Europeans (also referred to as the Occident) have produced stereotypical depictions of other cultures as the 'Other' to further perpetuate an 'us' versus 'them' dichotomy_(Mills et al. 1998, p. 98). Borrowing from Said's Orientalism, racialized women are also seen to occupy the eroticized subject position of the desired 'other.' There is a significant amount of post-colonial scholarship on gender and diaspora that explores and theorizes the gendered experiences of migration, displacement, and racism among ethnic-minority diasporic groups (Jiwani 2009; Razack 2008; Thobani 2000). As mentioned in the previous chapter, gender takes on new forms from the homeland to the diaspora, in which diasporic women are expected to conform to gendered cultural practices to preserve their cultural values. Scholars such as Sherene Razack (2008), Sunera Thobani (2007) and Yasmin Jiwani (2009) have explored how diasporic women have been constructed in both racialized and gendered ways within their 'Western' homelands. The scholars specifically draw our attention to the post-9/11 period in which Western media depicted Muslim women as victims of their oppressive cultures and fundamentalist religion. Similarly, the aforementioned Shafia murder cases in Kingston, Ontario in 2009 witnessed depictions of Muslim women throughout Canadian media as victims of honour killing.

Razack argues that in addition to media portrayals, Western feminist discourse depicts women of non-western societies as passive and voiceless victims (Razack 2008; Mohanty 1988). Specifically, Western feminists are charged with embodying the imperialist 
Westerner, who travels to a distant land to undertake the 'White man's burden' of civilizing barbaric cultures and saving native women from patriarchy (Razack 2008). The ongoing racialization of Muslim women within Western media and discourse has positioned Muslim women as needing rescue from their backwards and inequitable cultures by the "saviour" Canadian state. Notably, the veiled Muslim woman became a visual and textual symbol of oppression within Islamic countries. For example, the shrouded images of Afghan women during and after the 'War on terror,' particularly represented Afghan women as forcefully veiled, powerless and docile victims who are unable to defend themselves (Jiwani 2009; Khan 2014).

The racialized and gendered stereotypes experienced by Muslim women in Canada represent how feelings of not belonging are fostered. Belonging becomes tenuous particularly when minority-diasporic women are faced with social exclusion and significant structural and social barriers that impede successful integration and affect their sense of belonging in Canadian society. For example, Parin Dossa's (2006) research on Afghan immigrant women in Canada found that her participants efforts to socially interact with the broader community, experiences of racism and structural barriers made them feel excluded and "alienated" (Dossa 2006). While Dossa uses the term 'alien' to accentuate the way her participants feel, it can be argued that feelings of being 'othered' are imposed onto them through racialized tropes manipulated to sustain the images of these women as universally oppressed figures. It is imperative to distinguish feelings of exclusion that result from racialized gendered stereotypes of Afghan women.

The symbolic position of the racialized women as the 'other' is also noted by Brah (1996) who sees herself as being constructed within British society as a South Asian 
woman who is the 'inferiorized other' but as well as a "racialized insider/outsider" (Brah 1996, p. 9-10). This suggests that the 'othering' and 'exotizing' of racialized women, is simultaneously occurring and reoccurring both internally and externally also in a way that produces multiple identities. From Brah's assertion, it can be inferred that subjective feelings of otherness are constantly reworked in the experiences of racism and not belonging within the constructs of homeland nationhood.

The experiences of becoming 'othered' and feeling 'otherness' also resonate within many post-colonial writings on the challenges migrant women face in negotiating identity and sense of belonging. The writings of Ahmed (2000, and Dwyer (1996; 2000) discuss the intricacy of negotiating a sense of belonging in the midst of integrating into a society with misconceptions about their identities imposed upon them. Claire Dwyer's (2000) research on British South-Asian Muslim women contributes to this discussion as well; however, she also maintains that the racialization of Muslim women is experienced within and across generations. Dwyer posits that the perception of young racialized Muslim women also constructs them as oppressed victims who are coerced into arranged marriages and in some cases are discouraged from pursing higher education in the advent of marriage (Dwyer 2000 p. 480). Evidently, the western depictions of Muslim women signify the "White gaze" applied to both the racialized and gendered construction of the other - in this study, young Afghan-Canadian women.

\section{Literature Remarks}

Building on the theoretical framework set out in the literature review, in this final empirical chapter, I explore my participant's experiences of belonging and not belonging to 
their homeland cultures, and their efforts to maintain their hybrid identities despite identities imposed upon them by members outside of the diaspora. To do this, I draw on post-colonial scholarship (Amiri 2002; Jiwani 2009; Razack 2008; Thobani 2000) to identify the racialized and gendered stereotypes of Muslim women and illustrate how their identities are imposed upon them through the racialized gaze. Here, I also draw on Dwyer's research on young South Asian Muslim women to examine how the racialized and gendered gaze imposed on Muslim women pervades within and across generations; this includes the second-generation Afghan women in this study.

Avtar Brah's concept of homing desire is used to address how imaginaries of the homeland are sustained by the emotional connection to the origin country (Afghanistan) and by the desire to physically return to the homeland. This distinction allows me to show how second-generation Afghan women build their diasporic identities based on a sense of belonging and not belonging to multiple homelands (mainly Afghanistan, Canada, and a diasporic third space). They identify a homing desire that is distinct from a desire to return to their ancestral homeland. To further explore how second-generation Afghan women navigate the social and political terrains of not belonging to their national and cultural homelands, I also draw on Stuart Hall's argument that the diasporic subject creates multiple homelands because their identities are always 'becoming.' The idea of becoming vis-à-vis the perception of having 'arrived,' is used to understand the routes or pathways taken by my participants to construct and maintain their hybrid diasporic subjectivities. Thus, I will describe how the second-generation Afghan women within my study have both consciously and unconsciously challenge racialized and gendered tropes and also how they navigate their experiences as foreigners within Afghanistan and Canada. 


\section{Racialized Gaze}

In all ten interviews, participants were asked the following question: "How would you describe your interactions with others who are not members of the Afghan-Canadian community?" (S2, Q3, see Appendix A). All ten participants responded to this question by sharing narratives depicting the racialized stereotypes and misconceptions about their Afghan identity in their school, workplace, and in a variety of public spaces. I present these narratives to show how the racialized gaze operates within the everyday lives of my participants and situates them as outsiders within Canada.

\section{Understanding the Racialized gaze}

Racialized gaze is understood as the 'practices of visibility' that perpetuates racisms and misconceptions about the Other. Scholar Sue Hum theorizes racialized gaze as a visible practice that imposes hegemonic assumptions based upon the physical markers of the Other that re-inscribes the 'dominant cultures racist order' (Hum 2015, p. 193). My participants often discussed their encounters with White Canadians, both at school, work, and in general public spaces. Shafia, Parisa, and Alia, remarked that their ethnicity and physical appearance were often subjected to people guessing where they were from. The questions that were often asked of them included: "What are you?" "Where are you from?" or "Are you from [assumed ethnicity/ nationality]?" While presented as curiosity, these questions unavoidably imply that the participants are 'outsiders' who come from somewhere that is not Canada, signifying what Sara Ahmed's (2000) has called 'stranger fetishism.' Ahmed argues that the 'Other' is perceived as a stranger- who is familiar and recognized as someone who does not belong (Sara 2000, p. 22). This familiar process of 
'Othering' often continued even after participants affirmed their Afghan identities. This process is exemplified in Sharbat quote below, when her White peers ask her where she is from:

Every time I tell someone I'm Afghan they say, "Oh you don't look like your Afghan." It's [the] usual response from everybody....They [guess] "Arab, or Lebanese, or Indian." - Sharbat

Sharbat's peers are implying that her visible markers do not represent her ethnicself. Parisa also encounters the uninvited curiosity surrounding her ethnicity based off her physical appearance:

People will always [ask] me where [I'm] from. [They guess] Latino all the time, Mexican, Lebanese, Egyptian. I also get a lot of Turkish. - Parisa

Sharbat's and Parisa's statements illustrate that while their ethnic identities may not be perceived as Afghan, their physical appearance attracts racialization and stereotyping in a way that designates them as belonging to other minority-ethnic groups. The women I interviewed indicate this act of "guessing" reveals how the racialized gaze operates within their everyday encounters through: a three-step process. ${ }^{8}$ Step one, the ethnically White peer perceives and interprets the visible markers of the "Other" as different and not from Canada. Step two; the racialized gaze is employed to mark the Other based on perceived race, ethnicity, and religion. As Sharbat and Parisa's narratives reveal, this step often includes unwelcomed speculation and an uncomfortable "guessing game" of the real or true origin of the Other in question. Step 3 involves a brief inquisition that leads to an identity being assigned. This third step is illustrated in participant Alia's comment below:

\footnotetext{
${ }^{8}$ I cannot assert that this three-step process of the racialized gaze is experienced by every Afghan women or Muslim women. I propose this three-step process as it has been a significant finding within my interviews with participants.
} 
The first thing that comes to their mind is the [head] scarf. I have [heard] this question so many times: "If you're Afghan, where's your scarf? Why don't you wear it?" - Alia

From Alia's statement, it is apparent that the image of the exotic and oppressed Afghan woman who must wear a headscarf still resonates as the dominant image of Afghans within the Canadian context. Questions about the headscarf also demonstrate Alia's White coworkers' curiosity as to why Alia does not embody the traditional images of an Afghan Muslim woman. The absence of distinct visible markers such as the headscarf appears to trigger racial stress for Alia's white coworkers who are left confused and uncomfortable that their "truths" about Afghans are being challenged. Alia's statement also reveals that the third step of the racialized gaze includes invasive questions that are informed by racialized stereotypes and images of Afghan women as 'oppressed' and 'veiled', despite the fact that they did not embody any visible material markers that could be perceived to represent their religious or cultural identity, such a headscarf or a veil.

\section{Racialized Encounters in Everyday "White” Spaces}

The above discussion reveals how the racialized gaze is employed within the everyday encounters of participants Sharbat, Parisa, and Alia. My conversations with participants also revealed the challenges of finding a place of belonging in dominant White spaces ${ }^{9}$, where they seemed to experience heightened forms of racial discrimination. For example, $9 / 11$ became a significant marker for participants in their descriptions of the

\footnotetext{
${ }^{9}$ According to my participants, "White Spaces" describes the social spaces which are predominately occupied by White people and not frequented by other minorities.
} 
racialization of the Afghan diaspora in Canada. Both Salma and Parisa discuss the racist comments they have heard while living and growing up in Canada.

I hate telling people from school that I'm from Afghanistan... I feel like I'm just going to get judged... [A] White guy [asked] "are you a Taliban?" They think that if you're Afghan you're associated with the Taliban somehow. - Salma

Salma is compelled to be cautious of the ways her White peers may depict her. This caution reveals both a sense of fear and ambivalence over developing a sense of belonging in public and social spaces (her school) that she perceives as "belonging" to her White peers. In making the decision to reveal her Afghan identity, Salma worries about being categorized, judged, and eroticized as the 'Other.' Salma has to contend with the western perception of Afghan women as oppressed and the by-product of the corruption that has defined Afghanistan, such as the Taliban. Her comment also exemplifies the unequal power dynamic whereby Salma's ability to define herself is outweighed by her White peers' imposition of misconceptions and racialized depictions about her. As a result, Salma is protective of subjecting her Afghan identity to the White gaze.

Maryam also echoes the same sentiments in her experiences as a youth and adolescent in her school and work space:

When I say I am from Afghanistan... I am hesitant to tell them...like growing up, they [respond]: "Oh so your Osama bin Laden's daughter...the whole situation with ISIS, I have been hearing [the racist comments] in the past year more. It really frustrates me actually." - Maryam

Maryam's quote signifies how the depictions of Afghan women among her peers and co-workers are twofold: they are seen as oppressed victims of their patriarchal culture on the one hand, and representatives of the Afghan conflict on the other. The rise of the 
Islamic State of Iraq and Syria (ISIS) since 2014 has been viewed as a significant global threat to peace and security (Safi 2016). However, the exposure of ISIS's international crimes and the global responsibility for Syrian refugees has also increased Islamophobia against Muslims worldwide (Safi 2016). As my participants suggest, within Canada, Muslim-Canadians feel isolated, vulnerable, and fearful of the anti-Muslim sentiments that have surfaced, similar to the feelings of isolationism after 9/11 (Safi 2016). Like Salma, Maryam is also cautious of being categorized and assigned the stereotypes associated with Afghan women after 9/11. The narratives shared by Salma and Maryam depict the ways in which racialization and the process of "Othering" contribute to their feelings of not belonging to Canadian society and a fear of being excluded if their Afghan background is revealed.

As mentioned in the previous chapter, the Shafia honour killings received widespread media coverage after the bodies of the three women and the first wife of Mohammad Shafia were discovered in a sunken car in the Rideau Canal in Kingston, Ontario on June 30, 2009 and when Mohammad Shafia, his second wife, and their eldest son were charged with four counts of murder and were convicted in January 2012. Scholar Yasmin Jiwani (2014) has written extensively on the Shafia sisters and argues that within media coverage of the event, the tropes of culture clash were embedded within the Orientalist framing that worked to construct the young women as "worthy victims." These images informed the national imaginary of Canadian society as "egalitarian, tolerant and beyond gender violence (Jiwani 2014, p. 27). Jiwani contends that the honour-killing frame invoked both implicitly and explicitly, misconceptions about Afghan culture as "tribalistic and pre-modern" (Jiwani 2014, p. 28). 
The Shafia sisters have not only been depicted as belonging to a culture and a religion that is stigmatized as barbaric in the post 9/11 milieu, they were also perceived as young women who long to distance themselves from their own culture in favour of Western values and practices. For instance, the press coverage often circulated images of the Shafia sisters as women who adopted mainstream practices in dress and behaviour; however, they had the misfortune of belonging to "the backwards" and "traditionalist culture" that is safeguarded within the patriarchal Islam (Jiwani 2014, p. 28). These media images reinforced the racialized stereotypes of Afghan women within the international and domestic context as victims who need to be rescued. Following this case, depictions of violence against women became perceived as crimes that are only pervasive in so-called Oriental cultures (borrowing from Said). It can also be argued; however, that these depictions also informed the Canadian public's curiosity about Afghan-Canadian women and the treatment of them within their households. This is illustrated in the following quote from my conversation with Afia:

When teachers talk about the political issues [in Afghanistan] like Taliban, and that women have no rights there, they always bring up stuff like that...they want to know my views on it. They always ask me, "How is it like in your household?" They are curious about how my parents raised me... - Afia

From Afia's professor's point of view, Afia is the Afghan woman who does not appear to be oppressed due the absence of visible markers, such as the headscarf; but can still be assumed to be oppressed within her home because she comes from Afghanistan. While I have suggested before that my participants' white peers can sometimes unintentionally reinforce racialized stereotypes of the Other, the professor-student exchange described by Afia indicates racialized stereotypes can be assigned by powerful others. More important, 
they can be assigned in an intentional and publicly embarrassing way as was done through the probing questions asked of Afia by her professor. In other words, by asking Afia questions about her own household, the professor reduces her to an 'outsider Afghan women,' and fulfills her own imaginary of this demographic rather than allowing Afia the opportunity to educate or enlighten the class about her own life and the true situation of Afghan women.

Noble (2005) asserts within her own analysis on Arab Muslims in Australia that when the White gaze fixates on women's ethnic differences, they begin to 'invisibilize' the women's roles as autonomous social actors and reduces them to a category (Noble 2005, p.116). These forms of micro-aggressions experienced by my participants heightened not only their apprehension about belonging to Canadian society and their sense of cultural alienation; but it also increased their feelings of being perceived as a visible outsider. Their narratives reveal the ways that everyday encounters reflect on broader, structural processes that perpetuate or reinforce gendered and racialized stereotypes about their identities.

\section{Foreigner in Afghanistan}

While participants described their experiences of being "Othered" and treated as 'outsiders' by Canadian society, they also revealed experiences of not belonging when visiting Afghanistan where people also constructed them as "outsiders". I asked all participants the following question: "Have you ever visited Afghanistan?" and "do you ever wish to visit or go back permanently to live in Afghanistan?" (S3, Q2, see Appendix A). While all participants shared their willingness to visit Afghanistan, only one participant, 
Sarah, shared that she would live in Afghanistan and only if the application to sponsor her husband was not successful. All other participants expressed resistance to living in Afghanistan, due to either their past experiences of visiting the country or the negative experiences they heard from their friends who had visited in recent years. Not surprisingly, for all participants, Afghanistan's current socio-political conditions also rendered the country as an undesirable place to live and even visit for some.

Participants described a similar process of being constructed as foreigners during their visits to Afghanistan. They described a policing of physical gestures and encounters of street harassment - such as catcalling - that the participants were subjected to during their time in Afghanistan. Street harassment or Khaban Azari' is a prominent form of violence that many women experience in Afghanistan today. For the participants in this study, street harassment was a significant issue because they were seen as 'foreign' or more accurately non-resident Afghan women during their time in Afghanistan. Sabrina employs the term 'foreigner' to identify how the Afghan men made her feel.

To them I was a foreigner. They can tell from my body language that I'm not [living] here. I take pretty large steps when I walk, and I swing my arms and I like to look around. It was really awkward...Women there don't do that they just look straight ahead or look at the ground and walk and they take smaller steps. - Sabrina

Sabrina's quote illustrates how second-generation Afghan women may be perceived as outsiders in their "homeland". She describes that the swinging of her arms and other physical gestures are indicators that she does not live in Afghanistan anymore. Sabrina's quote also draws attention to the policing of women's bodies and behaviours by Afghan 
people that effectively differentiates between who is an Afghan insider and who is not. The bodily comportment, movements, and gestures that women in Afghanistan embody render anyone who does not conform to be a visible outsider raised elsewhere in the world. This sense of being different is a source of immense discomfort; however, the taunting by Afghan men adds a dimension of fear and uncertainty. As Salma notes in her description of her experience of street-harassment and her 'outsider' status when she was visiting Afghanistan in the summer of 2015:

[The Afghan men] would whistle at me all the time. There was one time I was wearing red lipstick and a guy said "I wish I could just suck on your red lips like sucking on cherries...They would know I'm not from [Afghanistan]. The way I would walk, I wouldn't even talk. They just knew. - Salma

Another participant, Tamana, describes this sense of fear when she explains both her own and her sister's experience of street-harassment when they visited Afghanistan in 2006:

My sister did not step out of the house because of the cat-calling and men would approach us [in groups] of seven on the street. It was very alarming. (Tamana)

Salma's visit to Afghanistan in 2015 and Tamana's visit in 2006 demonstrates how, despite the gap in years in which each traveled to Afghanistan, street harassment was a prominent issue for both of them. Salma and Tamana's experience of street harassment is an example of how second-generation Afghan women are seen as 'outsiders' or foreigners by Afghan men and, as such, can be treated with disrespect and hostility rather than with the politeness given to 'real' Afghan women. Sharbat has heard similar accounts from her female cousin in Afghanistan: 
The Afghans there know you're not from there because there are certain ways [women] hold [them] selves when [they] walk. A lot of the girls who visit Afghanistan, they're looking around or they walk differently, they walk [quicker]. - Sharbat

Sharbat and Sabrina both describe how second-generation Afghan women who visit Afghanistan may be immediately 'Othered' by Afghans who live there. Sarah also shared that prior to arriving in Afghanistan she prepares herself to avoid such forms of street harassment when visiting her husband:

On the plane to Afghanistan, I always change. I always make sure I have a head covering, get a long skirt, because you don't want that negative attention like the whistling and other stuff. - Sarah

Sabrina, Sharbat and Sarah's statements reveal how 'foreign' Afghan women visiting Afghanistan are easily distinguishable and subjected to street-harassment (catcalling), making them feel uncomfortable and unwelcome and, at times, fearful. For instance, Maryam who is twenty-three years old explains her experience of street-harassment when she was just eleven years old:

I wore regular clothes when I was in Afghanistan. I was 11. I was kid. These older men would look at me and say "Oh what is this? This girl? Why is she here." I had a homeless guy grab my butt and I had an old man grab my bust. It was horrible. - Maryam

Maryam's statement also reveals a sense of curiosity expressed by Afghan people over why these foreign Afghan women are even present in Afghanistan. Participants describe this curiosity as hauntingly similar to what they experience in Canada when people outside of the Afghan diasporic community ask where they are from. The difference is that, within Afghanistan, the participants are viewed through a gaze that is informed by a 
modicum of cultural authenticity. In this context, cultural authenticity is used to demonstrate how people in Afghan feel about foreign Afghans who are otherwise attempting to 'stage cultural authenticity.' The ultimate effect is similar, however. As a result, second-generation Afghan women are seen as, and made to feel like, 'outsiders' in both Canada and Afghanistan.

Participant's experience of visiting Afghanistan fostered feelings of cultural alienation and cultural judgement for being Canadian-Afghan. They felt that they did not belong in Afghanistan and were an outsider in Canada because the Afghanistan that exists today is different and perceived as a threat. As I will discuss in the next section, participants seem to have no choice but to construct an imaginary Afghanistan in the hopes of reclaiming of their identity.

\section{Creating an Hybrid Identity as Outsiders in Afghanistan and Canada}

Despite their outsider status in their multiple homelands, Afghanistan and Canada, participants are actively reclaiming their identity in three significant ways: through the construction of imaginary homelands that achieve their homing desire, by challenging the gendered and racialized depictions of their identities, and by using education as a source of empowerment. Participants illustrated the process of reclaiming their Afghan identities as occurring within a 'third space' (Bhabha, 1994) where their complex plural identities could be navigated to accommodate their homing desires and self-narratives. 


\section{Imaginary Afghanistan and reclaiming identity}

Participants remained keen to maintain their Afghan identity even though those identities were not seen as 'belonging' to their ancestral homeland. It is however, within this outsider space that participants constructed and maintained an alternative image of Afghanistan that existed only within their imaginaries. In many ways creating an imaginary offered a strategy for second-generation Afghan women to use to address the issues that existed when they visited Afghanistan such as catcalling. Additionally, the constructed imaginary of Afghanistan offered a method for the women to use to reclaim their identity and navigate their outsider status when in Canada. For all the participants, the Afghanistan that exists today is not the true Afghanistan that their mothers and grandmothers experienced for it is that imaginary they hold in their minds when thinking and talking about their origins and/or their sense of belonging. For example Afsoon shares how the 'true Afghanistan' lies within her mother's memories:

When my mother grew up, there wasn't turmoil and oppression against women. My mom would wear miniskirts and high-heels to school and there was no cat-calling. The stories my mother shares from when she was a teenager are very different from when she ended up coming to Canada and escaping from the oppression. - Afsoon

From Afsoon's statement it is apparent that for her the true Afghanistan is the country that was "lively and flourishing" when her mother was growing up. This 'flourishing' image of Afghanistan resides within the memories of Afghan mothers passed through to the next generation that participants shared with me. Thus, it is within this outsider space where they are reminded that the Afghanistan that they know of today is not the Afghanistan they or their mothers claim any sense of belonging to. In many ways participants are also aware that this imaginary homeland is just that - imaginary. For instances during my interview with Alia, she shares that she can never imagine an 
Afghanistan that will be free from "political and social violence," and restored to the imaginary Afghanistan that once existed:

No. No.... I don't think there will ever be a time when Afghanistan goes back [to what it once was], No.

For Alia, it is clear that the imaginary of Afghanistan cannot exist in reality. Like Alia and Afsoon, all participants constructed the imaginary homeland of Afghanistan through recalling the stories and images that have been shared by their family members. In many ways, creating this imaginary and maintaining its existence within the diasporic consciousness reveals a form of diasporic survival. However, participants are aware that this imaginary is subject to changing conditions and overlaps with Afghan history, culture, and power. For second-generation Afghan women, the imaginary of Afghanistan reconstructs the past that they would have belonged to if events had not made their family emigrate. What was significant within my findings was that, in sharing the images of what Afghanistan once looked like, participants constructed an Afghanistan that looked increasingly similar to the supposed characteristics of a nation that signified their hybridity. This perception is exemplified when Parisa discusses her mother's and grandmother's memories of Afghanistan:

My mom went to university; my grandmother went to university to study medicine. And when [they] talks about this, it's feels so unfortunate all this change happened within 30 years [in Afghanistan] and [my mom] would talk about how women used to work, there used to be really nice airlines, women didn't have to cover themselves, they wore pencil skirts...they can wear what they want and show their skin and that was fine. [My mom] could go to school and go out with her friends after without feeling like someone's going to kidnap her. And how she used to make fun of boys and how some of her friends used to have boyfriends and secret little [dating] stories like that... I really wish go back and see what she was talking about but that's far from today.-Parisa 
Parisa's statement illustrates her longing to belong to the Afghanistan her mother and grandmother had experienced. Her Afghanistan is a blend of the perceived social strengths of Canada with a familiarly of a lost Afghanistan: a space in which her hybridity operates. Parisa's personal memories living temporarily in Afghanistan exemplify her desire to create an imaginary Afghanistan that she would belong to in the present day. She briefly shares her memory of being 'deprived of school at [the age of] 9...' during the time she and her family lived in Afghanistan. She describes this experience as a 'crushing memory' of Afghanistan; however, she reconciles her perceptions of Afghanistan through creating an imaginary of the country, illustrating her homing desires of belonging.

Similar to Parisa, all other participants described a process of continuously constructing an imaginary space of belonging to both cultural and national worlds to compensate for their multiple homelands wherein they are seen as outsiders. The imaginary of Afghanistan is an enactment of agency that resists homelands that these women physically occupy, characterized by racialization, exoticization, fetishism, and othering.

\section{Challenging the racialized gaze in Canada}

The second-generation Afghan women I spoke with do not surrender to the racialized gaze that imposes fixed identities onto them in Canada; instead they employ strategies to challenge others' depictions of their Afghan identities. They do so by performing their identities strategically to reshape the existing narratives that construct their Afghanness and through exceeding in their educational attainments. This process is 
exemplified within Afia's response to her professors who exert their racialized curiosity onto her with their assumptions and questions:

I feel like it is [also] my job to show them it's not what they think...I tell [my professor and class-mates] that my parents aren't like that, [that] they raised girls and boys equally. - Afia

Afia feels compelled to defend her parents against racialized stereotypes and from the curiosity of professors and peers surrounding the 'exotic' and 'oppressed' Afghan woman. The exchange she describes above served as an integral moment for Afia who experienced an immediate need to resist this Orientalist narrative. Her act of resistance in telling the class that her parents raised girls and boys equally juxtaposes the stereotypical images of Afghan women as "helpless" women who lack agency or autonomy. It can be argued that within her educational institution, Afia also reclaims her Afghan identity by positioning herself as the defender of Afghan people and culture.

Afia feels compelled to defend her parents against racialized stereotypes and from the curiosity of professors and peers surrounding the 'exotic' and 'oppressed' Afghan woman. The exchange she describes above served as an integral moment for Afia to resist this Orientalist narrative. Her act of resistance juxtaposes the stereotypical images of Afghan women as "helpless" women who lack agency or autonomy. It can be argued that within her educational institution, Afia also reclaims her identity by positioning herself as the defender of Afghan people and culture. Sabrina shares a similar encounter with her professors and explains that she is "confused by those type of comments" that assume that she is oppressed or uneducated. 
I don't know how to explain [there comments]. It makes me feel really uncomfortable...over time I realized I was making an [excuse] for them...they need to know that they are ignorant.

Similar to Afia, Sabrina is uncomfortable with the remarks made about her Afghan identity and is determined to condemn the ignorance surrounding Afghan women. Many of my participants challenged such essentialist tropes on a daily basis - tropes that work to situate them in accordance to the western imaginary of Afghan women as powerless and submissive.

Another key way participants challenged the racialized gaze was through reaching high levels of educational attainments. All ten participants had either completed a university degree or were enrolled in an educational institution during the time of the interview. Six participants, Sharbat, Maryam, Parisa, Salma, Sarah, and Afia have completed their Bachelor's degree. Three participants, Alia, Tamana, and Sabrina completed their Master's degree and participant Afsoon is completing her final years at a Law school.

The racialized depictions of Afghan culture within the West have also perpetuated stereotypes about Afghan women being forced to marry at a young age without pursuing an education (Razack 2008). As a form of resistance, my participants expressed their determination to succeed in their respective educational fields, despite their marital status. Also significant from participants accounts, is that these women were not only reclaiming their identity through pursuit of education, but they were also disproving the racialized and essentialist tropes about Afghan men as barbaric and in alliance with the oppressive rules that keep women from pursuing education (Razack 2008). For instance, participants 
spoke about their Afghan fathers as the main supporters in their decisions to attend university. This situation is exemplified in Parisa's statement below where she explains her aspirations to become a diplomat:

I love politics and it kind of runs in our family and you know being from Afghanistan it kind of is that too. But my dad is a diplomat ... and a lot of my uncles are that as well so I was really inspired by that at a really young age.

Parisa's decision to pursue her field of study is influenced by the men in her family. Her educational pursuits allowed her to perform her Afghanness while also disrupting the stereotypes of Afghan people. She believes that with her "professional life and education," she can "tell [the world that] I'm Afghan and I can prove that I'm Afghan." For Parisa disrupting the racialized gaze is a political statement. Sarah also shares that the reason she has adjusted well into Canadian society after migrating with her parents to Canada was because of her father:

[My] dad was a huge part of education taking place at home and every time he wrote a book, he would ask us to proofread... he would actually hand write all the sentences and then ask me to type them up... -Sarah

The above quotes illustrate how Afghan male family members, especially fathers, have had positive influences on their daughters in a way that problematizes the essentialist tropes of forceful Afghan fathers and coerced Afghan daughters. Parisa and Sarah's decisions and experience in pursing and excelling in their educational pursuits resonate with all my participants. More importantly, all participants sought to disprove the West's negative portrayal of their identity, their families, and their community. 


\section{Reclaiming identity through changing cultural definitions}

Second-generation Afghan women are also reclaiming their identities by shifting cultural definitions that affirm their Afghan-Canadian identities. This process is exemplified strongly through their attempts to change definitions of feminine occupations and (re)value of care. For example, Alia, who is a registered nurse (RN), discusses how the job duties of an RN differ significantly in Afghanistan:

Registered nurse is a good title and is a degree program in Canada. In Afghanistan, nurses were paid minimum wage and were sort of maids... here I work in [a hospital unit], so there's no cleaning up. - Alia

Alia's decision to become an RN was not influenced by the Afghan cultural definitions applied to this field of work in Afghanistan. In Afghanistan, older women and women who did not have the means to pursue education usually work as nurses (Tefft 1989). When I asked Alia if there were any positive or negative reactions in her pursing this field, she stated that members of the Afghan community were shocked and unsupportive about her job as an RN until a matriarch (an older lady) of the Afghan community saw what the duties of an RN entailed:

They just had this perception of a nurse that all they do is clean up... people would say "oh my God, I can't believe it," in a negative way. Until this [Afghan lady] she became a very frequent patient that I took care of. She has a completely different perception of an [RN] now. She tells other [Afghan] people about it. - Alia

Alia played a significant role in changing the Afghan cultural definition of an RN within her community. While nursing is traditionally seen as job that is 'lower-status' in Afghanistan, Alia's job as an RN revealed to the matriarch that in Canada the job is highly commendable. Alia also shares that when she graduated from Nursing in 2009 "there 
weren't any Afghan nurses [in her graduation class]." Alia states however, that because there has been a shift in cultural definitions for what it means to be an RN, more Afghans are considering the field of work:

When I became a nurse, [Afghan people] began to [change their opinions] about an RN and now there are so many Afghan girls who are RN or medical students, and when my husband [arrived to Afghanistan] he began school and became an RN too. - Alia

Alia discusses how the change in the cultural definition of an RN within the Afghan community has encouraged many Afghan women she knows to pursue the field. The shift in cultural definitions of the job and changes to the gendered order of nursing resulted in her husband following her footsteps and becoming an RN as well. Within both the Western and Afghan cultural context, nursing is traditionally stereotyped as a feminine occupation; however, despite this stereotype, her husband becoming an RN demonstrates how there is also a cultural shift in conceptualizations surrounding occupations that are feminized - not a small achievement in a community perceived externally as patriarchal and oppressive to women

Sarah also discussed how the Afghan community is beginning to value occupations that are traditionally seen as feminine and 'lower status.' Sarah who is pursuing a degree in practical nursing shares that her parent's originally "wanted [her] to become a doctor." Within Afghan culture, practicing medicine for women is considered to be an exceptional field of work and many Afghan parents, including the parents of my participants, encouraged their daughters to become doctors. However, Sarah explains that her parents eventually accepted her decision to become a nurse when they witnessed what this job 
entailed in Canada:

My mom had recently been diagnosed with diabetes, so I would be [in the hospital] with her and she would see how hard the nurses worked, how tough their job is. The doctor would only see the patients for maybe 10 to 15 minutes, out of their 8 hour [shift] and it would be the nurses that she would see taking care of people. That's what's changed her mind about [nursing]. - Sarah

Sarah explains how her mother compared the care practices of a nurse to that of a doctor. For Sarah's mother, nursing became a valuable field of work when she saw the strong work ethic and "tough" responsibilities they encountered on a regular basis. Both Sarah and Alia's decisions to pursue nursing signals how various misconceptions surrounding feminine occupations are being re-assessed and care occupations are becoming re-valued within the Afghan community in Canada. In this way, through their educational and professional choices, the women in my study have constructed an AfghanCanadian identity that includes new cultural definitions regarding their occupations and the meanings applied to them. The participants have exercised their agency in reclaiming their identities by 'reworking' existing cultural definitions and narratives imposed on them by both their 'old' homeland (i.e. Afghanistan) and their 'new' homeland (i.e. Canada).

\section{Conclusion}

This chapter has focused on how second-generation Afghan women are negotiating their hybrid identities in the contexts of their multiple homelands, where they are subjected to different sets of racialized and gendered stereotypes that construct them as outsiders. Some of these stereotypes have constructed the participants as the 'exotic 
others' that do not fully belong within Canadian society. Likewise, participants have also experienced 'othering' in Afghanistan through the policing of their bodily comportment, dress, behaviours, gestures and experiences of street-harassment. I argue that the participants' experiences of being "othered" in both Canada and Afghanistan made them feel like they belong 'neither here nor there'. These feelings create room to construct new imaginaries, homing desires, and hybrid spaces. Considering these key themes outsiderness, belonging/not belonging, imaginary homelands- my findings reveal that these second-generation Afghan women are reclaiming their Afghan identities through small acts of resistance, transformation and exercising agency. They do so by employing both explicit and implicit strategies to relieve the tensions caused by their hybridity, such as seeking high educational attainments and by changing cultural definitions of spaces they occupy. Thus, in reclaiming their Afghan identities, participants are also creating an 'inbetween space' that includes appropriation and transformation of cultural and national elements of their homeland. 


\section{Chapter 7: Final Discussion}

Second-generation Afghan women's hybrid identities are not a mere "tracing [of] two original moments from which the third emerges" (Bhabha 1990, p. 211). These women are re-conceptualizing and continuously transforming their cultural hybrid identities, because they are in a 'constant state of flux.' Based on their shared and personalized narratives, these women often struggle to situate themselves fully into Canadian society and/or the Afghan diaspora. As an outcome, participants strategize to balance these two contrasting cultural identities by creating new imaginaries of belonging that also allow them to re-negotiate their complex and multi-faceted identities as second generation Afghan women.

This study applied a feminist methodological approach to ensure that secondgeneration Afghan women remain at the forefront of my inquiry as their narratives have largely been unexplored in the broader discourse on Afghan women in Canada.

Additionally, through using a gender lens, I was able to conceptualize the theoretical terms - diaspora, hybridity, and homing desire - to encapsulate the hybrid identities of second-generation Afghan women. Therefore, this thesis contributes a new narrative to the theoretical framing of cultural hybridity through identifying these women's hybrid identities as neither a happy nor undesirable mixture of two contrasting cultural identities, but rather an active construction of identity involving small acts of agency and resistance.

As exemplified in Chapter Four, "Nuancing Second-Generation' the findings in this discussion also add to the debates surrounding segmented assimilation. More specifically through using a gender lens, it is found that these women are autonomous social actors 
who have redefined or reformulated second-generation to make sense of their identities as Afghan-Canadians. More specifically, participants construct their own identities through negotiating gendered cultural practices, while also integrating into the broader society as Afghan-Canadians.

In Chapter Five, "Conformity and Resistance," many of the women I interviewed spoke about the reasons why they conformed to gendered cultural practices while also sharing their disapproval of cultural beliefs that reinforce unequal gendered roles within the Afghan diaspora. I posit that participants' decision to negotiate these practices signifies their diasporic consciousness and leads them to resist the racialized and gendered stereotypes applied by others. By symbolically locating themselves closer to their parent's cultural values, participants also demonstrated their agency in the ongoing construction of their cultural hybridity. The subjectivities of second-generation Afghan women have been and continue to be determined by discursive cultural scripts that result from their hybridity; however, they are not passive victims of the process but strong actors in their own right.

In Chapter Six, "Neither Here, Nor There" the data reveals a process of creating imaginary homelands that are deeply rooted in the formation of second-generation Afghan women's hybrid identities. The foundations of this imaginary homeland for the women I interviewed delineates imaginary spaces of belonging and homing desires-that allow the women to consider self as neither foreigners in Afghanistan nor as exotic others in Canada. Instead, they take what they consider to be the best parts of their mother's, aunts', and grandmother's experiences growing up in Afghanistan and integrate it as part of their own 
story of how Afghan women and Afghan culture truly exists. Throughout this research, Afghan women's efforts to reclaim their identity were further nuanced within narratives that depicted ambivalence, yet agency and empowerment. This study also stands witness to participants' efforts in sustaining differences whereby they do not identify as only Afghan or Canadian but as combination of the two based on their experiences as secondgeneration Afghan-Canadian women. Furthermore, the women openly assert their identities as Afghan-Canadian women in a way that, simultaneously challenges essentialist depictions of Afghan women by selectively appropriating western structural processes, such as education and employment and Afghan cultural practices, such as arranged marriages. These selective acts have worked to infuse new meanings within the Afghan diaspora surrounding their gender roles and stronger acceptance of the hybrid identities they have formed.

\section{Further Research and Limitations to this study}

This research relied exclusively on data gained through semi-structured qualitative interviews with 10 participants. My insider position as a second-generation Afghan woman enabled me to gain the trust of my participants mainly because I could relate to my participants experiences surrounding cultural scripts. I found participants to be more willing to share their personal experiences without discussing the details of concepts within Afghan culture. For instance, in Chapter two, Salma shares her personal narratives regarding the marital ceremony, Takht-jami, without sharing the definitions of this term. While the takht-jami is celebrated in different ways across the Afghan diaspora, the practice that takes place during this ceremony, such as the revealing of the bloody cloth as 
proof of virginity, is an element within this cultural custom that is unspoken and arguably not extensively written about. If I had not identified myself as being from Afghan cultural background, there is a strong possibility that Salma may not have shared this detail and the discussions surrounding the takht-jami may not have been included. In comparison, the participants' expectation that I knew the history of Afghanistan and their customs may have led them to minimize or eliminate details that may have limited my access to data and a deeper understanding of the impact that particular ideas or events may have had for them.

After analyzing the participants' narratives, religion and class emerged as significant factor in the construction of identity and negotiation of cultural hybridity; both of which I did not pursue in my line of questioning to the same extent as gender and race. As a result, these themes however, were not discussed as widely in the thesis. This leaves room for more research to be conducted by designing further studies with supplementary questions to tease out the ways in which religion and class intersect with gender and race to affect participants' lives.

Despite these limitations, the narratives shared through this research addressed the many ways in which second-generation Afghan-Canadian women construct their hybrid identities while also straddling two contrasting cultures. This exploratory study creates a theoretical and methodological space to better understand the lived experiences of secondgeneration Afghan women in Canada and serves as a call for more research to contribute to the overall discourse on Afghan women in Canada, as the experiences of these women can provide valuable insight on themes related to migration, settlement, and cultural identity. 
Qualitative studies on this demographic will also reveal the integration experiences of second-generation immigrants from minority diaspora's.

Research as a way of coming together

This research in the words of Salma was for her, an example of "a moment where second-generation girls can come together and share their stories, and stick together." Her comment serves as a reminder that while insider research aims to produce, contribute, and disseminates knowledge; the research process can also create a social space, which includes within it the sharing of stories and construction of new subjectivities. These social spaces can help foster "a safe space where we can talk about our struggles" (Salma) and encourage growth as a collective group within the Afghan diaspora. It is my hope that this type of research will continue to provide second-generation Afghan women the platform to share their stories that highlight their agency and resilience in being Afghan and Canadianbut also create a social space in which the dialogue between second-generation Afghan women continues. 


\section{Appendix A: Interview Questions}

\section{Section 1: Introduction and Demographic Interview Questions}

1. In what year were you born?

2. Do you attend university/college? (If Yes) What is the highest level of education that you have completed? What is your major/ interest in school?

3. What, if any, is your religious affiliation of preference?

4. What is your current marital status? (e.g. single, divorced, separated, married, widowed, common law)

5. What province in Afghanistan are you or your parents from?

6. When did your parents/family arrive to Canada?

7. As you think about your future, what is most important to you?

\section{Section 2: Second-Generation (Hybrid Identity):}

1. When I say the word "second generation," what comes to your mind?

2. Do you identify as "second generation?"

3. How would you describe your interactions with others who are not members of the AfghanCanadian community?

4. What are some community services that you would feel comfortable using as a "secondgeneration "Afghan woman? (If in Q. 2 they identify as such.)

5. In your experience, what do you feel is the biggest difference between "first-generation" Afghans and "second-generation" Afghans in Canada?

6. What language would you consider as your first language?

7. How do you think other Afghan-Canadians (without distinguishing between first and second generation here) perceive your status as a "second-generation" person?

8. Some of the research literature indicates children of immigrants experience obstacles in their "new" home country.

\section{Section 3: Transnationalism-Generation interstice and cultural identity}

1. What affinities, if any, do you feel that you hold with Afghanistan as a country?

2. In what ways do these affinities help to shape your identity? Have you ever visited Afghanistan? If yes, how would you describe your experience? Do you ever wish to visit or go back permanently to live in Afghanistan?

3. What are some Afghan cultural norms and traditions that you might practice?

4. What are some of the Afghan cultural norms and traditions that your family might practice?

5. What are some cultural expectations, if any, that you feel you are obligated to fulfill?

6. What are some of the strongest cultural differences that you notice about living in Canada versus Afghanistan?

7. Many researchers have found that there is a culture gap between the parents who move to a different country and their kids who are raised in that country. Do you agree with this? 
Appendix B: Recruitment Poster (Sample)

\author{
Carleton \\ U N I E R S T Y

\section{Afghan Women} \\ Participate in a study!
}

To participate in this study, you must be:

\title{
$\checkmark$ Be a Second-Generation Afghan Woman $\checkmark$ At least 18 years old $\checkmark$ Live in Ottawa or the surrounding area
}

You are invited to participate in a study about Afghan women's experience adjusting to Canadian life.

If you would like to be interviewed and want to share your story

Please contact the researcher, Saher Ahmed, for more details on this study at saherahmed@carleton.ca

This project has been reviewed and cleared by the Carleton University Research Ethics Board at 613-520-2517 or ethics@carleton.ca. 


\section{Glossary of Terms (Spoken in Dari):}

\begin{tabular}{|c|l|}
\hline Chatal'e Zameen & $\begin{array}{l}\text { The term 'Chatal' translates to dirty and } \\
\text { Zameen to floor. The conjoining of these } \\
\text { words translates to the expression 'dirty } \\
\text { floor' }\end{array}$ \\
\hline Khastegari & $\begin{array}{l}\text { This term refers to the Afghan cultural } \\
\text { tradition known as "honourable request." } \\
\text { The male suitor or his family member asks } \\
\text { for a woman's hand in marriage. }\end{array}$ \\
\hline Lavs-Dadan & $\begin{array}{l}\text { Refers to “word of approval," which is the } \\
\text { response that a woman and her family } \\
\text { members would deliver to the suitor if they } \\
\text { agree to the Khastegari }\end{array}$ \\
\hline Nowruz & $\begin{array}{l}\text { This term translate to a 'new-day,' marking } \\
\text { the first day of spring. On this day Afghans } \\
\text { celebrate the new year. }\end{array}$ \\
\hline Takht-jami & $\begin{array}{l}\text { Meaning the night after the wedding or the } \\
\text { wrap up program. This event traditional } \\
\text { takes place three nights after the wedding } \\
\text { and includes various cultural practices. }\end{array}$ \\
\hline & $\begin{array}{l}\text { To be decent or proper. The term is often } \\
\text { employed in Dari to describe modest } \\
\text { behaviour. }\end{array}$ \\
\hline &
\end{tabular}




\section{Works Cited}

Abbasi-Shavazi, Mohammad Jalal, Rasoul Sadeghi, Hossein Mahmoudian, and Gholamreza Jamshidiha. "Marriage and Family Formation of the Second-Generation Afghans in Iran: Insights from a Qualitative Study." International Migration Review 46, no. 4 (2012): 828-60.

Abbasi-Shavazi, Mohammad Jalal, and Rasoul Sadeghi. "Socio-Cultural Adaptation of Second-Generation Afghans in Iran." International Migration 53, no. 6 (2014): 89110.

Abu-Lughod, Lila. "A Contribution to Feminist Research Methodology." Women \& Performance: A Journal of Feminist Theory 11, no. 1 (1990): 21-27.

Acheraïou, Amar. Questioning Hybridity, Postcolonialism and Globalization. Houndmills, Basingstoke, Hampshire: Palgrave Macmillan, 2011.

Aguiar, Marian. "Arranged Marriage: Cultural Regeneration in Transnational South Asian Popular Culture." Cultural Critique 84 (2013): 181.

Ahluwalia, Muninder. K, Suzuki, Lisa. A, and Mir, Madeeha. "Dating, Partnerships, and Arranged Marriages." In Asian American Psychology: Current Perspectives, edited by Nita Tewari and Alvin N. Alvarez, 273-294. New York; London: Taylor and Francis Group. 2009.

Ahmed, Sara. Strange Encounters: Embodied others in Post-Coloniality. New York; London: Routledge, 2000.

Amer, Amena, Howarth, Caroline, and Ragini, Sen. "Diasporic Virginities: Social Representations of Virginity and Identity Formation amongst British Arab Muslim Women." Culture \& Psychology 21, no. 1 (2015): 3-19.

Anderson, Benedict R. O'G. Imagined Communities: Reflections on the Origin and Spread of Nationalism. (Revised and Extended. ed.). London: Verso, 1991.

Bhabha, Homi K. Nation and Narration. New York: Routledge, 1990.

Bhabha, Homi K. The Location of Culture. London: Routledge, 1994.

Bhopal, Kalwant. "Identity, Empathy and 'Otherness': Asian Women, Education and Dowries in the UK." Race Ethnicity and Education 12, no. 1 (2009): 27-39.

Bhopal, Kalwant. "Education Makes You Have More Say in the Way Your Life Goes: Indian Women and Arranged Marriages in the United Kingdom." British Journal of Sociology of Education 32, no. 3 (2011): 431-47. doi:10.1080/01425692.2011.559342. 
Bollen, Kenneth. A, Curran, Patrick. J. Latent Curve Models: A Structural Equations Perspective. Hoboken, New Jersey: John Wiley \& Sons, 2006.

Brah, Avtar. "Diaspora, Border and Transnational Identities." In Feminist Postcolonial Theory: A Reader, edited by Reina Lewis and Sara Mills. Edinburgh: Edinburgh University Press, 2003.

Brah, Avtar. Cartographies of Diaspora: Contesting Identities. London: Routledge, 1996.

Butterfield, Sherry-Anne. "Being Racialized Ethnics: Second Generation West Indian Immigrants in New York City." In Race and Ethnicity in New York City (Research in Urban Sociology, Volume 7), edited by J. Krase and Ray Hutchison, 107-136. Bingley, UK: Emerald Group Publishing Limited, 2004.

Caglar, A. "Hyphenated Identities and the Limits of Culture." In The Politics of Multiculturalism in the New Europe, edited by Tariq Modood and Pnina Werbner, 169-185. London; New York: Zed Books, 1997.

Charsley, Katharine. "Unhappy Husbands: Masculinity and Migration in Transnational Pakistani Marriages." The Journal of the Royal Anthropological Institute 11, no. 1 (2005): 85-105.

Chase, Susan. E. "Taking Narrative Seriously: Consequences for Method and Theory in Interview Studies." In Turning Points in Qualitative Research: Tying Knots in a Handkerchief, edited by Yvonna S. Lincoln and Norman K. Denzin, 273-296. Walnut Creek, California: AltaMira Press, 2003.

Chopra, Radhika, Caroline Osella, and Filippo Osella. South Asian Masculinities: Context of Change, Sites of Continuity. New Delhi: Women Unlimited an Associate of Kali for Women, 2004.

Clifford, James. "Diasporas." Cultural Anthropology 9, no. 3 (1994): 302-38.

Coyne Kathleen. Performing Virginity and Testing Chastity in the Middle Ages. London: Routledge, 2000.

Curran, Sara R., Steven Shafer, Katharine M. Donato, and Filiz Garip. "Mapping Gender and Migration in Sociological Scholarship: Is it Segregation or Integration?" International Migration Review 40, no. 1 (2006): 199-223.

Dasgupta, Shamita Das. "Gender Roles and Cultural Continuity in the Asian Indian Immigrant Community in the U.S." Sex Roles 38, no. 11 (1998): 953-74.

Dirlik, Arif. The Postcolonial Aura: Third World Criticism in the Age of Global Capitalism. Boulder, CO: Westview Press, 1997.

Donato, Katharine M. "A glass half full? Gender in Migration Studies." International Migration Review 40, no. 1 (2006): 3-26. 
Dossa, Parin. "'Witnessing' Social Suffering: Testimonial Narratives of Women from Afghanistan." BC Studies, no. 147 (September, 2005): 27-49.

Dossa, Parin. "Creating Politicized Spaces: Afghan Immigrant Women's Stories of Migration and Displacement." Affilia 23, no. 1 (2008): 10-21.

Dossa, Parin. Racialized Bodies, Disabling Worlds: Storied Lives of Immigrant Muslim Women. Toronto: University of Toronto Press, 2009.

Dossa, Parin. Afghanistan Remembers: Gendered Narrations of Violence and Culinary Practices. Toronto: University of Toronto Press, 2014.

Dwyer, Claire. "Veiled Meanings: Young British Muslim Women and the Negotiation of Differences [1]." Gender, Place \& Culture 6, no. 1 (1999): 5-26.

Dwyer, Claire. Negotiating Diasporic Identities: Young British South Asian Muslim Women. Women's Studies International Forum 23; 4 (2000): 475-86.

Dwyer, Claire, Shah, Bindi, and Tariq Modood. "Explaining Educational Achievement and Career Aspirations among Young British Pakistanis: Mobilizing 'Ethnic Capital'?" Sociology 44, no. 6 (2010): 1109-127. doi:10.1177/0038038510381606.

Faizi, Fatima. "Afghanistan: 'Farkhunda Will Not Be Forgotten'" Al Jazeera. March 18, 2016.

Farley, Reynolds and Alba, Richard. "The New Second Generation in the United States." International Migration Review 36; 3 (2002): 669-701.

Faulkner, Caroline L. Segmented Paths of Immigrant Incorporation? Assimilation Theory and the New Second Generation. ProQuest Dissertations Publishing. 2008.

Fielden, Matthew B. "The Geopolitics of Aid: The Provision and Termination of Aid to Afghan Refugees in North West Frontier Province, Pakistan." Political Geography 17, no. 4 (1998): 459-87.

Fonow, Mary Margaret, and Judith A. Cook. "Feminist Methodology: New Applications in the Academy and Public Policy." In Signs: Journal of Women in Culture and Society, 30, no. 4 (2005): 2211-2236.

Foroutan, Yaghoob. "Employment Differentials of Second-Generation Muslim Immigrants: Assimilation and Discrimination Hypotheses." Immigrants \& Minorities 26, no. 3 (2008): 219-241.

Gans, Herbert J. "Second-Generation Decline: Scenarios for the Economic and Ethnic Futures of the Post-1965 American Immigrants." Ethnic and Racial Studies, 15, no. 2 (1992): 173-192.

Gibson, M. A. "Immigrant Adaptation and Patterns of Acculturation." Human Development, 44 (2001): 19-23. 
Gill, Aisha and Wendy Aujla. "Conceptualizing 'Honour' Killings in Canada: An Extreme Form of Domestic Violence?" International Journal of Criminal Justice Science 9, no. 1 (2014): 153-166.

Gilroy, Paul. The Black Atlantic: Modernity and Double Consciousness. Cambridge, MA: Harvard University Press, 1993.

Gratton, Brian. "Race, the Children of Immigrants and Social Science Theory." Journal of American Ethnic History 21, no. 4 (2002): 74-84.

Gupta, M. D. "What is Indian about You? A Gendered, Transnational Approach to Ethnicity." Gender \& Society 11, no. 5 (1997): 572-96.

Hall, Stuart. "Cultural Identity and Diaspora" In Identity: Community, Culture, Difference, edited by Jonathan Rutherford. London: Lawrence \& Wishart, 1990.

Hall, Stuart. "The Question of Cultural Identity." In Modernity and its Futures, edited by Stuart Hall, David Held and Anthony McGrew, 274-316. Cambridge: Polity Press in Association with the Open University, 1992.

Hall Stuart. "When was the Post-Colonial? Thinking at the Limit." In The Postcolonial Question, edited by L. Curti \& I. Chambers, 242-260. New York: Routledge, 1996.

Handa, Amita. Of Silk Saris and Mini-skirts: South Asian Girls Walk the Tightrope of Culture. Toronto, Ont.: Women's Press, 2003.

Harding, Sandra. Feminism and Methodology. Bloomington: Indiana University Press, 1986.

Hirschman, Charles. "The Educational Enrollment of Immigrant Youth: A Test of the Segmented Assimilation Hypothesis." Demography 38, vol. 31 (2001): 317-336.

Hum, Sue. "Between the Eyes: The Racialized Gaze as Design." College English 77, no. 3 (2015): 191-215.

Hyder, Adnan A., Zarin Noor, and Emma Tsui. "Intimate Partner Violence among Afghan Women Living in Refugee Camps in Pakistan." Social Science \& Medicine 64, no. 7 (2007): 1536-1547.

Hynie, Michaela, Sepali Guruge, and Yogendra B. Shakya. "Family Relationships of Afghan, Karen and Sudanese Refugee Youth." Canadian Ethnic Studies 44, no. 3 (2013): 1128.

Jiwani, Y. "Helpless Maidens and Chivalrous Knights: Afghan Women in the Canadian Press." University of Toronto Quarterly 78; 2 (2009): 728-744.

Jiwani, Y. "Honour on Trial: The Shafia Murders and the Culture of Honour Killings by Paul Schliesmann." Canadian Ethnic Studies 46, vol. 2 (2014). 
Kalvir, Giti Eghbal. Iranian Women in Beautiful British Columbia: Economic Security among Iranian Immigrant Lone Mothers. Vancouver: Simon Fraser University Library, 2011.

Kamali, Mohammad Hashim. "Islam's Views on Sorcery and Black Magic." Islam and Civilizational Renewal 2, vol. 3 (2011).

Kargar, Zarghuna. Dear Zari: Hidden Stories from Women of Afghanistan. London: Chatto \& Windus, 2011.

Khan, Ayesha. "Afghan Refugee Women's Experience of Conflict and Disintegration." Meridians 3, vol. 1 (2002): 89-121.

Khan, S. "The Two Faces of Afghan Women: Oppressed and Exotic." Women's Studies International Forum 44 (2014): 101-109.

Khandelwal, Meena. "Arranging love: Interrogating the Vantage Point in Cross-Border Feminism." Signs 34 (3) (2008): 583-609.

Khanlou, Nazilla, Jane G. Koh, and Catriona Mill. "Cultural Identity and Experiences of Prejudice and Discrimination of Afghan and Iranian Immigrant Youth." International Journal of Mental Health and Addiction 6, issue. 4 (2008): 494-513.

Khatib, Maissa. "Arab Muslim Women's Experiences of Living in the United States: A Qualitative Descriptive Study." ProQuest Dissertations Publishing, 2013.

Kirk, Jackie. "Transferring Cultural Knowledge and Skills: Afghan Teachers for Afghan Students in Montreal." Refuge (Toronto. English Edition) 23, no. 1 (January 01, 2006): 45 .

Koplik, Sara. "The Demise of Afghanistan's Jewish Community and the Soviet Refugee Crisis (1932-1936)." Iranian Studies 36; 3 (2003): 353-79.

Lalonde, R. N. "The Role of Culture in Interpersonal Relationships: Do Second Generation South Asian Canadians Want a Traditional Partner?" Journal of Cross-Cultural Psychology 35, no. 5 (2004): 503-24.

Lindgren, Teri, and Juliene G. Lipson. "Finding a Way: Afghan Women's Experience in Community Participation." J Transcult Nurs Journal of Transcultural Nursing 15, no. 2 (2004): 122-30.

Loomba, Ania. Postcolonial Studies and Beyond. Durham: Duke University Press, 2005.

Medora, Nilufer P., Jeffry H. Larson, and Parul B. Dave. "East-Indian College Student's Perceptions of Family Strengths." Journal of Comparative Family Studies 31; 4 (2000): 407.

Milewski, Nadja, and Danny Otto. "The Importance of a Religious Funeral Ceremonies." Journal of Intercultural Studies 37, no. 2 (2016): 162-78. 
Miller, Jody, and Glassner Barry. "The 'Inside' and the 'Outside': Finding Realities in Interviews." In Qualitative Research, edited by David Silverman, 99-112. London: Sage Publications, 1997.

Mills, Sara, and Reina Lewis. Feminist Postcolonial Theory: A Reader. Edinburgh: Edinburgh University Press, 2003.

Mohanty, Chandra Talpade. "Under Western Eyes Revisited: Feminist Solidarity through Anticapitalist Struggles." Signs 28; 2 (2003): 499-535.

Nadim, Marjan. "Transnational Marriages and Second-Generation Women's Employment." Nordic Journal of Migration Research 4; 3 (2014): 99-107.

Nagasawa Richard, Qian Zhenchao, and Wong Paul. "Theory of Segmented Assimilation and the Adoption of Marijuana Use and Delinquent Behavior by Asian Paicific Youth." The Sociological Quarterly 42; 3 (2001): 351-372.

Naples, Nancy A. Feminism and Method: Ethnography, Discourse Analysis, and Activist Research. New York: Routledge, 2003.

Netting, Nancy S. "Two-Lives, One Partner: Indo-Canadian Youth between Love and Arranged Marriages." Journal of Comparative Family Studies 37, no. 1 (2006): 12946.

Noble, G. "The Discomfort of Strangers: Racism, Incivility and Ontological Security in a Relaxed and Comfortable Nation." Journal of Intercultural Studies 26, 1-2 (Feb-May) (2005): 107-120.

Nourpanah, Shiva. "A Study of the Experiences of Integration and Settlement of Afghan Government-Assisted Refugees in Halifax, Canada." Refuge (Toronto. English Edition) 30, no. 1 (January 04, 2014): 57.

Okin, Susan Moller. Is Multiculturalism Bad for Women? Princeton, NJ: Princeton University Press, 1999.

Omid, Safi. Is all Morality Gone? Condemning ISIS, and beyond, in a World of Suffering. Duke University, 2016.

Osella, Caroline. "Desires Under Reform: Contemporary Reconfigurations of Family, Marriage, Love and Gendering In a Transnational South Indian Matrilineal Muslim Community." Culture and Religion 13; 2 (2012): 241-264.

Otoukesh, S., M. Mojtahedzadeh, D. Sherzai, A. Behazin, S. Bazargan-Hejazi, and M. Bazargan. "A Retrospective Study of Demographic Parameters and Major Health Referrals among Afghan Refugees in Iran." International Journal for Equity in Health $11 ; 1$ (2012): 82 .

Pande, Raksha. "I Arranged My Own Marriage: Arranged Marriages and Post-Colonial Feminism." Gender, Place \& Culture 22, no. 2 (2014): 172-87. 
Pande, Raksha. "Geographies of Marriage and Migration: Arranged Marriages and South Asians in Britain." Geography Compass 8, no. 2 (2014): 75-86.

Payind, Alam. "Inside Afghanistan: 23 Years After the Soviet Withdrawal." Journal of Asian and African Studies 48; 2 (2013): 258-264.

Pigott, Peter. Canada in Afghanistan: The War So Far. Toronto, ON: Dundurn Group, 2007.

Portes, Alejandro and Dag MacLeod. "Educational Progress of Children of Immigrants: The Roles of Class, Ethnicity, and School Context." Sociology of Education 69; 4 (1996): 255-275.

Portes, Alejandro and Ruben G. Rumbaut. Immigrant America: A Portrait. Berkeley: University of California Press, 1996.

Portes, Alejandro and Ruben G. Rumbaut. Legacies: The Story of the Immigrant Second Generation. New York: Russell Sage Foundation, 2001.

Portes, Alejandro and Richard Schauffler. "Language and the Second Generation: Bilingualism Yesterday and Today." In The New Second Generation, edited by Aljandro Portes. New York: Russell Sage Foundation, 1996.

Portes, A.; Rumbaut, R.G. "Introduction: The Second Generation and the Children of Immigrants Longitudinal Study." Ethnic \& Racial Studies, vol. 28; issue 6 (2005): 983-999.

Portes, Alejandro and Min Zhou. "The New Second Generation: Segmented Assimilation and Its Variants." Annals of the American Academy of Political and Social Sciences 530 (1993): 74-96.

Portes Alejandro, Fernandez-Kelly Patricia, Haller William. Segmented Assimilation on the Ground: the New Second Generation in Early Adulthood. Ethnic and Racial Studies. 28; 6 (2005): 1000-1040.

Portes, A. and Rumbaut, R.G. Immigrant America. A Portrait. Berkeley: The California University Press, 2006.

Rajiva, Mythili. "Better lives: The Transgenerational Positioning of Social Mobility in the South Asian Canadian Diaspora." Women's Studies International Forum 36 (2013): $16-26$.

Razack, Sherene. Dark Threats and White Knights: The Somalia Affair, Peacekeeping and the New Imperialism. Toronto: University of Toronto Press, 2004.

Razack Sherene H. Casting Out: The Eviction of Muslims from Western Law and Politics. Toronto: University of Toronto Press, 2008.

Reinharz, Shulamit, and Lynn Davidman. Feminist Methods in Social Research. New York: Oxford University Press, 1992. 
Ribbens, J. and Edwards, R. Feminist Dilemmas in Qualitative Research: Public Knowledge and Private Lives. London: Sage, 1998.

Ross-Sheriff, Fariyal. "Afghan Women in Exile and Repatriation: Passive Victims or Social Actors?" Affilia 21; 2 (2006): 206-219.

Rumbaut, Rubén G. "Severed or Sustained Attachments? Language, Identity, and Imagined Communities in the Post-Immigrant Generation." The Changing Face of Home: The Transnational Lives of the Second Generation. New York: Russell Sage Foundation (2002): 43-95.

Rumbaut, Rubén G. "Ages, Life Stages, and Generational Cohorts: Decomposing the Immigrant First and Second Generations in the United States." International Migration Review 38; 3 (2004): 1160-1205.

Rumbaut, Rubén G. "The Crucible Within: Ethnic Identity, Self-Esteem, and Segmented Assimilation among Children of Immigrants." International Migration Review 28, no. 4 (1994): 748-94.

Rumbaut, Rubén G. "Assimilation and Its Discontents: Between Rhetoric and Reality.” The International Migration Review 31; 4 (1997): 923-960.

Rutland, A., D. Abrams, and S. Levy. "Introduction: Extending the Conversation: Transdisciplinary Approaches to Social Identity and Intergroup Attitudes in Children and Adolescents." International Journal of Behavioral Development 31, no. 5 (2007): 417-18.

Rytter, Mikkel. "In-laws and Outlaws: Black Magic among Pakistani Migrants in Denmark." Journal of the Royal Anthropological Institute 16, no. 1 (2010): 46-63.

Sadat, Mir Hekmatullah. "Hyphenating Afghaniyat (Afghan-ness) in the Afghan Diaspora." Journal of Muslim Minority Affairs 28, no. 3 (2008): 329-42. doi:10.1080/13602000802547898.

Safran, William. "Diasporas in Modern Societies: Myths of Homeland and Return." Diaspora Diaspora: A Journal of Transnational Studies 1, no. 1 (1991): 83-99.

Safran, William. "Deconstructing and Comparing Diasporas." In Diaspora, Identity, and Religion: New Directions in Theory and Research, edited by Waltraud Kokot, Khachig Tölölyan, and Carolin Alfonso. London: Routledge, 2004.

Said, Edward W. Representations of the Intellectual: The 1993 Reith Lectures. 1st American ed. New York: Pantheon Books, 1994. 
Shakya, Yogendra B., Sepali Guruge, and Michaela Hynie. "Aspirations for Higher Education among Newcomer Refugee Youth in Toronto." Canada's Periodical on Refugees 27; 2 (2010): 65-78.

Shaw, Alison. Kinship and Continuity: Pakistani Families in Britain. Amsterdam: Harwood Academic, 2000.

Shaw, Alison. "Kinship, Cultural Preference and Immigration: Consanguineous Marriage among British Pakistanis." The Journal of the Royal Anthropological Institute 7, no. 2 (2001): 315-334.

Shaw, Alison. "The Arranged Transnational Cousin Marriages of British Pakistanis: Critique, Dissent and Cultural Continuity." Contemporary South Asia 15, no. 2 (2006): 209-20.

Shaw, Alison, and Katharine Charsley. "Rishtas: Adding Emotion to Strategy in Understanding British Pakistani Transnational Marriages." Global Networks 6, no. 4 (2006): 405-21.

Sirkeci, Ibrahim. "Transnational Mobility and Conflict." Migration Letters 9; 4 (2012): 35363.

Smith, Dorothy E. "Women's Perspective as a Radical Critique of Sociology." Sociological Inquiry 44, no. 1 (1974): 7-13.

Smith, Dorothy E. A Sociology for Women. Vancouver: University of British Columbia, 1976.

Stack, Julie A.C., and Yoshitaka Iwasaki. "The Role of Leisure Pursuits in Adaptation Processes among Afghan Refugees Who Have Immigrated to Winnipeg, Canada." Leisure Studies 28, no. 3 (2009): 239-59.

Statistics Canada. "Post-Secondary Enrolment by Institution Type, Registration Status, Province and Sex." Government of Canada, 2010.

Statistics Canada. "Longitudinal Survey of Immigrants to Canada." Government of Canada, 2005.

Sundar, Purnima. "To "Brown It Up" or to "Bring Down the Brown": Identity and Strategy in Second-Generation, South Asian-Canadian Youth." Journal of Ethnic and Cultural Diversity in Social Work 17, no. 3 (2008): 251-78.

Rai, Rajesh, and Peter Reeves. "The South Asian Diaspora: Transnational Networks and Changing Identities." Vol. 11. New York; London: Routledge, 2009.

Thobani, Sunera. Exalted Subjects: Studies in the Making of Race and Nation in Canada. Toronto: University of Toronto Press, 2007.

Titzmann, Fritzi-Marie. "Changing Patterns of Matchmaking: The Indian Online Matrimonial Market." Asian Journal of Women's Studies 19, no. 4 (2013): 64-94. 
Toivanen, Mari. The Visual Lexica of (National) Belonging and Nonbelonging in the Accounts of Young Kurds in Finland. Nordic Journal of Migration Research 4; 4 (2014): 192-200.

Tölölyan, Khachig. "The Nation-State and its Others: In Lieu of a Preface." Diaspora: A Journal of Transnational Studies. Toronto: University of Toronto Press, 1;1 (1991): 3-7.

United Nations High Commission for Refugees. "UNCHR Eligibility Guidelines for Assessing the International Protections Needs of Asylum-Seekers from Afghanistan." August 6, 2013.

United Nations High Commission for Refugees. "2007 Global Trends: Refugees, AsylumSeekers, Returnees, Internally Displaced and Stateless Persons." UNHCR News, 2006.

United Nations High Commission for Refugees. "2004 Global Refugee Trends: Overview of Refugee Populations, New Arrivals, Durable Solutions, Asylum Seekers and Other Persons of Concern to UNHCR." UNHCR News. June 17, 2005.

Vincent, Louise. "Virginity Testing in South Africa: Re-traditioning the Postcolonial." Culture, Health \& Sexuality 8, no. 1 (2006): 17-30.

Waldinger Roger, Feliciano Cynthia. "Will the New Second Generation Experience 'Downward Assimilation?' Segmented Assimilation Re-Assessed." Ethnic and Racial Studies. 27; 3 (2004): 376-402.

Warren, Carol A. B., and Tracy X. Karner. Discovering Qualitative Methods: Field Research, Interviews, and Analysis. New York: Oxford University Press, 2010.

Warren Carol A. B., Karner T. The Interview, Discovering Qualitative Methods: Field Research, Interviews and Analysis. Oxford University Press, 2009.

Wikan, Unni. Generous Betrayal: Politics of Culture in the New Europe. Chicago: University of Chicago Press, 2002.

Wolf, Diane L. Feminist Dilemmas in Fieldwork. Boulder, CO: Westview Press, 1996.

Yuval-Davis, Nira. "Belonging and the Politics of Belonging". Patterns of Prejudice 40; 3 (2006): 197-214.

Zaidi, Arshia U., and Muhammad Shuraydi. "Perceptions of Arranged Marriages by Young Pakistani Muslim Women Living in a Western Society." Journal of Comparative Family Studies 33, no. 4 (2002): 495-514.

Zeleza, Paul Tiyambe. "The Politics and Poetics of Exile: Edward Said in Africa." Research in African Literatures 36; 3 (2005): 1-22. 